EVALUATION OF VIABILITY OF LACTOBACILLUS ACIDOPHILUS LA-5 DURING SIMULATED DIGESTION PROCESS USING A DYNAMIC IN VITRO MODEL STOMACH

\author{
A Thesis \\ presented to \\ the Faculty of California Polytechnic State University, \\ San Luis Obispo
}

\begin{abstract}
In Partial Fulfillment
of the Requirements for the Degree

Master of Science in Agriculture, with Specialization in Dairy Products Technology

by

Jenifer Tharani
\end{abstract}

May 2012 
(C) 2012

Jenifer Tharani

ALL RIGHTS RESERVED 


\section{COMMITTEE MEMBERSHIP}

TITLE:

EVALUATION OF VIABILITY OF LACTOBACILLUS

ACIDOPHILUS LA-5 DURING SIMULATED

DIGESTION PROCESS USING A DYNAMIC IN

VITRO MODEL STOMACH

AUTHOR:

JENIFER THARANI

DATE SUBMITTED: May 2012

COMMITTEE CHAIR: $\quad$ Dr. Amy Marie Lammert, Ph.D., Assistant Professor

COMMITEE MEMBER: $\quad$ Dr. Philip Tong, Ph. D., Professor

COMMITEE MEMBER: $\quad$ Dr. Rafael Jimenez-Flores, Ph. D., Professor

COMMITEE MEMBER: $\quad$ Dr. Po Sai Marie Yeung, Ph. D., Assistant Professor 


\title{
ABSTRACT \\ Evaluation of viability of Lactobacillus acidophilus La-5 during simulated digestion process using a dynamic in vitro model
}

\author{
Jenifer Tharani
}

In recent years, there has been an upsurge in medical research assessing the therapeutic benefits of probiotic bacteria and growing commercial interest in food fortification with these bacteria. Probiotic bacteria such as L. acidophilus are known to be predominant Lactobacilli species in the intestinal tract of healthy humans and suggested to provide clinical health benefits such as enhancement of immunity against intestinal infections, prevention of diarrhea and hypercholesterolaemia and improvement in lactose utilization. Many studies have demonstrated the possibility of incorporating probiotic bacteria in an ice cream matrix and shown its viability can be maintained throughout the shelf life of the ice cream. However, there is limited information about the protective effect of ice cream on viability of incorporated probiotic bacteria during simulated gastric digestion using an in vitro dynamic model stomach.

In phase one of this study, a preliminary study was conducted to determine the effect of air addition on the viability of L. acidophilus La-5. This was done by manufacturing low fat (4\%) non-fermented ice cream mix supplemented with $L$. acidophilus La-5 to yield an initial population of $10^{7} \mathrm{cfu} / \mathrm{g}$. The mix was processed with $60 \%$ and $100 \%$ overrun (OR) and stored at $-10^{\circ} \mathrm{C}$ for 90 days. The effect of air addition at different levels was tested post freezing and every 30 days throughout its shelf life of 90 days. The results showed less than one log reduction in the viable counts of $L$. 
acidophilus La-5 for both samples incorporated with $60 \%$ and $100 \%$ OR after freezing and the number of viable cells did not differ significantly ( $\mathrm{p}>0.05)$ from day 1 to day 90 . In phase two of this study, a $2^{2}$ full factorial experimental design was used to evaluate whether the viscous nature of ice cream mix plays an important role in improving the survivability of $L$. acidophilus La-5 during simulated digestion against low $\mathrm{pH}$ and presence of mechanical shear and to determine whether initial inoculation level has any effect on the viability of $L$. acidophilus La-5 at the end of $2 \mathrm{hr}$ simulated digestion. Non-fermented low fat (5\%) ice cream mixes with high and low viscosity were produced by changing the amount of stabilizer/emulsifier blend and each of the two mixes were supplemented with two levels of $L$. acidophilus La-5 to obtain an initial population of $10^{8} \mathrm{cfu} / \mathrm{g}$ and $10^{6} \mathrm{cfu} / \mathrm{g}$ before freezing. These mixes were frozen with $60 \%$ overrun. The ice cream samples were digested for $2 \mathrm{hr}$ in an in vitro model stomach called Human Gastric Simulator (HGS). This model included factors such as gastric secretions, mechanical shearing due to peristaltic contractions and temperature and $\mathrm{pH}$ control. No significant effect ( $\mathrm{p}>0.05$ ) of different levels of viscosity on the survivability of $L$. acidophilus La-5 was found during and at the end of $2 \mathrm{hr}$ simulated in vitro digestion, irrespective of the difference in initial inoculation level. The initial supplementation level of $L$. acidophilus La-5 had a significant impact $(\mathrm{p}<0.05)$ on its survivability during the simulated digestion of ice cream samples, irrespective of the difference in viscosity. The log survival of $L$. acidophilus La-5 was on an average 3.64 $\log \mathrm{cfu} / \mathrm{g}$ and $4.08 \mathrm{log} \mathrm{cfu} / \mathrm{g}$ for ice cream samples supplemented with higher and lower amount of L. acidophilus La-5, respectively at the end of $2 \mathrm{hr}$. Nevertheless, this difference in overall survival was not statistically significant ( $\mathrm{p}>0.05)$. 
These studies demonstrated the efficacy of low fat non-fermented ice cream in maintaining high viable numbers of $L$. acidophilus La-5 throughout its tested shelf life of 90 days. In addition, protective effect of ice cream on the viability of L. acidophilus La-5 against harsh stomach conditions was observed, but this effect was not as a result of viscosity of ice cream. It was also found that an ice cream supplemented with $10^{6} \mathrm{cfu} / \mathrm{g}$ would result in a similar overall $\log$ reduction of L. acidophilus La-5 at the end of $2 \mathrm{hr}$ simulated digestion compared to an ice cream supplemented with $10^{8} \mathrm{cfu} / \mathrm{g}$.

The aggressive stomach conditions had a negative impact on the survivability of L. acidophilus La-5 during digestion of all the ice cream samples, but this detrimental effect can be reduced by incorporating L. acidophilus La-5 into an ice cream matrix which would increase the opportunity of bacteria to reach the small intestine and provide the desired health benefit.

Keywords: L. acidophilus La-5, ice cream, overrun, viscosity, inoculation, HGS, survival 


\section{ACKNOWLEDGMENTS}

I would like to thank my advisor Dr. Amy Lammert for her continous support, advice and guidance throughout these 2.5 years. I would also like to thank my committee

members Dr. Marie Yeung, Dr. Phil Tong and Dr. Jimenez. In addition, I would like to thank Chr. Hansen for providing me with the cultures.

I would like thank California State University Agricultural Research Institute (ARI) and Community College/ California State University/ University of California Collaborative Research Funding for funding this project. I would like to thank Sean Vink, Andrea Laubscher and Jerry Mattas for their help and support. I would also like to thank my DPTC family.

Last, but not the least, I would like to thank Rahim, my family and friends for their love, encouragement and support. 


\section{TABLE OF CONTENTS}

LIST OF TABLES.................................................................

LIST OF FIGURES...................................................................

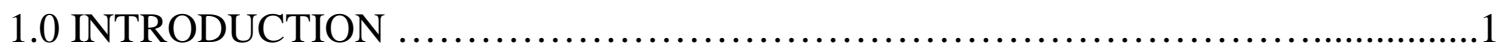

2.0 LITERATURE REVIEW

2.1 Concept of Probiotics...............................................................

2.1.1 Probiotic bacteria and current scenario....................................

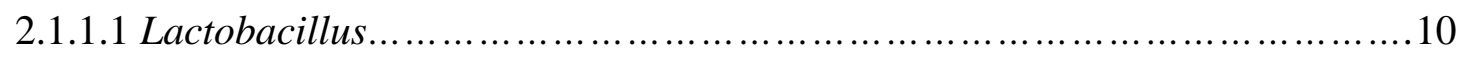

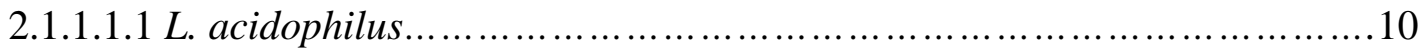

2.1.2 Probiotic bacteria and dairy products.....................................12

2.1.2.1 Fermented dairy products..................................................

2.1.2.2 Ice cream, a non-fermented dairy product.................................23

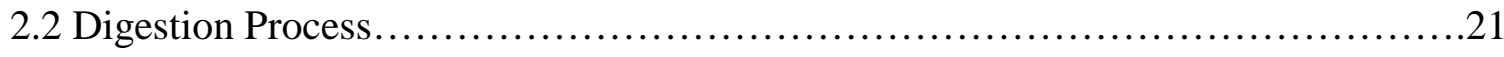

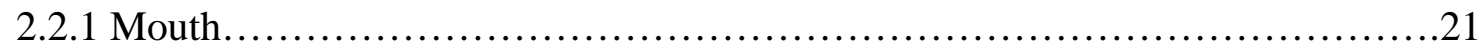

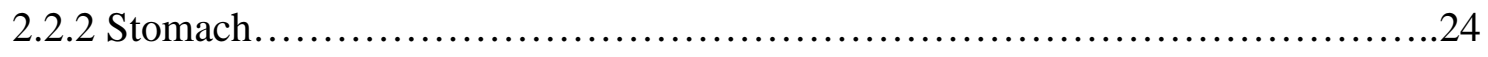

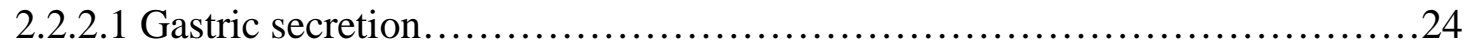

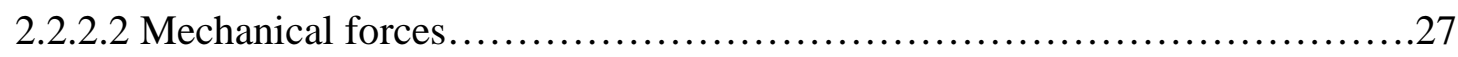

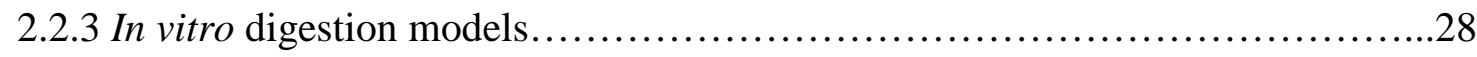

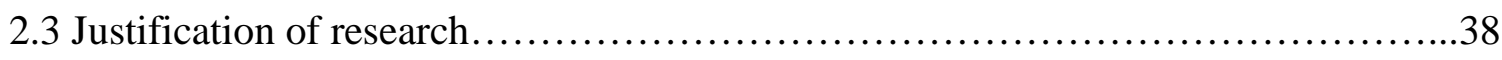

2.3.1 Research objectives......................................................41

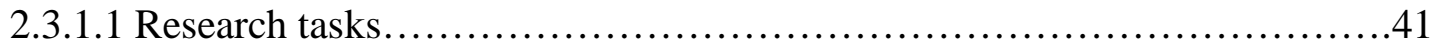

2.3.2 Research hypotheses..................................................... 43 


\subsection{MATERIALS AND METHODS}

3.1 Phase I: Survivability of L. acidophilus La-5 in nonfermented low fat ice cream.....44

3.1.1 Ice cream production................................................44

3.1.2 Enumeration of Lactobacillus acidophilus La-5..........................46

3.1.3 Physiochemical analysis of ice cream mix..............................46

3.1.4 Statistical analysis.................................................... 48

3.2 Phase II: Bench top experiments...............................................

3.2.1 Buffering capacity of ice cream mix, milk and PBS .......................48

3.2.2 Effect of shear and dilution on the survivability of L. acidophilus La-5..........50

3.2.2.1 Effect of simulated gastric shear................................... 51

3.2.2.2 Effect of simulated gastric dilution of ingested food......................51

3.2.3 Conventional acid resistance test in the presence and absence of ice cream......52

3.2.3.1 Acid resistance test in the absence of ice cream........................52

3.2.3.2 Acid resistance test in the presence of ice cream.........................53

3.2.4 Statistical analysis.................................................. 54

3.3 Phase III: In vitro digestion of ice cream..................................55

3.3.1 Shaking water bath..................................................55

3.3.2 Human Gastric Simulator (HGS).........................................

3.3.3 Statistical analysis......................................................

\subsection{RESULTS AND DISCUSSION}

4.1 Phase I: Survivability of L. acidophilus La-5 in nonfermented low fat ice cream.....63

4.1.1 Effect of processing and storage on the viability of L. acidophilus La-5.........63

4.1.2 Physicochemical analysis of ice cream containing L. acidophilus La-5..........67 
4.2 Phase II: Bench top experiments........................................ 71

4.2.1 Buffering capacity.....................................................

4.2.2 Effect of shear and dilution........................................ 74

4.2.3 Conventional acid resistance test........................................... 75

4.2.3.1 Survivability of L. acidophilus La-5 and L. paracasei 431 at $\mathrm{pH} 2.0$ and 5.0 in the absence of ice cream.......................................75

4.2.3.2 Survivability of L. acidophilus La-5 and L. paracasei 431 in the presence of

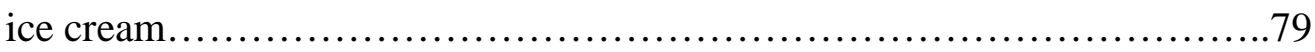

4.3 Phase III: In vitro digestion of ice cream...................................83

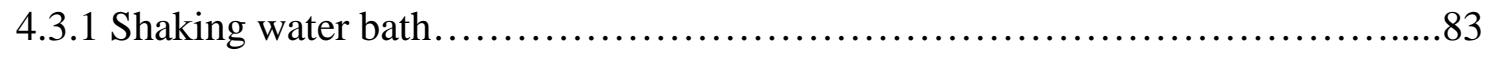

4.3.2 Human Gastric Simulator................................................88

5.0 CONCLUSIONS.......................................................97

6.0 FUTURE RESEARCH..............................................100

REFERENCES.......................................................... 101

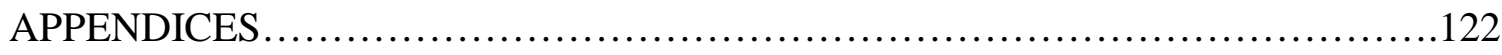




\section{LIST OF TABLES}

Table

2.1.1 Probiotic strains and their specific clinically proven health benefits..........4

2.1.1.1 Dairy products and probiotic bacteria.................................8

2.1.1.2 Non dairy products and probiotic bacteria................................9

2.1.2.1.1 Factors affecting viability of probiotic bacteria during ice cream production......................................................... 17

2.2.2.1.1 Principal components of gastric juice and their functions...................25

2.2.3.1 In vitro digestion models......................................... 30

2.2.3.3 In vitro models and probiotic bacteria.................................37

3.1.1.1 Probiotic and control ice creams - features and codes....................45

3.1.1.2 Experimental design - effect of overrun..............................45

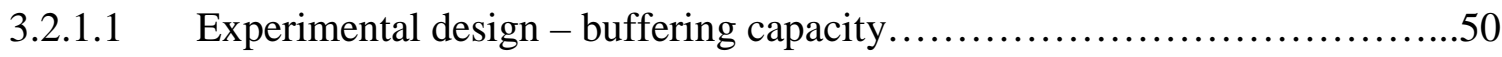

3.2.1.2 Indicators and color change...................................... 50

3.2.3.1 Experimental design - conventional acid resistance test...................54

3.3.1.1 Experimental design - shaking water bath...........................57

3.3.2.1 Probiotic ice cream samples and their codes............................59

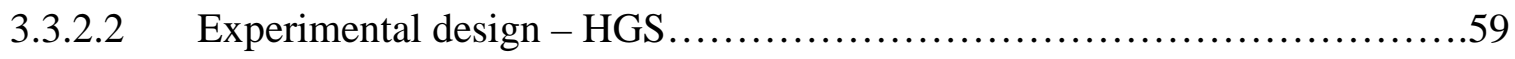

4.1.1.1 Effect of different amounts of air incorporation and freezing process on the viable counts of $L$. acidophilus La-5.........................63

4.1.1.2 Effect of storage of ice cream samples incorporated with $60 \%$ and $100 \%$ overrun at $-10^{\circ} \mathrm{C}$ for 90 days on the survivability of L. acidophilus La-5.............................................64

4.1.2.1 Physical and microbial analysis of ice cream mix after ageing..............67

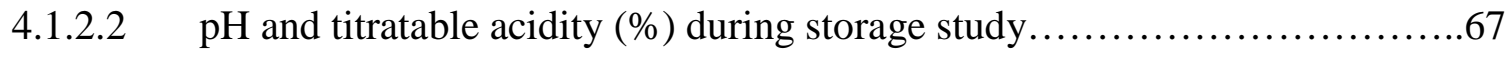

4.1.2.3 Consistency index $(\kappa)$ and flow behavior index $(n) \ldots \ldots \ldots \ldots \ldots \ldots \ldots \ldots . \ldots . \ldots . \ldots 6$ 
4.2.1.1 Comparison of amount of gastric juice required to lower the native $\mathrm{pH}$ of PBS, milk and ice cream mix with no added L. acidophilus La-5.....72

4.2.2.1 Effect of shear and dilution on survivability of L. acidophilus La-5 incorporated in low and high viscosity samples.........................75

4.2.3.1 Effect of $\mathrm{pH} 2$ on viability of selected probiotic strains during two hour incubation using conventional acid resistance test.......................76

4.2.3.2 Overall log reduction at $\mathrm{pH} 2$, $\mathrm{pH} 5$ and in the presence of ice cream for

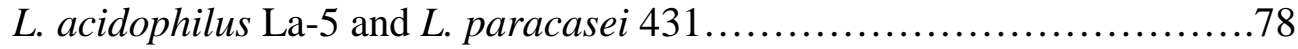

4.2.3.3 Effect of presence of ice cream mix on the viable counts of selected probiotic strains during $2 \mathrm{hr}$ of simulated digestion process.................80

4.3.1.1 Survivability of L. acidophilus La-5 during $2 \mathrm{hr}$ simulated gastric digestion of ice cream in shaking water bath model and HGS...............84

4.3.2.1 Consistency index $(\kappa)$ and flow behavior index $(n) \ldots \ldots \ldots \ldots \ldots \ldots \ldots \ldots . . . \ldots 9 . \ldots \ldots$

4.3.2.2 Effect of difference in viscosity and initial inoculation amount of L. acidophilus La-5 on the survivability of La-5 during 120 min of simulated digestion 
Figure

\section{LIST OF FIGURES}

2.1.1.1 Projected shares of global sales of probiotic ingredients, supplements and foods in 2015 (\%) compared to 2010 (\%)............................5

2.1.1.2 Research and randomized trials of probiotics published in the Medline

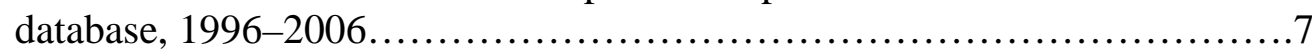

2.2.2.2.1 Propulsion, grinding, and retropulsion of solids by peristaltic contractions of distal stomach.................................................28

2.2.3.1 The multi-compartmental dynamic TIM-1 model of the gastrointestinal system. Vessels (A-D) constitute the gastric, duodenal, jejunal and ileal compartments, respectively. Modules (E) are semi-permeable hollow-fiber membrane dialysis units. (F) Peristaltic valves, $(\mathrm{G})$ ileo-caecal valves, (H) $\mathrm{pH}$ electrodes, (I) temperature sensor, (J) stomach secretion inlets, (K) duodenal secretions inlet, (L) and (M) bicarbonate secretion inlet, and (N) volume detecting sensors .........................................33

2.2.3.2 Dynamic Gastric Model. A- Main Body, B- Antrum, C- Emptying............33

2.2.3.3 HGS. (1) Motor; (2) latex lining; (3) mesh bag; (4) secretion tubing; (5) roller; (6) belt; (7) light bulb for temperature control; (8) plastic foam

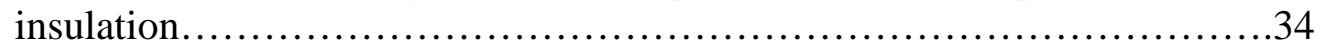

2.2.3.4 The dynamic in vitro human upper GI tract model system..................34

3.1.1.1 Probiotic ice cream manufacturing procedure..........................45

3.3.1.1 Effect of gastric digestion simulated using shaking water bath on the

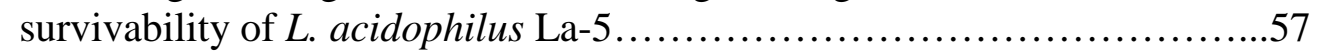

3.3.2.1 Human Gastric Simulator.........................................58

4.1.1.1 Effect of overrun and storage on the survivability of L. acidophilus La-5...64

4.1.2.1 Effect of shear rate $\left(\mathrm{sec}^{-1}\right)$ and temperature $\left({ }^{\circ} \mathrm{C}\right)$ on viscosity (Pa.s) of aged ice cream mix with and without added L. acidophilus La-5..........68

4.2.1.1 Buffering capacity (BC) of ice cream mix, milk and PBS at body and room temperature in the presence and absence of L. acidophilus La-5.....72

4.2.1.2 Buffering capacity (BC) of ice cream mix, milk and PBS for different $\mathrm{pH}$ values at body temperature in the presence and absence of

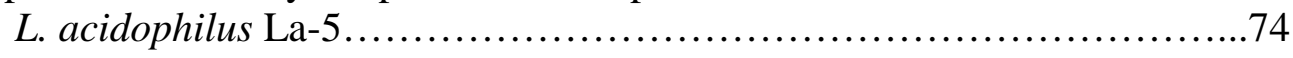


4.2.1.3 Buffering capacity (BC) of ice cream mix, milk and PBS for different $\mathrm{pH}$ values at room temperature in the presence and absence of L. acidophilus La-5..................................................74

4.2.3.1 Relative log survival of L. acidophilus $\mathrm{La}-5$ and L. paracasei 431 at $\mathrm{pH} 2.0$ and $\mathrm{pH} 5.0$ during $120 \mathrm{~min}$ incubation in citrate-HCl buffer................76

4.2.3.2 Relative log survival of L. acidophilus La-5 and L. paracasei 431 in the presence of ice cream mix during 120 min simulated digestion.............81

4.3.1.1 Relative log survival of L. acidophilus La-5 during 120min simulated digestion in shaking water bath and human gastric simulator................84

4.3.1.2 Postprandial $\mathrm{pH}$ decrease during simulated digestion of ice cream in shaking water bath and HGS.......................................... 85

4.3.2.1 Effect of gastric dilution on low viscosity ice cream sample during simulated digestion in HGS .............................................. 88

4.3.2.2 Effect of gastric dilution on high viscosity ice cream sample during simulated digestion in HGS ........................................... 89

4.3.2.3 Relative log survival of L. acidophilus La-5 during simulated digestion of ice cream in the HGS...................................92 


\subsection{Introduction}

Fermented dairy products especially yogurt and cheese have enjoyed consumer's attention because they are made from milk which is rich source of proteins and calcium and they contain live bacteria which provides health benefits. On the contrary, dairy product like ice cream is considered as a rich, indulgent treat because of high fat and sugar content and typically consumed during summer time. Low fat has become a buzz word among consumers and therefore, majority of them prefer low fat frozen desserts. Customers associate words like low fat and low sugar with a reduced risk of obesity, coronary heart diseases and diabetes (El-Nagar et al., 2002). Hence, food producers are concentrating their efforts in making ice cream like products nutritional and functional by supplementing them with probiotic bacteria so that they could be enjoyed every day.

Probiotics are defined as "live microorganisms which when administered in adequate amounts confer a health benefit on the host” (FAO/WHO, 2001). Lactobacillus and Bifidobacterium are the most common genera of bacteria used as probiotics for the production of fermented dairy products (Fuller, 1992). Generally, strains belonging to genus Lactobacillus have proven to be highly resistant to detrimental conditions during ice cream manufacturing process as well as more aerotolerant in comparison with Bifidobacteria strains (Talwalkar et al., 2001; Homayouni et al., 2008; Tamime et al., 2005). Some common probiotic species of Lactobacillus are L. acidophilus, L. reuteri, $L$. helveticus, and L. rhamnosus (Shah, 2007; Senok et al., 2005). Many studies have focused on survival of probiotic bacteria in fermented (Hekmat and McMahon, 1992; Magarinos et al., 2007; Turgut and Cakmakci, 2009) and non-fermented (Alamprese et al., 2002; Abghari et al., 2011; Nousia et al., 2011) ice cream and most of these studies have shown that ice cream can be an excellent environment for maintaining the viability 
of probiotic bacteria above the recommended level of $10^{6} \mathrm{cfu} / \mathrm{g}$ throughout its shelf life of more than 90 days. However, the viability of probiotic bacteria in an ice cream must be maintained not only during processing and shelf life, but also during transit through consumer's gastrointestinal (GI) tract to be able to reach the intestine in high viable cells to provide intended health benefits. Acid and bile tolerance are the two fundamental properties of probiotic microorganisms to be able to survive conditions in stomach and intestine (Prasad et al., 1998; Alamprese et al., 2002; Bhadoria and Mahapatra, 2011). To study the viability of bacteria in GI conditions, both in vivo and in vitro tests have been carried out.

In vivo studies are complex, labor intensive, and expensive to be used for preliminary and routine evaluation of foods containing probiotic bacteria (Sumeri et al., 2008; Fernández de Palencia et al., 2008). Thus, static (incubation of probiotic bacteria in the presence of acid and bile) and dynamic (TNO, Dynamic Gastric Model) in vitro models have been developed and used in numerous studies to determine the efficiency of dairy products such as fermented milk, yogurt, kefir as probiotic bacteria carrying vehicles (Conway et al., 1987; Charteris et al., 1998; Marteau et al., 1997; Mainville et al., 2005; Faye et al., 2012). A non-fermented ice cream supplemented with probiotic bacteria has been rarely studied in an in vitro digestion model to determine the contribution of its components (stabilizers, fat, and proteins) and properties (viscosity, buffering capacity and initial $\mathrm{pH}$ ) on survivability of probiotic bacteria during its simulated digestion in a model stomach. Therefore, in this study, efficacy of a non-fermented low fat ice cream as a probiotic bacteria carrying vehicle was tested by subjecting it to simulated digestion process using a dynamic in vitro model stomach called Human Gastric Simulator (HGS). 


\subsection{Literature Review}

\subsection{Concept of Probiotics}

One thing most people may have experienced more than once in their lifetime is taking antibiotics to cure bacterial infections. Antibiotics have been the "gold standards" in the management of diseases. However, the side effects like hypersensitivity, induction of yeast vaginitis, and sometimes even death associated with antibiotic cannot be ignored. In $21^{\text {st }}$ century, consumers are extremely concerned about living healthier and happier today and beyond. Hence, the food and pharmaceutical industry is spending research dollars to understand the mechanism of probiotic bacteria so that its ingestion can provide health benefits. In recent years, there has been an upsurge in clinical research assessing the therapeutic benefits of probiotic bacteria as well as growing commercial interest in food fortification with them (Czinn and Blanchard, 2009). Scientists are looking at possibilities of substituting antibiotics with probiotics by finding a link between probiotics and prevention of human diseases (Oliveira et al., 2001; Schrezenmeir and de Vrese, 2001; Teitelbaum and Walker, 2002).

The concept of probiotics came into existence around 1900 when the Nobel Prize winner Elie Metchnikoff made a remarkable observation and hypothesized that the Bulgarian peasants lived longer and healthier lives as a result of their consumption of fermented dairy products containing genus Lactobacillus (Ross et al, 2005). The word “probiotics” comes from two Greek words meaning "for life” (Hamilton-Miller et al., 2003) and was initially used as an antonym of the word “antibiotic”. The first description of probiotics was proposed by Kollath (1953) who defined it as "probiotics are common in vegetable food as vitamins, aromatic substances, enzymes and possibly other substances connected with vital process”. Later, various definitions for the term 
probiotics were proposed by scientists like Parker (1974), Fuller (1989), Salminen et al. (1998). In 2001, Food and Agriculture Organization of United Nations and World Health Organization (FAO/WHO, 2001) defined probiotics as "live microorganisms which when administered in adequate amounts confer a health benefit on the host”. Many commercially available probiotic bacteria may provide one or several proposed health benefits according to clinical studies (Parvez et al., 2006). A few examples of probiotic strain with clinically proven health benefits are shown in Table 2.1.1. Gorbach (2000) and Figueroa-Gonzalez et al. (2011) reported that beneficial effects of probiotic bacteria do not tie to specific genus or species, but instead are strain-specific which is also demonstrated in Table 2.1.1.

Table 2.1.1: Probiotic strains and their specific clinically proven health benefits (Shah, 2006)

\begin{tabular}{|l|l|}
\hline Probiotic Strain & Clinical Benefits \\
\hline L. acidophilus NCFM & $\begin{array}{l}\text { Lowers fecal enzyme activity, improves } \\
\text { lactose absorption and produces bacteriocin }\end{array}$ \\
\hline L. rhamnosus GG & $\begin{array}{l}\text { Plays a role in prevention of antibiotic and } \\
\text { rotavirus associated diarrhea }\end{array}$ \\
\hline L. casei shirota & $\begin{array}{l}\text { Helps in prevention of intestinal } \\
\text { disturbance, balancing intestinal flora and } \\
\text { lowering of fecal enzyme activity }\end{array}$ \\
\hline L. reuteri & $\begin{array}{l}\text { Colonizes the intestinal tract, shortens the } \\
\text { duration of rotavirus diarrhea, and helps in } \\
\text { immune enhancement }\end{array}$ \\
\hline B. animalis BB-12 & $\begin{array}{l}\text { Plays a role in treatment of rotavirus } \\
\text { diarrhea and balancing intestinal flora }\end{array}$ \\
\hline
\end{tabular}

\subsubsection{Probiotic bacteria and current scenario}

Currently, there is not an approved standard of identity for probiotics, but an established suitable level of viable cells to be ingested for therapeutic benefits is $10^{6} \mathrm{cfu} / \mathrm{g}$ or ml, representing a daily dose of 8 log (Cruz et al., 2009; Ding and Shah, 2009; Abghari et al., 2011). Additionally, the concentration of probiotic microorganisms needed for 
biological health benefits depends on the strain, the delivery medium and the desired health effect (Sanders et al., 2008; Champagne et al., 2005). High dosage is likely required to compensate for the possible decline of the number of viable probiotic cells during processing and storage of probiotic containing products and passage through the stomach and intestine (Waterman and Small, 1998).

Due to the increasing awareness about the health benefits provided by live bacteria, the number of commercially marketed probiotic products in the USA has tripled in the past 10 years. According to a new market research report, 'Probiotics Market (2009-2014)', published by Markets and Markets (2009), the global probiotics market is expected to be worth US\$ 32.6 billion by 2014, where Europe and Asia are exoected to account for nearly $42 \%$ and $30 \%$ of the total revenues, respectively. Probiotic dairy products are expected to hold the highest market share among all the products containing probiotic bacteria reaching a market size of almost $\$ 24$ billion by the end of 2014. It was predicted that products supplemented with probiotic bacteria will enjoy the largest market share by the year 2015 (Anonymous, 2009; Figure 2.1.1.1).

Figure 2.1.1.1: Projected shares of global sales of probiotic ingredients, supplements and foods in 2015 (\%) compared to 2010 (\%) (Anonymous, 2009)

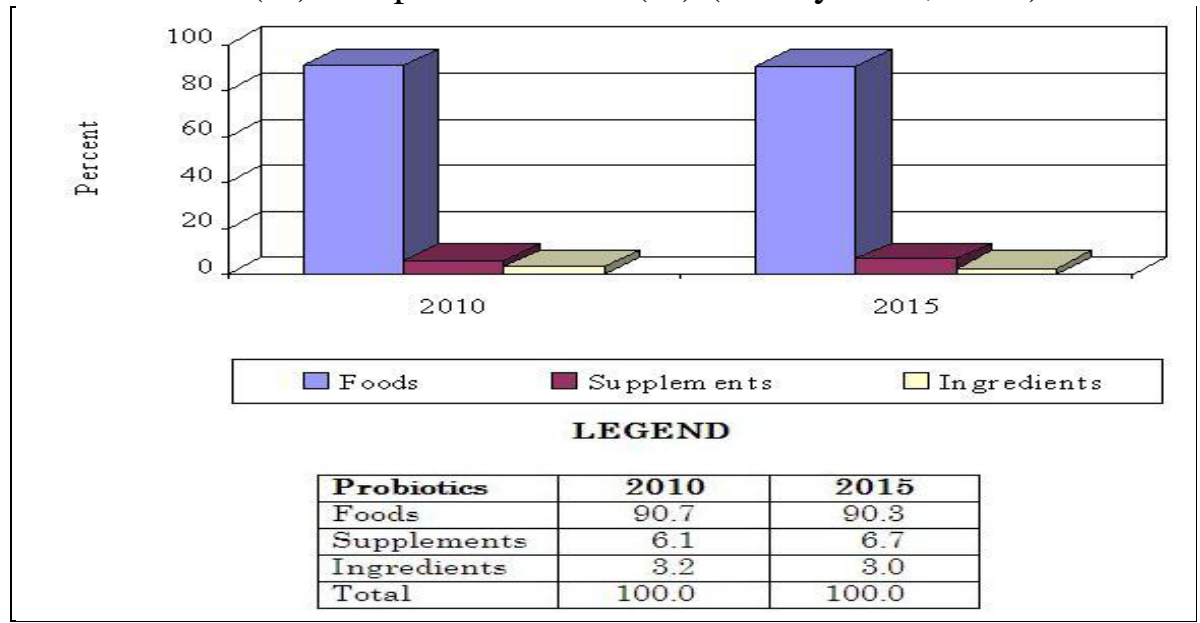


It is important to note that incorporating probiotic bacteria in a food product does not guarantee health benefits. It's essential to ensure that viability of probiotic bacteria during food production and throughout product's shelf life is maintained above recommended level. Many quality control studies of commercialized probiotic products have often revealed deficiencies in the number of viable Bifidobacteria (Gueimonde et al., 2004; Jayamanne and Adams, 2006; Masco et al., 2007; Shah et al., 1995; Tamime, 2002). For instance, a recent study tested viable numbers of Bifidobacteria in ten bioyoghurts sold in the UK market at the time of purchase and at the end of expiration date. The results from this comparison study found that most products contained optimum level of viable Bifidobacteria at the time of purchase but only few maintained high level of viable cells until the end of shelf life (Sanz, 2007). These discrepenses in results emphasize the importance of conducting studies to determine the viability of probiotic bacteria in a food matrix of interest throughout its shelf life and ensure that the viability is maintained at a high level of $10^{6} \mathrm{cfu} / \mathrm{g}$ at the time of its consumption.

Once the survivability of probiotic bacteria is maintained throughout product's shelf life, another important concern is whether the selected strain is resistant to gastric acidity and shear stresses in the stomach and bile toxicity in the small intestine (Collins and Thornton, 1998; Sanders et al., 1996; Chandan, 1999) and whether it's able to provide intended health benefits in vivo. Although, the number of articles on probiotic bacteria has increased exponentially in recent years, there are very few articles about randomized clinical trials (Figure 2.1.1.2; Hibberd and Davidson, 2008). Therefore, it's essential to conduct well planned experiments using in vitro digestion models to screen 
for gastric tolerance of probotic bacteria followed by in vivo studies to firmly establish health benefits (Chou and Weimer, 1999).

Figure 2.1.1.2: Research and randomized trials of probiotics published in the Medline database, 1996-2006 (Hibberd and Davidson, 2008)

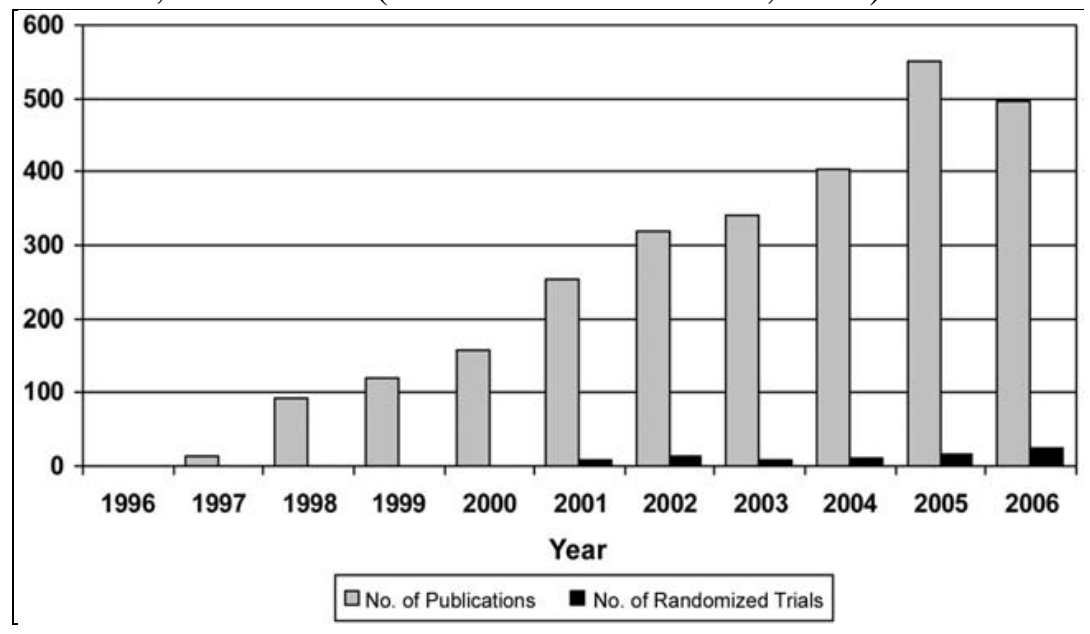

Various species of genera Lactobacillus and Bifidobacteria have been

incorporated in dairy and non dairy products (Table 2.1.1.1 and 2.1.1.2, respectively) over the years to study the effect of food vehicle on the survivability and functionality of selected probiotic bacteria. The Lactobacillus and Bifidobacteria genera are most commonly studied genera and have played an extensive role as probiotics because of their association with healthy human intestinal tract and specifically in the case of Lactobacilli, due to their association with fermented foods. 
Table 2.1.1.1: Dairy products and probiotic bacteria

\begin{tabular}{|c|c|c|}
\hline Products & Probiotic bacteria & References \\
\hline $\begin{array}{l}\text { Crescenza cheese; Cheddar } \\
\text { cheese; Cheese }\end{array}$ & $\begin{array}{l}\text { L.paracasei A13 and L. acidophilus H5; L. } \\
\text { acidophilus } 4962 \text {, L. casei } 279 \text {, B. longum } \\
\text { 1941, L. acidophilus LAFTI® L10, L. } \\
\text { paracasei LAFTI }{ }^{\circledR} \text { L26, B. lactis LAFTI® } \\
\text { B94; L. casei ATCC } 393\end{array}$ & $\begin{array}{l}\text { Burns et al., 2008; Ong et } \\
\text { al., 2006; Kourkoutas et al., } \\
2006\end{array}$ \\
\hline Frozen yogurt, ice cream & $\begin{array}{l}\text { B. longum, L. acidophilus; B. infantis, B. } \\
\text { brevi, B. longum; L. acidophilus La-5, B. } \\
\text { animalis subsp. lactis Bb-12; L. johnsonii } \\
\text { La1; B. bifidum Bb-12, } \\
\text { L. acidophilus La-5, L. casei 01; L. gasseri B- } \\
\text { 14168, L. rhamnosus B-445, L. reuteri B- } \\
\text { 14171, L. acidophilus La-5, B. bifidum Bb-12; } \\
\text { L. acidophilus La-5, L. casei Lc-01, B. } \\
\text { bifidum BB-12, B. longum BB-46; L. casei } \\
\text { Lc-01, B. lactis Bb-12; L. acidophilus DSMZ } \\
\text { 20079 B. bifidum DSMZ 200456; L. } \\
\text { acidophilus 74-2, L. acidophilus LAC 4; L. } \\
\text { acidophilus, L. Rhamnosus; L. acidophilus } \\
\text { LMGP-21381; }\end{array}$ & $\begin{array}{l}\text { Davidson et al., 2000; } \\
\text { Modler et al., 1990; } \\
\text { Magarinos et al., 2007; } \\
\text { Alamprese et al., 2002; } \\
\text { Taha et al., 2005; Salem et } \\
\text { al., 2005; Homayouni et al., } \\
\text { 2008; Turguti and } \\
\text { Cakmakci, 2009; Favaro- } \\
\text { Trindade et al., 2007; } \\
\text { Abghari et al., 2011; Nousia } \\
\text { et al., } 2011\end{array}$ \\
\hline Fermented milk & $\begin{array}{l}\text { L. acidophilus LAC4, B. longum BL; L. } \\
\text { acidophilus La-5 and L. rhamnosus LR35 }\end{array}$ & $\begin{array}{l}\text { Zacarchenco and } \\
\text { Massaguer-Roig, 2006; } \\
\text { Sodini et al, } 2002\end{array}$ \\
\hline Buttermilk & B. animalis subsp. lactis Bb12 & Antunes et al, 2009 \\
\hline Yogurt and yogurt drink & $\begin{array}{l}\text { L. acidophilus and B. lactis; L. acidophilus } \\
\text { and Bifidobacteria; L. acidophilus, B. } \\
\text { bifidum; L. acidophilus La-5, } \\
\text { B. animalis ssp. lactis, BB-12, Streptococcus } \\
\text { thermophilus, L. rhamnosus LGG }\end{array}$ & $\begin{array}{l}\text { Seelee et al, 2009; Dave and } \\
\text { Shah, 1998; Mortazavian et } \\
\text { al, 2008; Ramasubramanian } \\
\text { et al, } 2008\end{array}$ \\
\hline
\end{tabular}


Table 2.1.1.2: Non dairy products and probiotic bacteria

\begin{tabular}{|c|c|c|}
\hline Product & Probiotic bacteria & Reference \\
\hline Mayonnaise & B. bifidum DI, B. infantis 4038 & Khalil and Mansour, 1998 \\
\hline Fermented Pork Sausage & $\begin{array}{l}\text { L. acidophilus JCM1132T, L. crispatus } \\
\text { JCM1185T, L. amylovorus JCM1126T, L. } \\
\text { gallinarum JCM2011T, L. gasseri JCM1131T } \\
\text { L. johnsonii JCM2012T }\end{array}$ & Arihara et al, 1998 \\
\hline $\begin{array}{l}\text { Reduced fat }(60 \% \mathrm{w} / \mathrm{w}) \\
\text { edible table biospread }\end{array}$ & $\begin{array}{l}\text { L. casei ACA-DC 212.3, B. infantis ATCC } \\
\text { 25962, Mixed-strain powder preparation of } L \text {. } \\
\text { acidophilus and B. bifidum ABß Sweet }\end{array}$ & Charteris et al, 2002 \\
\hline Coleslaw & L. acidophilus, B. lactis, L. casei & Rodgers and Odongo, 2002 \\
\hline $\begin{array}{l}\text { French onion cheese based } \\
\text { dip }\end{array}$ & $\begin{array}{l}\text { L. acidophilus LAC1, L. paracasei subsp. } \\
\text { paracasei LCS1, B. animalis Bb12 } \\
\text { P. freudenreichii subsp. shermanii PS1, L. } \\
\text { rhamnosus LC } 705\end{array}$ & Tharmaraj and Shah, 2004 \\
\hline Oat Based Cereal Bar & B. lactis $\mathrm{Bb}-12$ & Ouwehand et al., 2004 \\
\hline Table Olives & $\begin{array}{l}\text { L. rhamnosus ATCC 53103, B. bifidum } \\
\text { ATCC 15696, B. longum ATCC 15708, L. } \\
\text { rhamnosus IMPC11 \& IMPC19, L. paracasei } \\
\text { IMPC2.1 }\end{array}$ & Lavermicocca et al., 2005 \\
\hline Chocolate mousse & L. paracasei subsp. paracasei LBC 82 & Cardarelli et al., 2008 \\
\hline Fresh cut apple slices & L. rhamnosus GG & Roble et al., 2010 \\
\hline $\begin{array}{l}\text { Nonfermented frozen soy } \\
\text { dessert }\end{array}$ & $\begin{array}{l}\text { L. acidophilus MJLA1, L. rhamnosus 100-C } \\
\text { B. lactis BDBB2, L. paracasei ssp. paracasei } \\
\text { Lp-01, B. lactis Bb-12, Saccharomyces } \\
\text { boulardii } 74012\end{array}$ & Heenan et al., 2004 \\
\hline
\end{tabular}




\subsubsection{Lactobacillus}

Lactobacilli are ubiquitous in nature, found in carbohydrate rich environments and are natural inhabitant of human gut. They are gram-positive rods or coccobacilli, non-spore forming and catalase negative organisms (Hammes and Vogel, 1995). They are fermentative (ferment carbohydrates into lactic acid) and facultative anaerobes (produce ATP energy in the presence of oxygen, but switch to fermentation in anaerobic conditions). Their preferred growth temperature depends on the specific species and subtype, but the range is generally $35-38^{\circ} \mathrm{C}$, with $37^{\circ} \mathrm{C}$ optimal for many and the ideal $\mathrm{pH}$ values for growth are slightly acidic, for example, 5.5-6.0 for Lactobacillus acidophilus. This is the most extensively studied genus comprising of 106 species and a few most commonly isolated species from human intestine are L. acidophilus, L. salivarius, $L$. casei, L. plantarum, L. fermentum, L. reuteri and L. brevis (Mitsuoka, 1992).

\subsection{Lactobacillus acidophilus}

L. acidophilus has been considered to be predominant Lactobacillus species in the intestinal tract of healthy humans (Arihara and Luchansky, 1994; Ray, 1996). Thus, it is the most studied species and variety of its strains such as La-5 and La-1 are widely used in commercial dairy and food products as well as dietary supplements (Salminen et al., 1998; Shah, 2001; Tannock, 2002; Holzapfel, 2006). Acidophilus milk is one of the oldest and most commonly found fermented milk products and approximately $80 \%$ of the yogurt manufactured in the US contains L. acidophilus (Sanders, 2003). Important characteristics of L. acidophilus include,

1. Gram- positive, rod shaped non motile, non-flagellated and non-sporing species of genus Lactobacillus. 
2. It is usually around 0.6 to $0.9 \mu \mathrm{m}$ in width and 1.5 to $6.0 \mu \mathrm{m}$ in length with rounded ends.

3. Cells may appear singularly or in pairs as well as in short chains.

4. It belongs to the homofermentative group of Lactobacilli and lactic acid is the only end product of the fermentation process.

5. The optimum growth occurs within $35-40^{\circ} \mathrm{C}$, but it can tolerate temperatures as high as $45^{\circ} \mathrm{C}$.

6. It can utilize lactose as well as sucrose effectively.

7. L. acidophilus has a high cytoplasmic buffering capacity in the $\mathrm{pH}$ range 3.72-7.74 which allows it to resist changes in cytoplasmic $\mathrm{pH}$ and become stable under acidic conditions (Godward et al., 2000; Tamime et al., 2005).

Several studies have been conducted to determine the potential of L. acidophilus to provide health benefits to humans. Lin and Chen (2000) tested six strains of $L$. acidophilus for their cholesterol reducing ability and found that they were able to reduce cholesterol in vivo. This ability of L. acidophilus was attributed to the assimilation of cholesterol by the cells and/or the attachment of cholesterol to the surface of $L$.

acidophilus cells. Several other studies such as Gilliland and Walker (1990) and Liong and Shah (2004) have found that L. acidophilus strains are capable of reducing cholesterol. Some strains of L. acidophilus namely L. acidophilus M92 was found to possess proteinaceous components called S-layer proteins which aid in its aggregation and adhesion to epithelial cells in the intestine as well as play a protective role during its transit through gastrointestinal tract (Frece et al., 2003 and 2005). In vitro tests conducted 
by Bhatia et al. (1989) showed that lactic acid produced by L. acidophilus inhibited the growth of Helicobacter pylori. Sheu et al. (2002) also conducted a clinical study to determine the effect of consumption of probiotic yogurt containing L. acidophilus and B. bifidum on suppression of $H$. pylori and found that supplementation of drugs with live cultures reduced the number of side effects and may enhance the action of drugs on inhibition of $H$. pylori. Another study conducted by Medellin-Pena and Griffiths (2008) tested the effect of presence of $L$. acidophilus La-5 on prevention of E. coli infection in vitro and in vivo. They found that in the presence of specific fractions of L. acidophilus La-5, adhesion and formation of lesions by E. coli was reduced in vitro. In addition, the gut colonization of mice by L. acidophilus La-5 resulted in decreased amount of E.coli counts in feces. L. acidophilus La-5 produces certain molecules that prevent adhesion of E. coli cells to the intestinal epithelial cells. Rajpal and Kansal (2009) demonstrated that consumption of yogurt containing L. acidophilus and B. bifidum may play a role in slowing down the process of ageing as a result of improved antioxidant activity in rats. These studies have demonstrated potential clinical health benefits that could be provided by L. acidophilus strains when consumed in food products or as supplements.

\subsubsection{Probiotic bacteria and dairy products}

Our diet is considered as one of the major factors participating in the regulation of intestinal flora. In addition, food also acts as a buffer for bacterial transit through the stomach to the intestine. Food matrix with appropriate $\mathrm{pH}$ and buffering capacity could play an important role in maintaining the viability of probiotic bacteria during its transit through the stomach. Other matrix factors influencing probiotic viability include fat content, concentration and type of proteins, sugars, the processing and storage conditions 
during product’s shelf life (Kailasapathy and Chin, 2000). Some evidence has indicated that adequate colonization may be achieved in the intestine as a result of maintenance of viability of probiotic bacteria through the stomach when administered in food (Alander et al., 1999). In the United States, as mentioned earlier, the major outlets for probiotic bacteria are dairy foods and dietary supplements.

\subsubsection{Fermented dairy products}

Dairy products like yogurt and fermented milk form the largest segment of the market for probiotic products mainly because they are considered as an ideal vehicle for successfully delivering probiotic bacteria to the human intestine because of their suitable $\mathrm{pH}$, buffering capacity (significantly increases gastric $\mathrm{pH}$ ), presence of fat and possible encapsulation by milk proteins (Ross et al., 2005; Charteris et al., 1998). Fermented dairy foods seem to fit naturally with probiotics because of their long term association with live cultures and positive health image. It's easy for consumers to naturally correlate fermented dairy products with live cultures and perceive a benefit in their presence (Sanders, 2000). However, it is essential to take into account possible synergistic or antagonistic interaction that may occur during production of fermented probiotic dairy product between probiotic bacteria and starter cultures. Studies have reported few antagonistic effects due to the production of bacteriocins (peptides or proteins exhibiting antibiotic properties) and lactic acid (lowering $\mathrm{pH}$ of the product) by starter culture and probiotic bacteria during fermentation causing negative effects on each other's survivability. The ability to produce bacteriocins and lactic acid are both desirable characteristic of probiotic bacteria (Salminen et al., 1996), but when supplemented in addition to starter bacteria could result in detrimental effects limiting the possibility of 
co-existence of starter cultures and probiotic bacteria in the same product (Joseph et al., 1998). Tabasco et al. (2009) conducted a study to identify the bacteriocin produced by $L$. acidophilus La-5 and the factors causing the production of bacteriocin. They found that presence of live yogurt starter cultures such as S. thermophilus and L. delbrueckii subsp. bulgaricus induced bacteriocin production by L. acidophilus La-5. On the contrary, $L$. acidophilus La-5 did not produce any bacteriocin in the presence of non viable cells of yogurt bacteria.

Other factors influencing the viability of probiotic bacteria in fermented dairy products include hydrogen peroxide produced by starter bacteria, availability of nutrients, osmotic pressure due to presence of sugars, dissolved oxygen, inoculation level, fermentation time and storage temperature (Shah, 2000). Kopeloff et al. (1934), Gilliland and Speck (1977) and Ng (2009) found that some strains of L. acidophilus had limited stability in fermented products like traditional acidophilus milk and yogurt because of progressive increase in the acidity of products during storage termed as post acidification since the starter culture bacteria are active at refrigerated temperature.

A few other dairy products which have been explored for supplementation with probiotic bacteria are frozen yogurt, fermented ice cream and cheese. The combination of starter culture and probiotic bacteria could possibly defeat the purpose of addition of probiotic bacteria in the ice cream due to the reasons mentioned above in case of yogurt. Hekmat and McMahon (1992) and Akalin and Erisir (2008) reported significant decrease in L. acidophilus counts in fermented ice cream after storage for 17 weeks at $-29^{\circ} \mathrm{C}$ and 13 weeks at $-18^{\circ} \mathrm{C}$, respectively. The sensory properties of ice cream could be negatively affected due to acidification of the ice cream mix. In addition, there is some evidence that 
consumers prefer less acidic products like frozen probiotic ice cream over fermented probiotic yoghurt like products (Hekmat and McMahon, 1992; Mashayekh and Brown, 1992; Christiansen et al., 1996). In a study conducted Salem et al. (2005), all fermented ice cream treatments scored slightly lower values in melting quality and color attributes than control treatment. This indicates that fermentation of ice cream may result in adverse effects on its attributes. They also found that the viable counts of $L$. acidophilus La-5 reduced by 2 logs at the end of 12 weeks of frozen storage at $-26^{\circ} \mathrm{C}$.

\subsubsection{Ice cream, a non-fermented dairy product}

Ice cream is a popular frozen dessert and enjoyed by all ages. Its production has become a profitable industry because of recent advances and rapidly developing technology (Turgut and Cakmakci, 2009). In 2003, 5333 million liters of ice cream were produced in the US utilizing $10 \%$ of the total milk production and $16 \%$ of the processed milk for this purpose. In 2006, although an overall decrease in the product sales was registered in the American supermarkets, the sale of light and diet ice creams increased by $15 \%$ from January to June (Cruz et al., 2009). This data suggests that consumers are quickly adopting healthier ice cream alternatives when given those choices. What if food producers could give consumers a functional and therapeutic ice cream alternative by supplementing it with probiotic bacteria? Incorporation of probiotic bacteria in ice cream would improve its value as a frozen dessert and provide alternatives to consumers. It may also offer certain advantages over fermented dairy products like frozen yogurt, fermented milk, yogurt in terms of delivery of viable probiotic bacteria, such as neutral $\mathrm{pH}$, low storage temperature and absence of metabolic activity during storage preventing changes in organoleptic properties of ice cream (Taha et al., 2005; Cruz et al., 2009). Ice cream is 
a frozen mixture of fat, proteins, sweeteners, stabilizers, emulsifiers and flavoring agents (Marshall et al., 2003) which makes it a good vehicle for probiotic bacteria. Milk fat and air bubbles act as insulators by reducing the transfer of heat through the frozen foam (Magarinos et al, 2007). Stabilizers bind to the water molecules restricting the growth of ice crystals during storage resulting in minimum damage caused to microbial cells due to increasing size of ice crystals (Jay, 1992).

As a general rule, the addition of probiotic strains into a food product requires producers to ensure that the survivability of probiotic bacteria is maintained at above recommended level at the end of shelf life (Stanton et al., 2003). In order to achieve this goal, a number of factors should be strictly controlled such as the selection of oxygen tolerant and low $\mathrm{pH}$ resistant probiotic bacteria, the initial supplementation level, the appropriate step for adding cultures and the strict control of the storage temperature (Cruz et al, 2009). Successful incorporation of probiotic bacteria involves overcoming intrinsic hurdles (Table 2.1.2.1.1) during processing of the ice cream. These include mixing and shearing step when air is incorporated and freezing step when ice crystals are formed and storage at subzero temperature (Cruz et al., 2009; Mohammadi et al., 2011). 
Table 2.1.2.1.1: Factors affecting viability of probiotic bacteria during ice cream production (Cruz et al, 2009)

\begin{tabular}{|c|c|c|}
\hline Step & Problem & Solutions \\
\hline $\begin{array}{l}\text { Adequate choice of } \\
\text { formulation ingredients } \\
\text { (fruit pulp/juice) }\end{array}$ & $\begin{array}{l}\text { 1. High acidity of final product may lead } \\
\text { to decreased probiotic survival } \\
\text { 2. Some ingredients may have inhibitory } \\
\text { activity against probiotic strains }\end{array}$ & $\begin{array}{l}\text { Preferably use of fruit } \\
\text { pulp/juices with a lower } \\
\text { natural acidity }\end{array}$ \\
\hline $\begin{array}{l}\text { Decision about addition } \\
\text { of probiotic bacteria }\end{array}$ & $\begin{array}{l}\text { 1. If starter cultures are added along with } \\
\text { probiotic bacteria, fermentation due to } \\
\text { starter cultures could result in lowering } \\
\text { of pH which in turn could result in loss } \\
\text { of viability of probiotic strains } \\
\text { 2. If probiotic bacteria is added in the ice } \\
\text { cream mix and allowed to ferment and } \\
\text { produce acid, it can impart acidic } \\
\text { flavors. Perception of an acidic taste } \\
\text { can have a negative effect on the } \\
\text { consumer since ice cream is expected } \\
\text { to be a sweet delicacy vs. sour frozen } \\
\text { yogurt like. }\end{array}$ & $\begin{array}{l}\text { 1. Start with one probiotic } \\
\text { strain of interest and } \\
\text { study it from strain level } \\
\text { to its efficacy as a } \\
\text { theraputic ingredient } \\
\text { 2. Avoid using mixed } \\
\text { strains in the ice cream } \\
\text { preparation } \\
\text { 3. Perform preliminary tests } \\
\text { on combination strains of } \\
\text { interest to determine any } \\
\text { detrimental effects } \\
\text { caused by one strain to } \\
\text { the other }\end{array}$ \\
\hline $\begin{array}{l}\text { Beating/air } \\
\text { incorporation }\end{array}$ & $\begin{array}{l}\text { Oxygen represents a factor of toxicity } \\
\text { for probiotic bacteria }\end{array}$ & $\begin{array}{l}\text { Selection of oxygen } \\
\text { tolerant strain }\end{array}$ \\
\hline Freezing and storage & $\begin{array}{l}\text { Stress induced by freezing results in } \\
\text { cell damage. This damaged cell } \\
\text { eventually dies during storage }\end{array}$ & $\begin{array}{l}\text { 1. Increased inoculum } \\
\text { concentration } \\
\text { 2. Avoid temperature abuse } \\
\text { of the product during } \\
\text { storage }\end{array}$ \\
\hline
\end{tabular}


Many studies have been conducted to study the effect of ice cream manufacturing process on the viability of added probiotic bacteria after processing and throughout shelf life (Taha et al., 2005; Salem et al., 2005; Magarinos et al., 2007; Abghari et al., 2011; Nousia et al., 2011 and Ferraz et al., 2012). An important aspect to consider while producing ice cream supplemented with probiotic bacteria is the step during ice cream manufacturing process during which probiotic bacteria must be added. Abghari et al. (2011) found that the capacity of L. acidophilus to survive the freezing and air incorporation step was higher when it was added before ageing and allowed to interact with ice cream components during ageing at $4^{\circ} \mathrm{C}$ compared to those reported by other researchers who added probiotic microorganisms after the ageing of ice cream mix (Christiansen et al., 1996; Akin et al., 2005). Taha et al. (2005) compared effect of two treatments on the viability of mixed culture of L. acidophilus La-5, B. bifidum BB12 and L. casei 01 after processing and during storage for three months. They aged the mix and added mixed culture to the ice cream mix an hour before freezing and for another treatment ice cream mix was fermented. They found that freezing and air incorporation step resulted in less than one log reduction for all the three probiotic bacteria in two different treatments. In addition, at the end of storage, the viability of all the three bacteria was maintained above 8 log cfu/g and did not decrease significantly throughout storage for both the treatments.

Once the probiotic bacteria are added to the ice cream mix, a process called freezing is used to convert the unfrozen ice cream mix into a frozen dairy product. It is an important step since it defines the structure of the final product and for palatability and production of ice cream; on the contrary, it can affect the number of viable probiotic cells 
incorporated in the mix (Dave and Shah, 1998; Hekmat and McMahon, 1992;

Kailasapathy and Sultana, 2003; Ravula and Shah, 1998). In a study conducted by Magarinos et al. (2007), it was found that $8.7 \%$ and $9.9 \%$ of L.acidophilus La-5 and B. lactis, respectively was lost after freezing, whereas, $4.3 \%$ and $0 \%$ for L. acidophilus La-5 and B. lactis, respectively was lost after storage. These results indicate that the adverse effect of freezing on both the tested probiotic bacteria was higher compared to effect of storage at $-25^{\circ} \mathrm{C}$ for 60 days and survival was species specific. Hagen and Narvhus (1999) found that freezing resulted in $\sim 1$ log reduction in viable bacterial cells. The numbers of viable cells were found to be $7 \log \mathrm{cfu} / \mathrm{g}$ for $B$. bifidum BB-12, $7.4 \log \mathrm{cfu} / \mathrm{g}$ for L. rhamnosus GG and $6.75 \log$ cfu/g for L. acidophilus La-5 in the frozen ice cream shortly after freezing. These results indicate that ice crystal formation during freezing results in injury or death of viable cells and the intensity of the detrimental effect is species specific.

Air addition to the ice cream mix during the freezing process results in overrun. It is defined as percent increase in the volume of ice cream mix as a result of air addition. It results in light texture, partial coalescence and destabilization of the fat present in the mixture and influences the physical properties of the ice cream (Bolliger et al., 2000; Sofjan and Hartel, 2004). Oxygen can be introduced into the ice cream at various steps such as during culture addition into the ice cream mix and intended air incorporation during freezing. After production, atmospheric oxygen can enter into the product during filling and packaging as well as it can diffuse through the packaging material during storage (Talwalkar and Kailasapathy, 2004; Talwalkar et al., 2004). Since air incorporation is a valuable step, it is essential to select oxygen tolerant probiotic strains to 
maintain their viability during ice cream manufacturing process. Oxygen tolerance is also a strain specific characteristic of probiotic bacteria (Kawasaki et al., 2006). The genus Bifidobacteria of probiotic bacteria are more sensitive to oxygen compared to Lactobacillus (Vasiljevic and Shah, 2008). Since most of the Lactobacillus strains are microaerophilic and Bifidobacteria strains are strictly anaerobic, their oxygen scavenging system is reduced or completely absent. This results in an incomplete reduction of oxygen to hydrogen peroxide eventually leading to cell death (Champagne et al., 2005; Talwalkar and Kailasapathy, 2004; Vasiljevic and Shah, 2008). Ferraz et al. (2012) conducted a study to determine the effect of $45 \%, 60 \%$ and $90 \%$ overrun on the viability of $L$. acidophilus DOWARU ${ }^{\mathrm{TM}}$. The probiotic bacteria were added right before freezing the ice cream mix. They found that the survival of L. acidophilus DOWARU ${ }^{\mathrm{TM}}$ was maintained at 8 log cfu/g after freezing with $45 \%, 60 \%$ and $90 \%$ overrun. The effect of amount of air addition was observed during the frozen storage during which the number of viable cells dropped to $7 \mathrm{log}$ cfu/g and $6.06 \mathrm{log}$ cfu/g for samples incorporated with $60 \%$ and $90 \%$ overrun, respectively. The authors suggested that the observed effect of different amounts of air addition was a result of accumulation of toxic metabolites interacting with proteins, lipids and nucleic acids resulting in cell death.

The effect of storage on the viability of probiotic bacteria during ice cream's shelf life is also an important factor that must be studied to ensure viability of tested probiotic bacteria is mentained in excess of recommended level of $10^{6} \mathrm{cfu} / \mathrm{g}$ in the ice cream at the time of consumption. Nousia et al. (2011) studied the effect of low temperature storage of non-fermented ice cream on the survivability of $L$. acidophilus and found that regardless of the storage temperature $\left(-15^{\circ} \mathrm{C}\right.$ versus $\left.-25^{\circ} \mathrm{C}\right)$, the viable cells of L.acidophilus LMGP- 
21381 remained above $10^{7} \mathrm{cfu} / \mathrm{g}$ and did not differ significantly $(\mathrm{p}>0.01)$ throughout the storage study of 45 weeks. These findings were in accordance with those reported by other authors (Godward and Kailasapathy 2003; Magarinos et al. 2007; Turgut and Cakmakci 2009) who indicated that L. acidophilus counts did not change significantly during storage of ice cream at temperatures lower than $-20^{\circ} \mathrm{C}$. Buriti et al. (2010) tested the effect of storage temperature on the viability of L. acidophilus La-5 incorporated in guava mousses and found that survival of L. acidophilus La- 5 reduced by more than 1 log at the end of 28 days storage at $4^{\circ} \mathrm{C}$. On the contrary, the viable cells were maintained at greater than $7 \log \mathrm{cfu} / \mathrm{g}$ at the end of frozen storage at $-18^{\circ} \mathrm{C}$ for 112 days and did not differ significantly throughout storage. These results show that storage temperature may also impact the survival of L. acidophilus La-5 at the end of product's shelf life. The results from these studies indicate that the combination of L. acidophilus and nonfermented ice cream seem to be a promising one that could be further challenged in an in vitro digestion model to determine whether ice cream matrix helps $L$. acidophilus to survive through the stomach in high viable counts.

\subsection{Digestion Process}

The mouth and the stomach are the major parts of human body where food is broken into small size particles whereas small intestine is the major site of nutrient absorption. Digestion of foods begins with chewing in the mouth which is a rapid but important step in digestion. Saliva is secreted in the mouth which consists of mucus, enzyme $\alpha$-amylase and electrolytes. The gastric digestion of foods includes numerous influencing factors such as fed/fast state $\mathrm{pH}$, gastric acid, enzymatic reactions, and hydrodynamic and mechanical forces. This indicates the complexity of digestion process 
which upon ingestion the probiotic bacteria must battle to survive in high numbers and reach the intestine to provide clinical health benefits.

\subsubsection{Mouth}

"Mastication is a process during which pieces of food are ground into a fine state, mixed with saliva, and brought to approximately body temperature ready for transfer to the stomach where most of the digestion takes place” (Bourne, 2004). The presence of food in the mouth is a powerful stimulus to salivation. Saliva is a clear, mucoserous exocrine secretion which is composed of water, a variety of electrolytes (including sodium, potassium, calcium, magnesium, bicarbonate and phosphates) and enzymes such as $\alpha$-amylase and mucin (Guyton and Hall, 1996; Drago et al., 2011).

Water helps to moisten the food particles for easier breakdown. The dominating salivary enzyme, $\alpha$-amylase begins starch digestion in the mouth resulting in a decreased perceived thickness of foods and therefore plays an important role in mouth feel perception. Saliva is secreted from different glands in the mouth and therefore, the magnitude of activity of its components differs based on the location of secretion (Humphery and Williamson, 2001). The magnitude of $\alpha$-amylase activity was reported to be $60-70 \mathrm{U} / \mathrm{ml}$ in whole saliva and $50-60 \mathrm{U} / \mathrm{ml}$ in saliva secreted from parotid gland by Mackie and Pangborn (1990) and Froelich et al. (1987), respectively. The salivary mucin has lubrication properties that helps in formation of a food bolus that can be easily be swallowed (Tabak, 1995). Electrolytes like bicarbonates and phosphates modulate pH and the buffering capacity of saliva. In summary, salivary functions include lubrication and protection, buffering action, maintenance of tooth integrity, antibacterial activity, taste perception and digestion (Moss, 1995). Saliva also plays an important role in 
clearing the esophageal acid because of normal reflux activity (Helm et al., 1983 and 1984) which indicates that the probiotic bacteria comes in contact with low $\mathrm{pH}$ and acid only in the stomach.

In healthy, non-medicated adults, the saliva flow rates are on an average 0.3 $\mathrm{mL} / \mathrm{min}$ and $1.5 \mathrm{~mL} / \mathrm{min}$ for unstimulated and stimulated whole saliva, respectively (Bertram, 1967; Heintze et al., 1983; Sreebny, 2000). There is great variation in the values found in literature for unstimulated and stimulated salivary flow rate. This is because the composition of saliva and its flow rate is influenced by the type and size of gland from which saliva is secreted (Ericson, 1971), state of hydration (Shannon, 1966), nutritional state (Johansson et al., 1992), the time of collection (Dawes, 1975), nature, characteristics and duration of stimulus (Dawes, 1969) and emotional state of the subject (Bolwig and Rafaelsen, 1972). The average $\mathrm{pH}$ value of saliva reported in literature is between $6 \pm 0.5$ (unstimulated) to $7 \pm 0.5$ (stimulated) (Drago et al., 2011; Davidson et al.,1998; Engelen et al.,2003; Humphrey and Williamson, 2001).

The effect of saliva on the viability and in vitro oral colonization potential of probiotic bacteria was tested by Haukioja et al. (2006). They found that the Lactobacillus and Bifidobacterium strains survived for $24 \mathrm{hr}$ in saliva except for two strains that showed decreased counts after $24 \mathrm{hr}$ incubation. None of the tested strains grew in saliva. The results from this study showed that some strains might be sensitive to the component(s) of saliva and therefore, it's essential to consider testing probiotic survivability in a simulated mastication process in addition to simulated in vitro gastric transit. 


\subsubsection{Stomach}

The human stomach is a "J"- shaped, hollow and elastic organ that is divided into four major regions: fundus, body, antrum and pylorus. The three main functions of the stomach include storage of large particles of food for further disintegration, mixing of food with the contents of gastric juice and emptying of small particles into the intestine. The reservoir function of the stomach is achieved through its flexible volume which is capable of expanding to accommodate upto $4 \mathrm{~L}$ of food. Digestive juice which consists of hydrochloric acid ( $\mathrm{HCl})$ and enzymes is secreted to promote the enzymatic splitting of proteins, carbohydrates, and fats, while peristaltic contractions of the entire gastrointestinal tract (GIT) generate mechanical forces to promote mechanical and chemical breakdown of the food, absorption, and emptying. These intensity of secretory and motor responses of the GIT is affected by the individual, digestion time, and the amount, composition, and physicochemistry of the meal (Coupe et al., 1991; Camilleri and Prather, 1994; Mayer 1994; Parada and Aguilera, 2007).

\subsubsection{Gastric secretion}

Food stimulates Central Nervous System (CNS) activity, which results in the release of acid and gastrin hormone (Debas and Carvajal, 1994). Upon ingestion of food, alterations in stomach $\mathrm{pH}$ caused due to the food's buffering capacity and volume results in hydrochloric acid $(\mathrm{HCl})$ secretion. The mechanism of $\mathrm{HCl}$ secretion involves $\mathrm{G}$ cells in the antrum to secrete gastrin hormone which signals parietal cells to secrete gastric acid until the fasting state $\mathrm{pH}$ is restored (Wollin, 1987). Once the fasting state $\mathrm{pH}$ is restored, D cells secrete somatostatin to down regulate acid and gastrin hormone release (Chew, 1983; Magami et al., 2002; Schubert et al., 1987) protecting the stomach from excessive 
acidity (Guyton and Hall, 1996). Principal components of gastric secretion (Table 2.2.2.1.1) include hydrochloric acid ( $\mathrm{HCl}), 0.8$ to $1 \mathrm{mg} / \mathrm{ml}(=1 \mathrm{~g} / \mathrm{L})$ pepsin, about 1.5 mg/ml (=1.5g/L) mucin (Vertzoni et al, 2005; Dean and Ma, 2007; Guyton and Hall, 1996b) and cations are sodium (about 70mM) and potassium (about 15mM), whereas the principal anion is chloride (about 100mM) (Dressman et al., 1998; Vertzoni et al., 2005; Kalantzi et al., 2006).

Table 2.2.2.1.1: Principal components of gastric juice and their functions (Glass, 1968)

\begin{tabular}{|c|c|c|}
\hline Components & Concentration & Function \\
\hline $\mathrm{HCl}$ & Variable & $\begin{array}{l}\text { 1. Helps in breaking down of connective tissue and } \\
\text { muscular fibers } \\
\text { 2. Modifies gastric osmolarity by bringing the } \\
\text { hyperosmotic and hyposmotic chyme to isosmotic } \\
\text { level } \\
\text { 3. Activates pepsinogen into pepsin by lowering the pH } \\
\text { to a range where pepsin is active } \\
\text { 4. Prevents bacterial growth and colonization } \\
\text { 5. Stimulate secretin and pancreozymin production in } \\
\text { the duodenum which in turn results in the secretion of } \\
\text { bicarbonates and enzymes by pancreas. }\end{array}$ \\
\hline Pepsin & $0.8-1 \mathrm{~g} / \mathrm{L}$ & $\begin{array}{l}\text { 1. The activation of pepsinogen results into pepsin at a } \\
\text { pH range } 1.0-2.0 \text {. } \\
\text { 2. Pepsin helps in protein digestion. } \\
\text { 3. It clots milk in human stomach similar to rennin in } \\
\text { cows stomach due to denaturation of proteins in the } \\
\text { milk }\end{array}$ \\
\hline Mucin & $1.5 \mathrm{~g} / \mathrm{L}$ & $\begin{array}{l}\text { Mucin forms a gelatinous coating over the mucosal } \\
\text { surface to prevent the digestion of stomach itself by } \\
\text { hydrochloric acid }\end{array}$ \\
\hline
\end{tabular}

The resting volume of stomach in the fasted state rarely exceeds $50 \mathrm{ml}$ (Glass, 1968). Dressman et al. (1990) and Malagelada et al. (1976) reported empty (fasting) state stomach $\mathrm{pH}$ to be in the range 1.3-2.5 with a considerable degree of inter subject variation. They also found that the fasting state $\mathrm{pH}$ increased to on an average $\mathrm{pH}$ of 6.7 following ingestion of 6oz of hamburger, 2 slices of bread, $20 \mathrm{z}$ of hash brown potatoes, 1tbsp each of ketchup and mayonnaise, $1 \mathrm{oz}$ each of tomato and lettuce and $8 \mathrm{oz}$ of milk 
(total $1000 \mathrm{kcal}$ ) meal and pH 5.0 after consumption of coarsely ground tenderloin steak, cooked and seasoned with $0.1 \mathrm{~g}$ of salt; $25 \mathrm{~g}$ of white bread with $8 \mathrm{~g}$ of butter; $60 \mathrm{~g}$ of vanilla ice cream topped with $35 \mathrm{~g}$ of chocolate syrup and $240 \mathrm{ml}$ of water, respectively. This increase in $\mathrm{pH}$ upon consumption of meal clearly reflects the buffering effect of the food consumed. The higher the $\mathrm{pH}$ upon consumption of a meal, the more acid will be secreted in order to restore the $\mathrm{pH}$ back to the fasting state $\mathrm{pH}$. Besides $\mathrm{pH}$, other important factors that could lead to an increased rate of gastric secretion, acidity and dilution include food composition, its properties (protein and fat content, initial $\mathrm{pH}$ and viscosity) and the ingested quantity.

Meal viscosity also plays an important role since increase in meal viscosity causes an increase in the rate of secretion. The stomach responds to a high viscosity meal by increasing the rate of gastric secretion resulting in dilution and decrease in ingested meal viscosity. Marciani et al. (1999) reported that the viscosity of a meal containing $1.5 \mathrm{~g}$ locust bean gum per $100 \mathrm{~g}$ fell from 11 to 2 Pa.s immediately after ingestion and further decreased to 0.3 Pa.s after 30 min of digestion. Malagelada et al (1979) found that solidliquid meals induced a stronger gastric secretory response (acid, pepsin, and volume) resulting in higher gastric acidity and volume compared to homogenized meals. This demonstrates the dynamic mechanism of gastric secretion in response to the food composition and its properties. Since probiotic bacteria are incorporated in a food product, it's very important to understand how composition of the food is able to enhance rate of gastric secretion and may consequently affect the survivability of probiotic bacteria during gastric transit. 
During passage through the stomach, the viability of probiotic bacteria incorporated in a food matrix is influenced by stress factors like acid, enzymes and mechanical shear due to strong peristaltic contractions (Heatley and Sobala, 1993; Simon and Gorbach, 1987). Many probiotic bacteria are known to be acid sensitive (Shah and Jelen 1990; Berrada et al., 1991; Mituoka 1992; Shah and Lankaputhra 1997; Gardiner et al, 2000). In vivo and in vitro studies have found that initial $\mathrm{pH}$ of the stomach and its decrease from fed state $\mathrm{pH}(4-6)$ to fasting state $\mathrm{pH}(<3.0)$ during digestion are the principal factors affecting the viability of probitic bacteria during its gastric transit (Conway et al, 1987; Pitino et al, 2010; Kheadr et al, 2009). Therefore, it’s crucial to carefully select the food matrix for incorporating probiotic bacteria. Alternatively, a meal with high buffering capacity and fat content may protect the bacteria against acidic conditions during the digestion process before the bacteria is exposed to the restored fasting state $\mathrm{pH}$.

\subsubsection{Mechanical forces}

The pattern of stomach motility is distinctly different in the fasting and fed states. There is a four phase movement in the fasting state and continuous movement in the fed state. There are two types of contractions namely regular tonic contractions and peristaltic contractions. Tonic contractions move food from the top to the bottom of the stomach and peristaltic contractions are responsible for grinding, kneading and mechanical disintegration of food (Kong and Singh, 2010). Gastric waves pass along both the lesser and the greater curvatures. Usually they do not proceed simultaneously along both the curvatures, so that there is generally some backlog between downward moving waves along both curvatures of the stomach (Glass, 1968). As the peristaltic wave 
reaches the pylorus, the contraction width increases and indentations deepen (Bilecen et al., 2000; Schulze, 2006). Meanwhile, the pylorus contracts and the sphincter narrows so that only small particles or liquid can empty into the intestine whereas, the large particles are squirted back into the stomach for further disintegration. This action is called retropulsion (Figure 2.2.2.2.1). Magnitude of peristaltic contractions depend on various biological factors such as age, body mass index, hormonal factor, gender, blood glucose level and whether a person is suffering from any disorders. In addition, stomach increases or decreases the force of these contractions depending on the physical properties of food like solid, liquid, high viscosity, fat and protein content to result in complete digestion and emptying of food (Marciani et al., 2001).

Figure 2.2.2.2.1: Propulsion, grinding, and retropulsion of solids by peristaltic contractions of distal stomach (Kong and Singh, 2008)

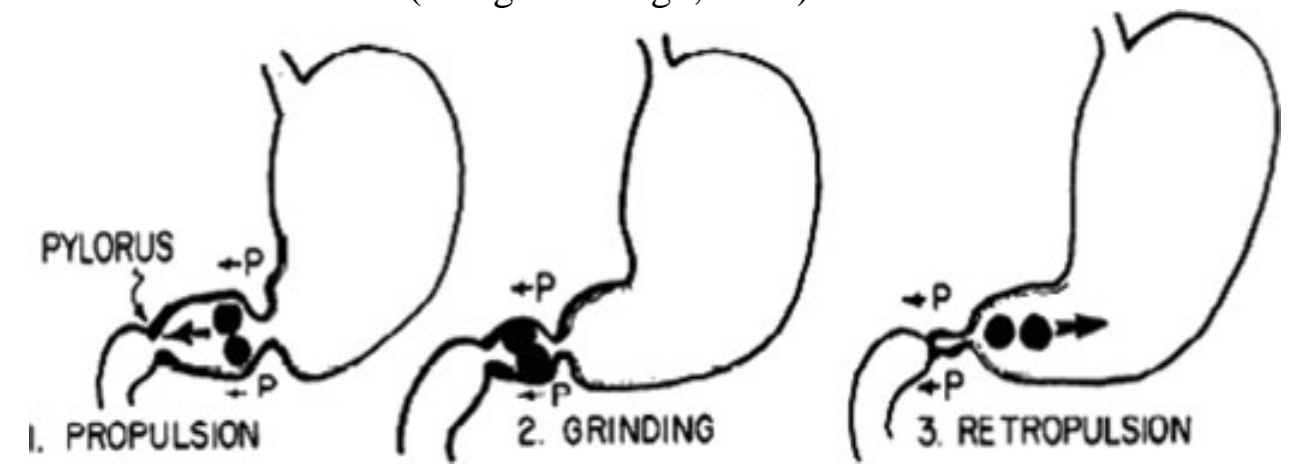

\subsubsection{In vitro digestion models}

Methods that simulate the gastrointestinal digestion process in the laboratory are known as gastrointestinal models (GIMs) or in vitro digestion models (Parada and Aguilera, 2007). In vivo assays using humans or animals may provide the most accurate results, but they are costly, labor intensive, time consuming and causes ethical concern (Boisson and Eggum, 1991). Therefore, GIMs are used as a suitable alternative to in vivo assays to perform prescreening studies. Based on the results obtained from GIMs, 
accurate experimental planning can be done for validating its results in in vivo studies. GIMs can be categorized at static and dynamic models. Static models mainly include chemical digestion process while the mechanical disintegration is often ignored. Dynamic models typically simulate both chemical and mechanical aspects of the complex digestion process (Parada and Aguilera, 2007). A few examples of dynamic models are TNO (TIM) (Figure 2.2.3.1), Dynamic Gastric Model (DGM) (Figure 2.2.3.2), Human Gastric Simulator (HGS) (Figure 2.2.3.3) and Dynamic Model of Human Upper Gastrointestinal Tract (Figure 2.2.3.4). A comparison between the currently available in vitro models is shown in Table 2.2.3.1. Hur et al. (2011) did a survey on various in vitro digestion models and found that they differ from one another in their operation:

1. The number and type of steps included in the digestion sequence, e.g., mouth, stomach, small intestine, large intestine.

2. The composition of the digestive fluids used in each step, e.g., enzymes, salts, buffers, biological polymers, and surface active components.

3. The mechanical stresses and fluid flows utilized in each step in the digestion sequence, e.g., magnitude and direction of applied stresses, flow geometries, and flow profiles. 
Table 2.2.3.1: In vitro digestion models

\begin{tabular}{|c|c|c|}
\hline Model & Model Description & Reference \\
\hline $\begin{array}{l}\text { TNO (TIM) developed at } \\
\text { TNO Nutrition and Food } \\
\text { Research (Zeist, The } \\
\text { Netherlands) }\end{array}$ & $\begin{array}{l}\text { 1. Four serial compartments simulating the stomach, } \\
\text { duodenum, jejunum, and ileum, are connected with } \\
\text { each other by computer-controlled valve pumps. } \\
\text { 2. The temperature is kept at } 37^{\circ} \mathrm{C} \text { and system is kept } \\
\text { anaerobic by flushing with } \mathrm{N}_{2} \text { gas. } \\
\text { 3. Change in water pressure simulates peristaltic } \\
\text { movements } \\
\text { 4. The pH values are controlled via the computer by } \\
\text { secreting either water or } 1 \mathrm{M} \text { HCI into the stomach, or } \\
\text { by secreting either water or } 1 \mathrm{M} \text { NaHC03 into the } \\
\text { duodenum, via syringe pumps. } \\
\text { 5. Secretions of gastric electrolytes and enzymes, bile and } \\
\text { pancreatic juices are regulated by using computer- } \\
\text { controlled syringe pumps. }\end{array}$ & $\begin{array}{l}\text { Minekus et al, 1995; } \\
\text { Yoo and Chen, } 2006\end{array}$ \\
\hline $\begin{array}{l}\text { Dynamic Gastric Model } \\
\text { Developed at Model Gut } \\
\text { Platform - Institute of Food } \\
\text { Research Norwich Research } \\
\text { Park }\end{array}$ & $\begin{array}{l}\text { The DGM is built on a modular design of two stages:- } \\
\text { 1. Stomach: The first part simulates the main body of the } \\
\text { stomach (fundus). This stage of the model mimics the } \\
\text { mixing dynamics, diffusion profiles of both acid and } \\
\text { enzymes and emptying cycles measured within the } \\
\text { main body of the human stomach. This is followed by a } \\
\text { unique emptying routine into a second module } \\
\text { simulating the antrum (the lower part of the stomach). } \\
\text { Here the digesta is subjected to high shear (as } \\
\text { measured using EPI), forcing mechanical breakdown of } \\
\text { the food structure. } \\
\text { 2. Small intestine: Material emptied from the DGM can } \\
\text { be then processed within a simulation of the small } \\
\text { intestine. Here, intestinal mixing dynamics and } \\
\text { diffusion are integrated with the addition of }\end{array}$ & Wickham et al, 2009 \\
\hline
\end{tabular}




\begin{tabular}{|c|c|c|c|}
\hline & & $\begin{array}{l}\text { bicarbonate, phospholipids, bile and digestive enzymes } \\
\text { simulating the complex environment of the small } \\
\text { intestine. }\end{array}$ & \\
\hline $\begin{array}{l}\text { Dynamic model of human } \\
\text { upper gastrointestinal tract } \\
\text { developed at Food Research } \\
\text { and Development Centre, } \\
\text { Agriculture and Agri-Food } \\
\text { Canada }\end{array}$ & & $\begin{array}{l}\text { The model consists of two } 1 \mathrm{~L} \text { jacketed glass beakers } \\
\text { representing the stomach and the duodenum. } \\
\text { Stomach Reactor include pH electrode, a temperature } \\
\text { probe, and two entry ports for meal and HCl delivery } \\
\text { into the stomach. } \\
\text { For the duodenum reactor, there are three entry ports } \\
\text { for stomach digesta, NaOH, and Oxgall bile. } \\
\text { A magnetic stir bar is placed inside each vessel and } \\
\text { agitation is controlled via a magnetic stirrer plate. This } \\
\text { mimics shear caused in the stomach as a result of } \\
\text { contractions } \\
\text { The temperature inside the reactors is controlled by } \\
\text { circulating water at } 37^{\circ} \mathrm{C} \text { through the jacketed beakers. } \\
\text { Peristaltic pumps are used to control the delivery of the } \\
\text { products to be added, as well as the emptying rate of } \\
\text { the stomach reactor into the duodenum reactor. }\end{array}$ & Mainville et al, 2004 \\
\hline $\begin{array}{l}\text { Human Gastric Simulator } \\
\text { developed at Dept. of } \\
\text { Biological and Agricultural } \\
\text { Engineering, Univ. of } \\
\text { California, } \\
\text { Davis, U.S.A }\end{array}$ & & $\begin{array}{l}\text { HGS consists of round cylindrical stomach vessel made } \\
\text { of latex rubber. } \\
\text { The main latex body has a diameter of } 102 \mathrm{~mm} \text { and a } \\
\text { depth of } 280 \mathrm{~mm} \text {, and it has a collective volume of } 5.7 \\
\text { L. } \\
\text { The bottom end of the latex vessel is tapered with an } \\
\text { angle of } 75 \text { degrees to reduce the diameter to } 25 \mathrm{~mm} \text {. } \\
\text { Plastic tubing with internal diameter } 3.2 \mathrm{~mm} \text { connects } \\
\text { the vessel bottom to a peristaltic pump for emptying } \\
\text { digesta from the vessel. } \\
\text { During digestion trials, a thin polyester mesh bag with } \\
\text { net pore size of } 1.5 \mathrm{~mm} \text { is placed inside the latex }\end{array}$ & $\begin{array}{l}\text { Kong and Singh, } \\
2010\end{array}$ \\
\hline
\end{tabular}




\begin{tabular}{|c|c|c|}
\hline & 6. & $\begin{array}{l}\text { vessel, covering the inner wall of the latex. This bag } \\
\text { allows small particulates of }<1 \text { to } 2 \text { mm to pass } \\
\text { through the mesh for emptying and retains large } \\
\text { particulates for further breakdown, thus simulating a } \\
\text { "sieving effect” of pylorus. } \\
\text {. A mechanical driving device consisting of } 12 \text { rollers, } 4 \\
\text { belts, driving shafts, and pulley system has been } \\
\text { installed to create peristaltic contractions on } 4 \text { sides of } \\
\text { the latex stomach vessel. The driver is set to create } 3 \\
\text { contractions per minute on the latex vessel, to simulate } \\
\text { the actual stomach contraction frequency of } 3 \text { cycles } \\
\text { per minute. } \\
\text { A variable flow mini peristaltic pump delivers } \\
\text { simulated gastric juice into the simulated stomach } \\
\text { chamber through a } 6.4 \text {-mm ID plastic pipe splitting } \\
\text { into } 5 \text { polythylene tubing (I.D. } 0.86 \text { mm). A control } \\
\text { valve is used to adjust the flow rate for the tubing. } \\
\text { Two } 60 \text { W light bulbs are installed to maintain the } \\
\text { temperature at } 37^{\circ} \mathrm{C} \text { and a thermostat is used to turn } \\
\text { on/off the bulbs automatically. }\end{array}$ \\
\hline
\end{tabular}




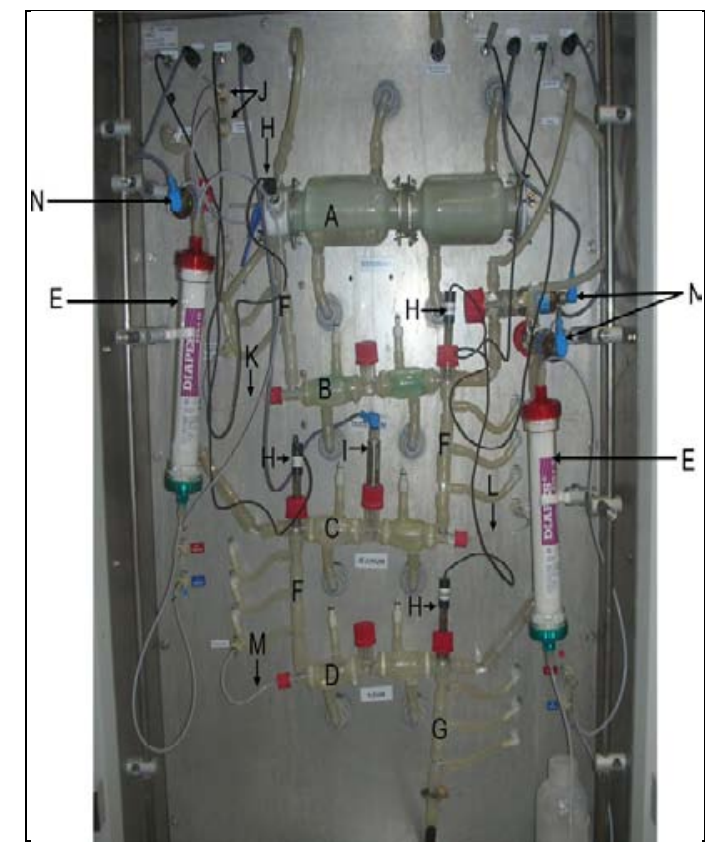

Figure 2.2.3.1: The multi-compartmental dynamic TIM-1 model of the gastrointestinal system. Vessels (A-D) constitute the gastric, duodenal, jejunal and ileal compartments, respectively. Modules (E) are semi-permeable hollow-fiber membrane dialysis units. (F) Peristaltic valves, (G) ileo-caecal valves, (H) $\mathrm{pH}$ electrodes, (I) temperature sensor, (J) stomach secretion inlets, (K) duodenal secretions inlet, (L) and (M) bicarbonate secretion inlet, and $(\mathrm{N})$ volume detecting sensors (Khalf et al, 2010)

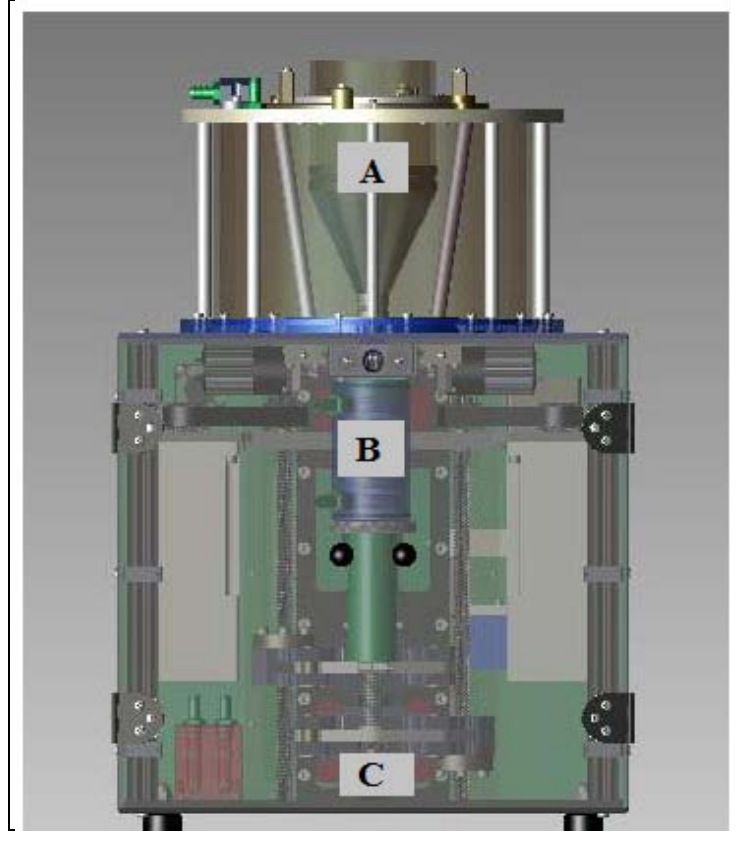

Figure 2.2.3.2: Dynamic Gastric Model. A- Main Body, B- Antrum, C- Emptying (Model Gut called Dynamic Gastric Model, PBLTechnology, 2006) 


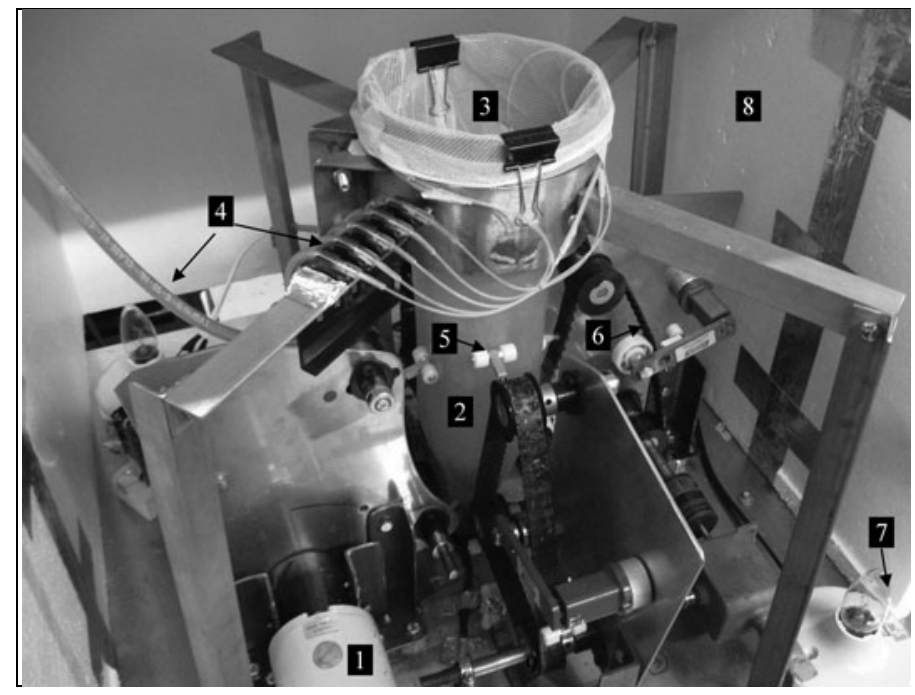

Figure 2.2.3.3: HGS. (1) Motor; (2) latex lining; (3) mesh bag; (4) secretion tubing; (5) roller; (6) belt; (7) light bulb for temperature control; (8) plastic foam insulation (Kong and Singh, 2010)

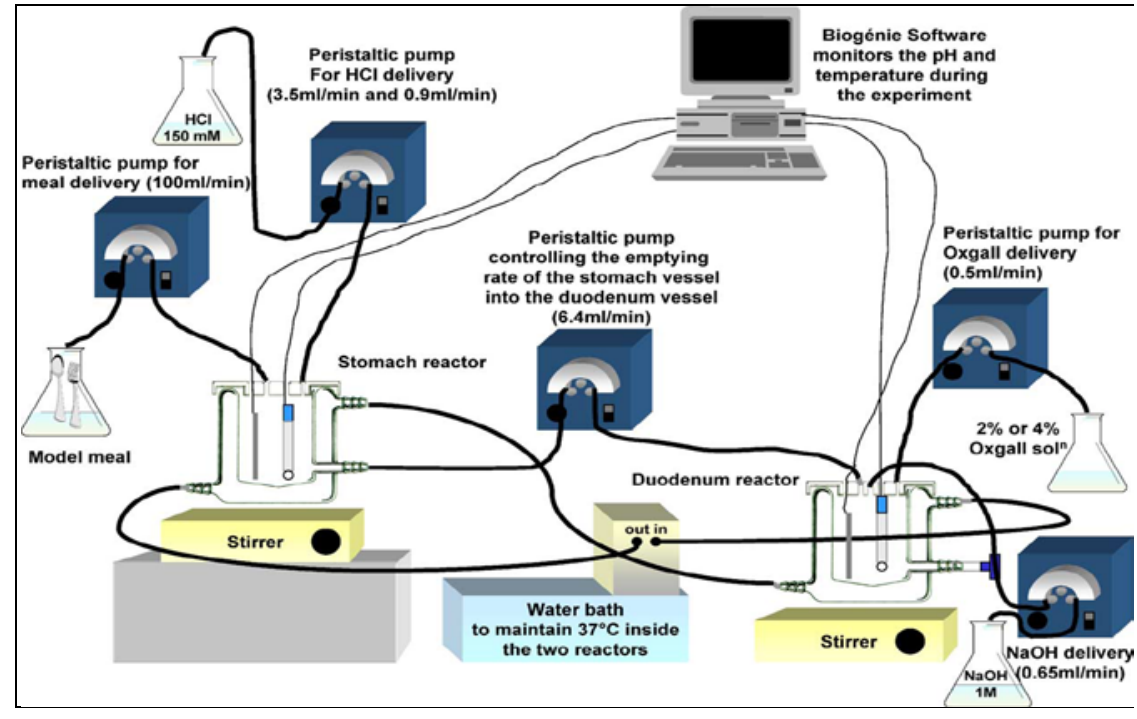

Figure 2.2.3.4: The dynamic in vitro human upper GI tract model system (Mainville et al., 2005) 
During the past few years, food and animal scientists have utilized a number of these in vitro digestion models (both static and dynamic) to test the structural and chemical changes that occur in different foods during digestion process. In vitro models have been successfully used in assessing the quantitative release of functional ingredients and nutrients from food and drugs, such as tyrosol in enriched custards (Sanz and Luyten, 2006); carotenoids in carrot matrix (Garrett et al., 1999; Hedren et al., 2002); antioxidants in wholegrain foods (Nagah and Seal, 2005); stability and composition of the major polyphenols in chokeberry juice (Bermudez-Soto et al., 2007); isoflavonoids in soy bread (Walsh et al., 2003); disintegration kinetics of solid foods (Kong and Singh, 2008); and determining probiotic bacteria survivability during GI transit (Marteau et al, 1997; Pitino et al., 2010; Mainville et al., 2005). Marteau et al. (1997) reported no significant difference between the in vitro and in vivo data indicating that DGM has a predictive value for the survival of probiotic bacteria in humans. Limited foods and beverages have been studied using in vitro models.

Both static and dynamic models have been extensively used for assessing probiotic survivability during simulated digestion (gastric juice-low $\mathrm{pH}$, presence of bile and peristaltic contractions) (Marteau et al., 1997; Maathuis et al., 2009; Kheadr et al., 2009; Pitino et al., 2010), to determine the protective effect of food matrix on the viability of probiotic bacteria (Khalf et al., 2010; Possemiers et al., 2010), to validate in vitro probiotic survivability with in vivo data (Ritter et al, 2009; Martinez et al, 2011), to determine the effect of selected prebiotic on the survivability of probiotic bacteria (Buriti et al., 2010; Martinez et al., 2011) as well as to validate the label claim about the level of live bacteria present in commercial products like yogurt, Gefilus milk, Gefilus, Emmental 
cheese, Tutteli baby formula (Sumeri et al, 2008). A list of probiotic bacteria that have been tested in dynamic in vitro models is shown in Table 2.2.3.3.

Few studies have been conducted to determine the effect of food matrix and resistance of L.acidophilus La-5 to gastrointestinal stress and the effect of prior stress such as cold or low pH on its viability during digestion (Fernandez de Palencia et al., 2008; Sumeri et al., 2008; Buriti et al., 2010). Fernandez de Palencia et al. (2008) tested the effect of incubating L. acidophilus La-5 in skim milk acidified to $\mathrm{pH}$ 5.0, 4.1, 3.0, 2.1 and 1.8 for 20 min at each $\mathrm{pH}$ simulating conditions during digestion. They found more than $90 \%$ survival at the end of 20 min incubation each at $\mathrm{pH} 5.0$ and $4.1, \sim 80 \%$ survival after incubation at $\mathrm{pH} 3.0, \sim 60 \%$ survival after incubation at $\mathrm{pH} 2.1$ and less than $20 \%$ survival of L. acidophilus La-5 at the end of 20 min incubation at $\mathrm{pH} 1.8$. These results indicate that $\mathrm{pH}$ below 2.0 caused highest percent mortality of L. acidophilus La-5. Buriti et al. (2010) studied the impact of storage temperature and simulated gastric conditions on the viability of $L$. acidophilus La-5 incorporated in guava mousse. The authors subjected L. acidophilus La-5 to simulated gastric conditions by incubating at $\mathrm{pH} 1.9$ or lower for $2 \mathrm{hr}$ and found that as the days of storage at $4^{\circ} \mathrm{C}$ progressed, the sensitivity of $L$. acidophilus La-5 towards low pH increased and on days 21 and 28 its viability was below $2 \log \mathrm{cfu} / \mathrm{g}$ at the end of $2 \mathrm{hr}$ simulated digestion. Whereas, the viability of L. acidophilus La-5 was improved for samples stored at $-18^{\circ} \mathrm{C}$ and found to be 4 log cfu/g or slightly below when subjected to low pH for $2 \mathrm{hr}$ on days 7, 35, 56, 84 and 112. The authors attributed this difference in viability of $L$. acidophilus La-5 to the initial stress of cold storage resulting in their better response to stress due to acidic conditions and they called this “cross-protective stress response”. 
Table 2.2.3.3: In vitro models and probiotic bacteria

\begin{tabular}{|c|c|c|c|}
\hline Model & Delivery Matrix & Strains & Reference \\
\hline TNO & $\begin{array}{l}\text { Olifus, yogurt; Lactose } \\
\text { solution ( } 5 \% \text { w/v in water), } \\
\text { fructose solution ( } 5 \% \text { w/v in } \\
\text { water), milk; Fermented milk; } \\
\text { Maple sap; experimental meals } \\
\text { (with prebiotic, skimmed milk } \\
\text { and with other probiotic } \\
\text { bacteria) }\end{array}$ & $\begin{array}{l}\text { B. Bifidum and L. acidophilus; } \\
\text { L. delbrueckii ssp. bulgaricus strain LB9; } \\
\text { Streptococcus thermophilus strain ST20; } \\
\text { Bacillus coagulans BC 30; Pediococcus } \\
\text { acidilactici UL5; B. animalis E508, L. } \\
\text { paracasei E510, L. rhamnosus E522, L. } \\
\text { plantarum E98; B. bifidum BB12 and L. } \\
\text { rhamnosus GG; L. amylovorus DSM 16698, B. } \\
\text { animalis subsp. lactis Bb-12 }\end{array}$ & $\begin{array}{l}\text { Marteau et al, 1997; } \\
\text { Maathuis et al, 2009; } \\
\text { Kheadr et al, 2009; } \\
\text { Miettinen et al, 1998; } \\
\text { Khalf et al, 2010; } \\
\text { Martinez et al, 2011 }\end{array}$ \\
\hline SHIME & Chocolate & $\begin{array}{l}\text { L. helveticus CNCM I-1722 and B. longum } \\
\text { CNCM I-3470 }\end{array}$ & Possemiers et al, 2010 \\
\hline DGM & $\begin{array}{l}\text { MRS broth; Sterile water and } \\
\text { UHT whole milk }\end{array}$ & $\begin{array}{l}\text { Six L. rhmanosus strains: D44, F17, H12, H25, } \\
\text { N24, R61; L. casei subsp. shirota, L. casei } \\
\text { subsp. immunitas, L. acidophilus subsp. } \\
\text { johnsonii }\end{array}$ & $\begin{array}{l}\text { Pitino et al, 2010; } \\
\text { Curto et al, 2011 }\end{array}$ \\
\hline $\begin{array}{l}\text { Dynamic } \\
\text { model of the } \\
\text { human upper } \\
\text { gastrointestinal } \\
\text { (GI) tract }\end{array}$ & Irradiated kefir & $\begin{array}{l}\text { B. infantis ATCC 27920G, L. acidophilus ATCC } \\
\text { 4356, L. johnsonii NCC533 La-1, L. rhamnosus } \\
\text { ATCC } 53103 \text { GG }\end{array}$ & Mainville et al, 2005 \\
\hline $\begin{array}{l}\text { Single } \\
\text { bioreactor } \\
\text { system } \\
\text { gastrointestinal } \\
\text { tract simulator } \\
\text { (GITS) }\end{array}$ & $\begin{array}{l}\text { Lactose containing complex, } \\
\text { Gefilus milk, Gefilus daily } \\
\text { dose drink, Gefilus Emmental } \\
\text { cheese, Gefilus peptide Tutteli } \\
\text { baby formula; UHT skim milk; } \\
\text { MRS medium frozen in } \\
\text { nitrogen beads }\end{array}$ & $\begin{array}{l}\text { L. acidophilus La-5, L. johnsonii NCC 533, L. } \\
\text { casei strain shirota, L. rhamnosus GG; L. gasseri } \\
\text { K7, B. animalis subsp. lactis } 14403, \text { B. longum } \\
\text { subsp. infantis } 14390, \text { B. longum 14383, B. } \\
\text { adolescentis } 14377, \text { B. longum } 14382, \text { B. breve } \\
\text { 14938, B. longum 14406; L. acidophilus La-5, L. } \\
\text { rhamnosus GG, and L. fermentum ME-3 }\end{array}$ & $\begin{array}{l}\text { Sumeri et al, 2008; } \\
\text { Ritter et al, 2009; } \\
\text { Sumeri et al, 2010 }\end{array}$ \\
\hline
\end{tabular}




\subsection{Justification of work}

The most common outlet for probiotic bacteria is found to be fermented dairy products such as fermented milk and yogurt since consumers are well aware of the existence of live bacteria in these products and the positive health image associated with them. However, several studies have shown that fermented dairy products do not sustain adequate populations of viable probiotic bacteria during their shelf life. The main obstacle for achieving and maintaining the required levels of probiotic bacteria in fermented dairy products is the poor survival due to interactions between species present, increased acidity, culture conditions, chemical composition of the product, availability of nutrients, growth promoters and inhibitors, concentration of sugars, level of inoculation, incubation temperature, fermentation time and storage temperature (Shah 2000; Heller 2001; Antunes et al. 2005; Donkor et al. 2007; Mortazavian et al. 2007). Thus, it’s important to study the effect of alternative non-fermented dairy products such as ice cream on the survivability of probiotic bacteria during product manufacture, storage and gastric transit. This will eliminate the adverse effects of fermentation process preserving the benefits of milk components like fat and proteins on the survival of probiotic bacteria.

To encourage consumer acceptance of alternate products, it's extremely important to minimize negative effects of probiotic supplementation on the organoleptic properties of these products. Therefore, it's important to choose a form of probiotic bacteria that would cause least impact on the flavor. In addition, it should be convenient and easy for big factories to supplement products with probiotic bacteria to result in better efficiency and productivity. Abghari et al. (2011) conducted a study to evaluate the efficiency of non-fermented ice cream for delivering L. acidophilus and L. rhamnosus to consumers 
and to determine its effect on organoleptic properties of ice cream. Sensory analysis indicated that panelists were able to distinguish between control and inoculated samples based on flavor difference. The cause of off-flavor in the ice cream could possibly be due to harvested cells from MRS medium that were used to inoculate the ice cream mix (Abu-Taraboush et al, 1998). Therefore, using freeze dried form of bacterial culture could possibly ensure better palatability in addition to least processing requirements for ice cream factories.

Numerous studies have tested survival of $L$. acidophilus La-5 during ice cream manufacture and storage at subzero temperature (Salem et al., 2005; Taha et al., 2005; Magarinos et al., 2007). They found that viability of L. acidophilus La-5 after feeezing and at the end of shelf life is mainatained above the recommended level of $10^{6} \mathrm{cfu} / \mathrm{g}$. The consumption of high level of L. acidophilus La-5 may not guarantee the intended health benefits because it must reach the intestine in high viable numbers to be able to provide these benefits. Hence, it is extremely important to study its viability in the presence of acid, enzymes and mechanical shear caused due to peristaltic contractions during simulated digestion process. A few studies have investigated the effect of food products on the survivability of $L$. acidophilus La-5 when subjected to gastric stress using an in vitro digestion model (Fernandez de Palencia et al., 2008; Sumeri et al., 2008; Buriti et al., 2010). None of these studies have looked at the effect of incorporating L. acidophilus La-5 in an ice cream on its viability during simulated digestion process. Hence, in the present study, low fat non-fermnted ice cream was supplemented with L. acidophilus La5 and its survival was determined during simulated digestion of $2 \mathrm{hr}$ using an in vitro model stomach called Human Gastric Simulator (HGS). 
Abghari et al. (2011) conducted a conventional acid resistance test by incubating cells in MRS broth adjusted to $\mathrm{pH}$ 1.5, 2.5, 3.5 and 6.5 to determine whether frozen thawed cells (from ice cream) displayed a similar or different acid shock response compared to fresh cells. This study was conducted with a possibility of acid tolerant strains becoming acid sensitive after going through the mixing, churning, freezing and air incorporation process as well as storage at sub zero temperatures. Since probiotic bacteria must survive low $\mathrm{pH}$ conditions during their transit through the stomach; there would be no reason to incorporate acid tolerant strains into the product that could become acid sensitive at the end of food production and storage. Their results showed that at $\mathrm{pH} 2.5$, the number of L. acidophilus cells decreased significantly $(\mathrm{p}<0.05)$ by 3 log units after 1 hr of incubation for fresh cells, whereas, frozen thawed cells were completely inhibited at the end of $1 \mathrm{hr}$ incubation at $\mathrm{pH}$ 2.5. On the contrary, Alamprese et al (2002 and 2005) reported no significant reduction in frozen thawed cells at the end of $3 \mathrm{hr}$ incubation at pH 2.5 and 3.5 in comparison to fresh cells for L. johnosnii La-1 and L. rhamnosus GG. Therefore, it's essential to ensure that the selected strain does not become acid sensitive after production and storage.

Convention acid resistance test has its own limitations since the bacteria are exposed to the same $\mathrm{pH}$ throughout the incubation time partially contradictory to conditions in vivo, it oversimplifies the mixing patterns and does not reproduce temporal nature of gastric and duodenum processing, mechanical forces that probiotic bacteria will encounter in the stomach resulting from contractions of the stomach wall, dilution of food and particle size reduction which can affect the digestion rate are ignored (Kong and Singh, 2010; Curto et al., 2011). This could lead to rejection of probiotic strains that have 
potential to reach the intestine in high numbers and provide health benefits (Mainville et al, 2005). Therefore, it's important to test the acid resistance of probiotic bacteria in an in vitro model closely simulating digestion conditions in vivo. Therefore, in the present study, conventional acid resistance test was conducted suing a static model and the results were compared with those obtained from HGS. This in vitro dynamic model is capable of simulating both chemical and mechanical conditions that occur during digestion in in vivo. In addition, it is the only in vitro dynamic digestion model available in the U.S. Using this model will allow more research to be conducted in the U.S and save time and money that would be spent in its absence by going to other countries to use the in vitro models.

\subsubsection{Research Objectives}

1) To determine the effect of air addition on the viability of L. acidophilus La-5

2) To determine the effect of simulated digestion process on the viability of $L$. acidophilus La-5

\subsubsection{Research Tasks}

Phase I: Survivability of L. acidophilus La-5 in nonfermented low fat ice cream

a) To manufacture low fat nonfermented probiotic ice cream by inoculating the ice cream mix with freeze dried form of $L$. acidophilus La-5 and determine the effect of addition of La-5 on the physicochemical properties of ice cream.

b) To determine the effect of two levels of over run and freezing on the viability of L. acidophilus La-5 immediately after freezing and during storage at $-10^{\circ} \mathrm{C}$ for 90 days. 
Phase II: Bench top experiments

a) To evaluate in vitro buffering capacity of ice cream mix, milk and PBS in the absence of L. acidophilus La-5 and compare it with buffering capacities of samples in the presence of La-5.

b) To assess the effect of simulated gastric shear and dilution on the survivability of L. acidophilus La-5 in low viscosity and high viscosity ice cream samples.

c) To determine the effect of incubation of L. acidophilus La-5 and L. paracasei 431 at $\mathrm{pH} 2.0$ and $\mathrm{pH} 5.0$ in the absence of ice cream mix for two hours on its survivability during and at the end of $2 \mathrm{hr}$.

d) To compare survivability of each of the tested probiotic bacteria (L. acidophilus La-5 and L. paracasei 431) at $\mathrm{pH} 2.0, \mathrm{pH} 5.0$ and during simulated static digestion in the presence of ice cream mix.

Phase III: In vitro digestion of ice cream

a) To determine the acid tolerance of $L$. acidophilus La-5 incorporated in a low fat non-fermented ice cream during a closely replicated gastric digestion after its storage at $-10^{\circ} \mathrm{C}$ for 30 days.

b) To compare the buffering effect of ice cream observed in the static model stomach experiments with two different in vitro model stomachs namely shaking water bath and human gastric simulator (HGS).

c) To determine whether presence of mechanical shear caused due to peristaltic contractions (similar to the ones found in the stomach during digestion) had an impact on the survivability of $L$. acidophilus La-5 in addition to the impact of $\mathrm{pH}$. 
d) To assess the role of viscosity as an important factor in maintaining the viability of Lactobacillus acidophilus La-5 during simulated digestion process.

\subsubsection{Research Hypotheses}

1. The ice cream sample incorporated with $100 \%$ overrun will pose significant detrimental impact on the viability of L. acidophilus La-5 post freezing process compared to the ice cream sample incorporated with $60 \%$ overrun.

2. The modeled digestion of ice cream in human gastric simulator (HGS) will result in significantly lower survival rate of L. acidophilus La-5 at the end of $2 \mathrm{hr}$ digestion compared to the shaking water bath model stomach.

3. The high buffering capacity and viscosity of the ice cream will provide protection and improve viability of $L$. acidophilus La-5 during simulated gastric digestion in Human Gastric Simulator.

4. The high initial inoculation level of L. acidophilus La-5 in the ice cream will result in higher percent survival at the end of simulated digestion of $2 \mathrm{hr}$ in HGS compared to the low initial inoculation level. 


\subsection{Materials and Methods}

3.1 Phase I: Survivability of L. acidophilus La-5 in non-fermented low fat ice cream

\subsubsection{Ice cream production}

Ice cream was manufactured to study the effect of two levels of over run (OR) namely $60 \%$ and $100 \%$ on the survivability of Lactobacillus acidophilus La-5 (Figure 3.1.1.1). Raw milk, 3.5\% fat (Cal Poly Dairy, San Luis Obispo, CA) and pasteurized cream, 38\% fat (Producers Dairy, California, U.S.A) were used in the ice cream mix as fat sources. Nonfat dry milk (Grade A, Dairy America, USA), sugar (Extra fine granulated cane sugar, Classic SYSCO), Corn syrup solids (Cargill, USA) and stabilizer/emulsifier blend (Grindsted ${ }^{\circledR}$ Ice Pro 2516 LF, Danisco, USA) were also used in making the ice cream mix. The ice cream formulation was based on $4 \%$ fat, $12 \%$ nonfat milk solids, 15\% sugar, 4\% Corn Syrup Solids, 0.65\% stabilizer/emulsifier and 35\% total solids (Appendix I).

Two batches of ice cream mix were made (100 lbs each), one control mix and one probiotic test mix. The probiotic test mix was inoculated with probiotic bacteria strain Lactobacillus acidophilus La-5 (Chr. Hansen, Wisconsin, U.S.A) and mixed thoroughly to yield an initial population of $10^{7} \mathrm{cfu} / \mathrm{g}$. After 24 hours of ageing at $4^{\circ} \mathrm{C}$, for both mixes, half of the mix was frozen with a $60 \%$ OR and the other half was frozen with a $100 \%$ OR using batch scrap surface freezer (Technogel, Greensboro, NC) with a draw temperature of $-4^{\circ} \mathrm{C}$. The overrun was regulated by using the air incorporation screw from the heat exchanger, which was adjusted to the desired amount. Throughout processing, the screw was adjusted two times, resulting in the following overrun levels: 60\% (P60) and 100\% (P100) (Table 3.1.1.1). All the ice cream samples supplemented with La-5 were the 
experimental samples (P60 and P100). Control and experimental ice cream samples were

filled in $3.50 z$ cups, placed in the hardening freezer at $-26^{\circ} \mathrm{C}$ and then moved to $-10^{\circ} \mathrm{C}$

freezer for 90 days for shelf life study.

Table 3.1.1.1: Probiotic and control ice creams - features and codes

\begin{tabular}{|l|l|l|}
\hline Ice cream samples & Features & Code \\
\hline Probiotic ice cream 60 & $60 \%$ over run level & P60 \\
\hline Probiotic ice cream 100 & $100 \%$ over run level & P100 \\
\hline Control ice cream 60 & $60 \%$ over run level & C60 \\
\hline Control ice cream 100 & $100 \%$ over run level & C100 \\
\hline
\end{tabular}

Figure 3.1.1.1: Probiotic ice cream manufacturing procedure

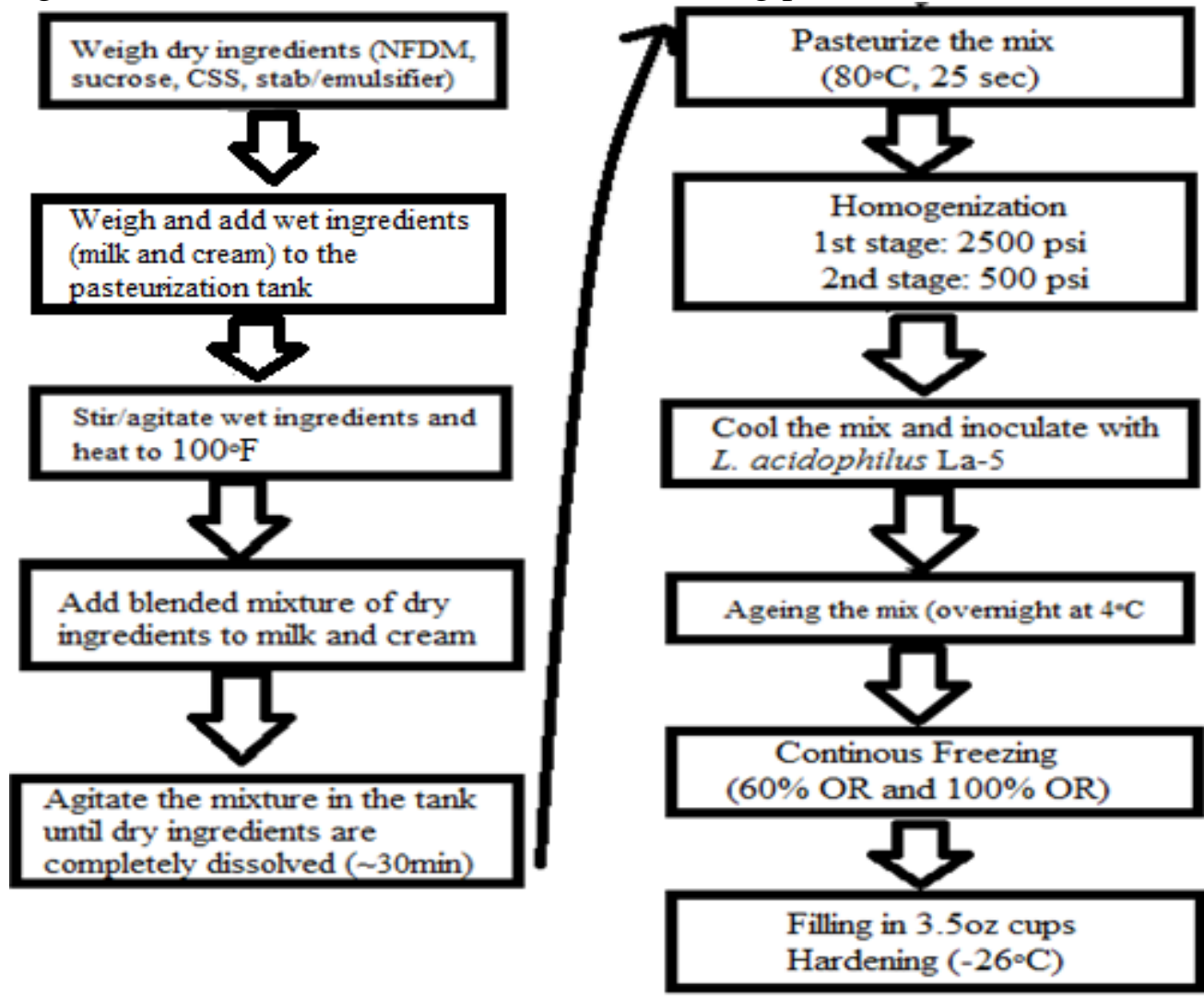

Table 3.1.1.2: Experimental Design Effect of two levels of over run (OR) on survivability of Lactobacillus acidophilus La-5

\begin{tabular}{|l|l|l|l|}
\hline Factor & Treatment levels & Response & Repetition \\
\hline \multirow{2}{*}{$\begin{array}{l}\text { Level of } \\
\text { overrun }\end{array}$} & $60 \%$ & $\begin{array}{l}\text { Survival of } \\
\text { L.acidophilus La-5 }\end{array}$ & 2 \\
\cline { 2 - 3 } & $100 \%$ & \multirow{2}{*}{ L.acidop } & \\
\hline
\end{tabular}




\subsubsection{Enumeration of L. acidophilus La-5}

Experimental samples were collected prior to and immediately after freezing (soft ice cream at $-4^{\circ} \mathrm{C}$ ) and after hardening to determine the effect of air addition on the rate of survival of L. acidophilus La-5 in the ice cream. During the three months of storage, P60 and P100 ice cream samples were examined every 30 days for L. acidophilus La-5 viability. To determine the counts of viable $L$. acidophilus La-5, $11 \mathrm{~g}$ of individual experimental samples were transferred to a sterile bag containing $99 \mathrm{~mL}$ of phosphate buffered saline (PBS, pH 7.2, Hardy Diagnostics, Santa Maria, CA). Further 10 fold dilutions were made from this dilution, and the counts were performed in duplicate by using the pour plating technique using MRS (de Man, Rogosa and Sharpe, Difco) agar. L- Cys- $\mathrm{HCl}$ was added to MRS agar at $0.05 \%$ (wt/vol) to reduce the redox potential of the medium for the growth of L. acidophilus La-5 (Taha et al., 2005). The plates were placed in an anaerobic jar and the resulting colonies on the plates were counted after 48 $\mathrm{hr}$ incubation at $37^{\circ} \mathrm{C}$ in a closed incubator containing $5 \% \mathrm{CO}_{2}$ (v/v) (Abghari et al., 2011).

\subsubsection{Physiochemical analysis of ice cream mix}

Microbial analysis, fat, moisture and total solids analysis was conducted after making the ice cream mix, whereas, $\mathrm{pH}$ and viscosity tests were conducted after ageing the ice cream mix.

Microbial Analysis: All mixes produced were analyzed for standard plate count and E.coli/Coliform (EC/CC) before inoculation with probiotic bacteria to validate that the mix was properly pasteurized. Standard plate counts were determined by plating $1 \mathrm{~mL}$ of each sample in duplicate on aerobic plate count (APC) Petrifilm (3M, St. Paul, MN) 
and incubating at $32^{\circ} \mathrm{C}$ for $48 \mathrm{hr}$. Coliform counts were determined by plating $1 \mathrm{~mL}$ of each sample in duplicate on E.coli/Coliform Petrifilm and incubating at $35^{\circ} \mathrm{C}$ for $24 \mathrm{hr}$.

Fat, moisture and total solids (TS): Percent fat was determined using Mojonnier fat extraction method (Wehr, 2004). Each sample was tested in duplicate. Moisture and TS was measured using CEM Corporation LabWave9000, Microwave Moisture/Solids Analyzer (Modler et al, 1990). All the samples were tested in triplicate by spreading approximately 2.0 grams of ice cream mix sample on a sample pad and heated for 5 min at $60 \%$ power. The final moisture content and TS were recorded.

$\mathrm{pH}$ and titratable acidity: The $\mathrm{pH}$ values were measured in triplicate for aged control and experimental samples at room temperature using $\mathrm{pH}$ meter (Orion, Model 410) standardized to $\mathrm{pH} 4.0$ and $\mathrm{pH}$ 7.0. The average of three readings was recorded. Acidity of mixes was determined in duplicate by titration with $\mathrm{NaOH} 0.1 \mathrm{~N}$, using phenolphthalein as an indicator (Richardson, 1986)

Mix Viscosity: A Brookfield viscometer, model 1/4 RV DV II+ (Brookfield Engineering Laboratories, Stoughton, MA, USA) was used to measure the apparent viscosity of the ice cream mix samples (with and without added probiotic bacteria) after overnight ageing at $4^{\circ} \mathrm{C}$. Samples were tested in duplicate at $4^{\circ} \mathrm{C}$ and $37^{\circ} \mathrm{C}$ with spindle \#18. Temperature was maintained by connecting the water bath (VWR North American Ca\# 13271-074, Model 1160S) to the sample holder. Samples were loaded into the sample cup and allowed to equilibrate at the desired temperature. Viscosity was then recorded after samples were sheared for about $20 \mathrm{sec}$ in the shear rate range of 2.64 to 66 $\sec ^{-1}$ at $4^{\circ} \mathrm{C}$ and in the range of 13.2 to $66 \mathrm{sec}^{-1}$ at $37^{\circ} \mathrm{C}$. The power law model was used to describe the apparent viscosity of the mix as a function of shear rate and to calculate the 
flow behavior index (n) and consistency index ( $\kappa$ ) of the different ice-cream mixes (Goff et al, 1994).

$$
\eta=\kappa D^{n-1}
$$

Where,

$\eta=$ the relative viscosity

$\mathrm{D}=$ the shear rate

$\mathrm{n}=$ the flow behavior index

$\kappa=$ the consistency index

\subsubsection{Statistical Analysis}

Data was statistically analyzed using General Linear Model of Minitab 16.0 software (PA, USA) to determine significant effects of freezing process, percentage of overrun and storage at $-10^{\circ} \mathrm{C}$ on the survivability of L. acidophilus La-5. Significant differences in the viable cells of La- 5 between samples pre and post freezing were determined using one way analysis of variance (ANOVA) with viable counts as response and level of overrun as main effect. Significant differences in the viable cells of La-5 during storage (30, 60 and 120 days) were also evaluated using one way analysis of variance (ANOVA) with viable counts as response and storage time and level of over run as main factors. The significance level used for all the analysis was $5 \%$.

\subsection{Phase II: Bench top experiments}

\subsubsection{Buffering capacity of ice cream mix, milk and PBS}

A comparison study was conducted to determine the amount of gastric juice (GS) required to restore fasting state stomach $\mathrm{pH}(\sim 2.0)$ once the $\mathrm{pH}$ of GS in the simulated empty stomach increases upon addition of ice cream mix (Cal Poly ice cream mix, 10\% fat), milk (3.5\%, pasteurized milk) and 1x PBS, $\mathrm{pH} \sim 7.0$ (10x PBS, $0.017 \mathrm{M}$ potassium phosphate monobasic (Fisher Sci. cat \#P-0662), 0.1 M potassium phosphate dibasic (EMD Chemicals, cat \#PX1570-2), 1.49 M NaCl (Fisher Sci. cat \#S640-3)). All the 
experiments were conducted at room $\left(22 \pm 1^{\circ} \mathrm{C}\right)$ and body temperature $\left(37 \pm 1^{\circ} \mathrm{C}\right)$, in the presence and absence of $L$. acidophilus La-5 and in the presence of ice cream mix, milk or PBS. Simulated GS was prepared fresh by dissolving pepsin (1 g/L; Laboratory Grade; Powder; cat\# P53 100, Fisher Scientific, USA), gastric mucin (1.5 g/L; mucin from porcine stomach, cat\# M2378-100G, Sigma-Aldrich, USA), and NaCl (8.775 g/L) in deionized water. The $500 \mathrm{~mL}$ of GS was added to an acidometer and placed on a heat plate adjusted to $39^{\circ} \mathrm{C}$ so that the temperature of the GS in the flask is maintained at $37 \pm 1^{\circ} \mathrm{C}$ taking into account any heat loss. Once the temperature of GS was at $\sim 37^{\circ} \mathrm{C}$, its $\mathrm{pH}$ was adjusted to $1.5 \pm 0.05$. A 4 oz glass cup was filled with $9 \mathrm{~mL}$ of ice cream, milk or PBS with or without $1 \mathrm{~g}$ of $L$. acidophilus La-5. The native $\mathrm{pH}$ was recorded before adding GS to the samples. A list of indicators used to indicate a decrease in $\mathrm{pH}$ by a change in color as GS was consistently added to the sample cup is shown in Table 3.2.1.2. Three to four drops of bromocresol purple $(0.04 \%(\mathrm{w} / \mathrm{v})$ aqueous solution, CAS \# 62625-30-3, Ricca Chemical, TX, USA) was added to the sample cup to detect the pH change of the sample from its native $\mathrm{pH}$ to $\mathrm{pH}$ 5.0. Once, the indicator changed color from purple to yellow (Table 3.2.1.1), amount of GS added as well as pH was recorded. A similar process was repeated with methyl red $(0.02 \%(w / v)$ aqueous solution, CAS \# 845-10-3, Ricca Chemical, TX, USA), bromocresol green (0.04\% (w/v) aqueous solution, CAS\# 62625-32-5, Ricca Chemical, TX, USA) and congo red (0.1\% (w/v) aqueous solution, CAS\# 573-58-0, Ricca Chemical, TX, USA) indicators for $\mathrm{pH}$ change from native $\mathrm{pH}$ of sample to $\mathrm{pH} 4.0,3.0,2.0$, respectively. 
Table 3.2.1.1: Experimental design - buffering capacity

\begin{tabular}{|l|l|l|l|}
\hline Factors & Treatment levels & Response & Repetition \\
\hline \multirow{3}{*}{ Product } & Ice cream mix & Amount of gastric & 2 \\
& Milk & juice required to \\
& restore pH of $~ 2.0$ & \\
\cline { 2 - 2 } & PBS & & \\
\cline { 2 - 2 } Temperature & Room & & \\
\cline { 2 - 2 } & Body & & \\
\hline Probiotic bacteria & Presence & & \\
\hline & Absence & & \\
\hline
\end{tabular}

Table 3.2.1.2: Indicators and color change

\begin{tabular}{|l|l|l|l|}
\hline Indicator & Color $(\mathrm{pH}>5.0)$ & Final color change & Final $\mathrm{pH}$ \\
\hline Congo Red & Red & Blue & 2 \\
\hline Bromocresol green & Blue & Yellow & 3 \\
\hline Methyl red & Red & Pink & 4 \\
\hline Bromocresol Purple & Purple & Yellow & 5 \\
\hline
\end{tabular}

3.2.2 Effect of shear and dilution on the survivability of L. acidophilus La-5

Bench top experimental set up was used to determine the effect of continuous shear for $2 \mathrm{hr}$ and dilution with GS at regular intervals on the survivability of $L$.

acidophilus La-5 incorporated in low and high viscosity ice cream samples. The viscosity of ice cream mixes was changed by varying the amount of added stab/emulsifier. The ice cream formulation was based on a) 5\% fat, 11\% MSNF, 15\% sugar, 4\% CSS, $0.65 \%$ stab/emulsifier (Appendix II) and b) 5\% fat, 11\% MSNF, 15\% sugar, 4\% CSS, 1.3\% stab/emulsifier (Appendix III). Each of the two ice cream mixes were inoculated with $L$. acidophilus La-5 to yield an initial count of $10^{8} \mathrm{cfu} / \mathrm{g}$ before freezing. After ageing, the mixes were frozen with 60\% overrun. Experimental samples were collected pre and post freezing and plated in duplicate (section 3.1.2). DV II+ Pro Viscometer (Brookfield Engineering Laboratories, Stoughton, MA, USA), consisting of jacketed cylindrical sample holder and connected to water bath (VWR North American Ca\# 13271-074, 
Model 1160S) was used for these experiments. Spindle SC4-21 was used for low viscosity samples and spindle SC4-27 was used for high viscosity samples.

\subsubsection{Effect of simulated gastric shear}

In order to determine effect of simulated gastric shear on the survivability of $L$. acidophilus La-5, slightly different procedure was followed for low viscosity samples compared to high viscosity samples due to equipment constraints. Low viscosity ice cream cup (3.5oz) was placed at room temperature for thawing. The water bath was set at $4^{\circ} \mathrm{C}$. Once the temperature of the water bath was equilibrated, $10 \mathrm{~mL}$ of ice cream was added to the sample cup and the temperature of water bath was set at $37^{\circ} \mathrm{C}$ to simulate change in temperature that occurs upon consumption of ice cream. The sample was sheared at a rate $22.32 \mathrm{sec}^{-1}$ (Brenelli et al., 1997) for $2 \mathrm{hr}$. One $\mathrm{mL}$ of ice cream samples were collected before starting the experiment at $4^{\circ} \mathrm{C}$, once the temperature of sample was adjusted to $37^{\circ} \mathrm{C}$, at the end of 60 and 120 min and pour plated on MRS agar (Section 3.2.3.1). Similar process was repeated for high viscosity sample except for the shear rate which was $21.76 \mathrm{sec}^{-1}$.

\subsubsection{Effect of simulated gastric dilution of ice cream}

Simulated GS was prepared (section 3.2.1) and its $\mathrm{pH}$ was adjusted at 7.0 by using $0.1 \mathrm{~N} \mathrm{NaOH}$. Two $\mathrm{mL}$ of GS was added to the sample cup. Usually the $\mathrm{pH}$ of the empty stomach is in the range of 1.5 to 2.5 , but gastric juice at $\mathrm{pH} 7.0$ was used in this experiment to prevent the effect of low $\mathrm{pH}$ in addition to effect of dilution on the survivability of $L$. acidophilus La-5. The primary goal was to determine the effect of dilution of ice cream upon ingestion and during digestion on the viability of La-5. Once the temperature of gastric juice was adjusted to $37^{\circ} \mathrm{C}, 5 \mathrm{~mL}$ of thawed ice cream $\left(\sim 4^{\circ} \mathrm{C}\right)$ 
was added to the sample cup containing GS. The mixture was sheared at a rate of 22.32 $\sec ^{-1}$ and $21.76 \mathrm{sec}^{-1}$ for low and high viscosity ice cream samples, respectively. One mL sample was collected before adding ice cream to GS in the sample cup and after the temperature of ice cream and GS increased and equilibrated at $37^{\circ} \mathrm{C}$. Four mL GS was added to the mixture after first 15 and 45 min of the experiment to mimic progressive gastric secretion in vivo. One mL sample was collected at the end of 30, 60 and $120 \mathrm{~min}$ and all the samples were immediately pour plated on MRS agar (section 3.2.3.1).

\subsubsection{Conventional acid resistance test in the presence and absence of ice cream}

\subsubsection{Acid resistance test in the absence of ice cream}

Probiotic strains of L.acidophilus La-5 and L. paracasei 431 were obtained from Chr. Hansen (Wisconsin, U.S.A) in the DVS frozen pellet form. One gram was carefully weighed and added to $10 \mathrm{~mL}$ of Phosphate Buffered Saline (PBS; section 3.2.1). The mixture was thoroughly mixed using a bench top vortex to dissolve the frozen pellets and disperse homogeneously in a $10 \mathrm{~mL}$ PBS tube. One $\mathrm{mL}$ of sample was collected, serially diluted, and pour plated on MRS agar to determine the initial number of bacteria (cfu/g). This was the control. To determine acid tolerance of the two probiotic strains, a $50 \mathrm{~mL}$ falcon tube was filled with $16 \mathrm{~mL}$ of citrate-HCl buffer $(29.40 \mathrm{~g} / \mathrm{L}$ tri sodium citrate. $2 \mathrm{H}_{2} \mathrm{O}$ and $1 \mathrm{M} \mathrm{HCl}$; Ritter et al., 2009) adjusted to $\mathrm{pH}$ 2.0. This tube was tied to a bench top rotator (Labquake, Barnstead International, IA, USA; Model \# 415110) and placed on a platform shaker (Innova 2000, New Brunswick Scientific, CT, USA) in an incubator set at body temperature $\left(37^{\circ} \mathrm{C}\right)$ to allow the temperature of the buffer to equilibrate with the incubator temperature. 
Four $\mathrm{mL}$ of PBS plus probiotic bacteria mixture was carefully pipetted into $50 \mathrm{~mL}$ falcon tube containing citrate- $\mathrm{HCl}$ buffer, $\mathrm{pH} 2.0$ to mimic fed state stomach conditions. The mixture was continuously mixed by shaking at $50 \mathrm{rpm}$ to simulate gastric mixing and shear due to peristaltic contractions during digestion (Oomen et al., 2003). A similar procedure was followed to determine acid tolerance of $L$. acidophilus La-5 and $L$. paracasei 431 at pH 5.0 (Ruiz-Moyano et al., 2008). One mL of experimental sample was collected immediately after administration of PBS and probiotic bacteria into citrate$\mathrm{HCl}$ buffer and at the end of 60 and $120 \mathrm{~min}$. One $\mathrm{mL}$ of experimental sample was serially diluted with 9 mL of PBS (pH 7.2, Hardy Diagnostics, Santa Maria, CA). Further 10-fold dilutions were made from this dilution and the counts were performed in duplicate using the pour plating technique and MRS agar (section 3.1.2).

\subsubsection{Acid resistance test in the presence of ice cream}

Cal Poly creamery ice cream mix (10\% fat) was used to determine protective effect of ice cream components on the survivability of $L$. acidophilus La-5 and $L$. paracasei 431 during simulated digestion conditions. One gram of frozen pellets was carefully weighed and added to $10 \mathrm{~mL}$ of PBS (section 3.2.1). The mixture was thoroughly mixed. Four $\mathrm{mL}$ of this mixture was added to nine $\mathrm{mL}$ of ice cream mix and thoroughly mixed again. To mimic fasting state stomach conditions, $16 \mathrm{~mL}$ of simulated GS (section 3.2.1) was added to a $100 \mathrm{~mL}$ empty plastic tube and similar experimental setup was followed as in section 3.2.3.1. Once the temperature of GS was equilibrated to $37 \pm 1^{\circ} \mathrm{C}$, its $\mathrm{pH}$ was adjusted to 2.0 (Mainville et al., 2005) using $6 \mathrm{~N} \mathrm{HCl}$.

To mimic fed state stomach conditions, $4 \mathrm{~mL}$ of ice cream mix and probiotic bacteria mixture was carefully pipetted into $100 \mathrm{~mL}$ plastic tube containing $16 \mathrm{~mL}$ GS 
(pH 2.0) and immediately the $\mathrm{pH}$ of the mixture was recorded. Preliminary studies showed that the $\mathrm{pH}$ of the GS increased due to the addition of ice cream mix and probiotic mixture into the GS due to the buffering effect of the ice cream mix. Therefore, during bench top study, GS $\left(\mathrm{pH} 2.0,37 \pm 1^{\circ} \mathrm{C}\right)$ was manually added in $10-15 \mathrm{~mL}$ increments for $120 \mathrm{~min}$ to the mixture in order to restore fasting state stomach $\mathrm{pH}$ of 2.5 (Malagelada et al., 1976). Sample collection and bacterial enumeration was done as shown in section 3.2.3.1.

Table 3.2.3.1: Experimental Design - conventional acid resistance test

\begin{tabular}{|l|l|l|l|}
\hline Factors & Treatments levels & Response & Repetition \\
\hline \multirow{2}{*}{$\mathrm{pH}$} & 2.0 & Survival of L. acidophilus & 2 \\
\cline { 2 - 2 } & 5.0 & La-5 and L. paracasei 431 & \\
\hline \multirow{2}{*}{ Probiotic bacteria } & L. acidophilus La-5 & & \\
\cline { 2 - 2 } & L. paracasei 431 & & \\
\hline
\end{tabular}

\subsubsection{Statistical analysis}

Buffering capacity of ice cream mix, milk and PBS: Data was statistically analyzed using GLM to determine the significant effect of sample, temperature and presence of $L$. acidophilus La- 5 on the buffering capacities of ice cream, milk and PBS. Tukey's pairwise comparison in one way analysis of variance (ANOVA) was used to determine significant differences among samples in the presence and absence of $L$. acidophilus La-5 each at room and body using $\mathrm{BC}$ as a response and samples as the main factor. The effect of $\mathrm{pH}$ on the $\mathrm{BC}$ of samples was determined using GLM. The significance level used for all the analysis was 5\%.

Effect of shear and dilution on the survivability of $L$. acidophilus La-5: GLM was used to determine the effect of shear and dilution on the viability of L. acidophilus La-5 added in low and high viscosity ice cream samples. Tukey's pairwise comparison test was done using one way analysis of variance (ANOVA) to determine which of the 
treatment pairs were significantly different among low viscosity samples by using survival rate of La-5 as response and treatment effect as main factor. The significance level used for all the analyses was 5\%.

Conventional acid resistance test in the presence and absence of ice cream: The impact of incubation $\mathrm{pH}$ (2.0 and 5.0) and the sampling time (0, 60 and 120min) on the viable counts of L. acidophilus La-5 and L. paracasei 431 was determined using GLM. Tukey’s pairwise comparison test was done using one way analysis of variance (ANOVA) to determine the significant differences between survival rate at different sampling points and between survival rate of L. acidophilus La-5 and L. paracasei 431 at each sampling point. Tukey’s pairwise comparison test was also used to determine significant differences among the overall log reduction of L. acidophilus La-5 using survival rate as response and treatment ( $\mathrm{pH} 2.0, \mathrm{pH} 5.0$ and presence of ice cream) as main effect. Similar comparison was done for L. paracasei 431. The significance level used for all the analyses was 5\%.

\subsection{Phase III: In vitro digestion of ice cream}

\subsubsection{Shaking water bath}

Shaking water bath was used as an in vitro model stomach to determine the protective effect of frozen ice cream on the survivability of L. acidophilus La-5. This method is often used to simulate gastric conditions (Muir and O’Dea, 1992) except for peristaltic contractions observed in the stomach during digestion. As shown in Figure 3.3.1.1, a shaking water bath (Model YB531, American Scientific Products) was adjusted to body temperature $\left(37^{\circ} \mathrm{C}\right)$ and two $500 \mathrm{~mL}$ glass beakers were held in a rack placed in the water bath. The beakers will be addressed as beaker \# 1 and beaker \# 2. Fifty mL of 
freshly prepared GS (section 3.2.1) adjusted at pH 1.8 using $6 \mathrm{~N} \mathrm{HCl} \mathrm{(Vertzoni} \mathrm{et} \mathrm{al,}$ 2005) was added to beaker $\# 1$ to simulate fasting state stomach conditions and $400 \mathrm{~mL}$ of gastric juice ( $\mathrm{pH}$ 1.8) was added to beaker \#2 to be used during simulated digestion process. Contents in both the beakers were maintained at body temperature.

A 3.5oz ice cream (Appendix II) cup was randomly selected and thawed for about thirty minutes. A mercury thermometer and $\mathrm{pH}$ probe connected to a $\mathrm{pH}$ meter (IQ Scientific Instruments, ISFET \#12 probe) were placed in beaker \#1 to consistently record temperature and $\mathrm{pH}$, respectively throughout the $2 \mathrm{hr}$ simulated digestion process. A sample of thawed ice cream was collected to determine the viable cells of L. acidophilus La-5 before the simulated digestion process and frozen to inhibit any activity until plating. The rest of the ice cream was added to beaker\#1 to simulate fed state stomach conditions. The rack containing beaker \#1 and beaker \#2 was immediately shaken at a frequency of 120 strokes/min for $2 \mathrm{hr}$ (Kong and Singh, 2010) and the peristaltic pump (Masterflex Pump Controller 7553-50/7090-42 Pump, Cole-Parmer, Chicago, Ill., U.S.A.) was turned on to secrete $3.5 \mathrm{~mL} / \mathrm{min}$ (Mainville et al, 2005) of GS from beaker \#2 into beaker \#1 containing ice cream to simulate shear and secretion from stomach walls, respectively during digestion. Once the $\mathrm{pH}$ of the simulated gastric digesta in beaker \#1 was restored to $\mathrm{pH} 2.5$, the secretion rate was lowered to $0.9 \mathrm{~mL} / \mathrm{min}$ (Mainville et al, 2005) to simulate gastrin hormone inhibition which signals the stomach to stop secreting $\mathrm{HCl}$.

Samples were collected after 30, 60 and 120 min to determine the effect of simulated digestion on the viability of La-5 and refrigerated until plating. Enumeration of L. acidophilus La-5 was performed immediately after the simulated digestion process was 
complete according to the procedure in section 3.2.3.1. The whole simulated digestion process was repeated twice.

Figure 3.3.1.1: Effect of gastric digestion simulated using shaking water bath on the survivability of L. acidophilus La-5

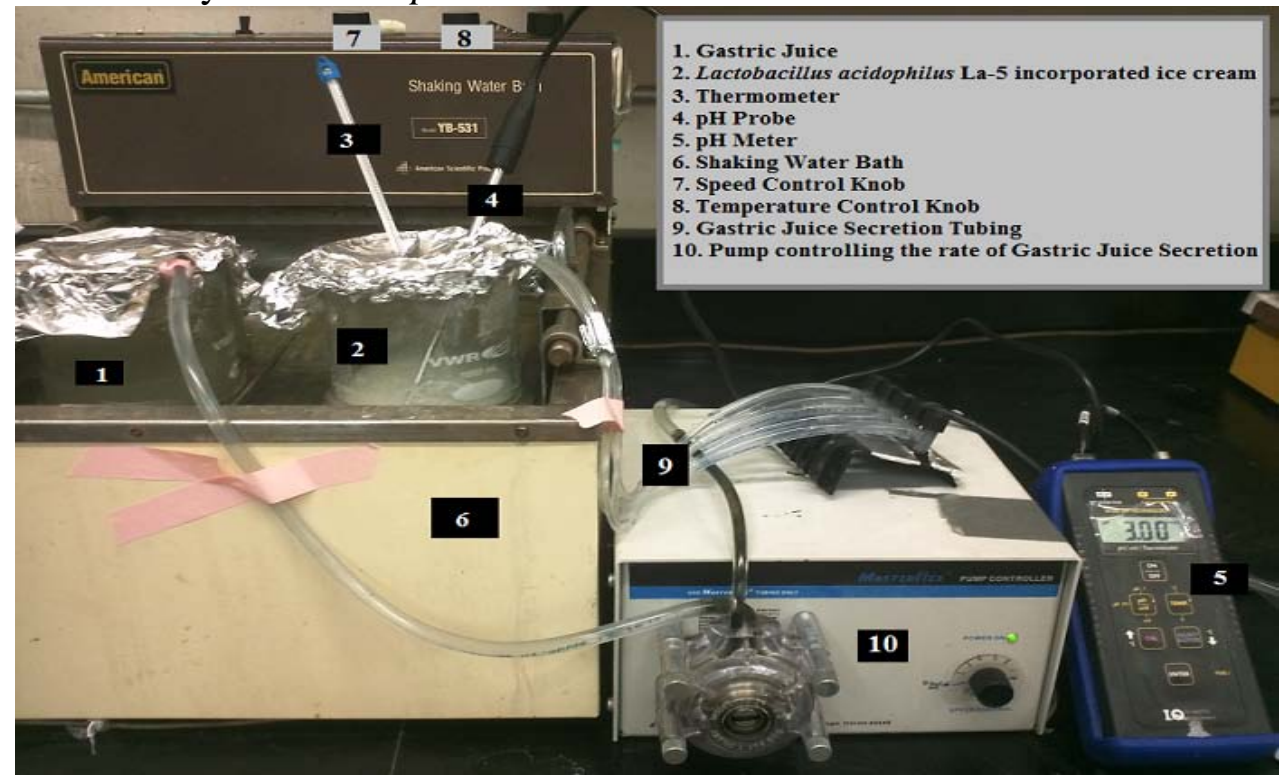

Table 3.3.1.1: Experimental Design - shaking water bath

\begin{tabular}{|l|l|l|l|}
\hline Factor & Treatment level & Response & Repetition \\
\hline \multirow{2}{*}{$\begin{array}{l}\text { In vitro digestion } \\
\text { model }\end{array}$} & Shaking water bath & Survival of L. \\
\cline { 2 - 2 } & $\begin{array}{l}\text { Human Gastric } \\
\text { Simulator (HGS) }\end{array}$ & 2 & \\
\hline
\end{tabular}

\subsubsection{Human Gastric Simulator (HGS)}

Protective effect of ice cream on the survivability of L. acidophilus La-5 was validated using dynamic in vitro model stomach called Human Gastric Simulator (HGS) developed at UC Davis by Dr. Paul Singh. The main components of the HGS are a latex lining chamber to mimic stomach, mechanical driving system composed of 12 rollers secured on belts pushing the stomach walls driven by a motor assembly, gastric secretion and temperature and $\mathrm{pH}$ control (Figure 3.3.2.1). The entire system was placed on a large aluminum base plate and covered by specially designed insulated plastic foam chamber to 
prevent heat loss. For detail description of the model stomach, refer to Kong and Singh (2010).

Figure 3.3.2.1: Human Gastric Simulator

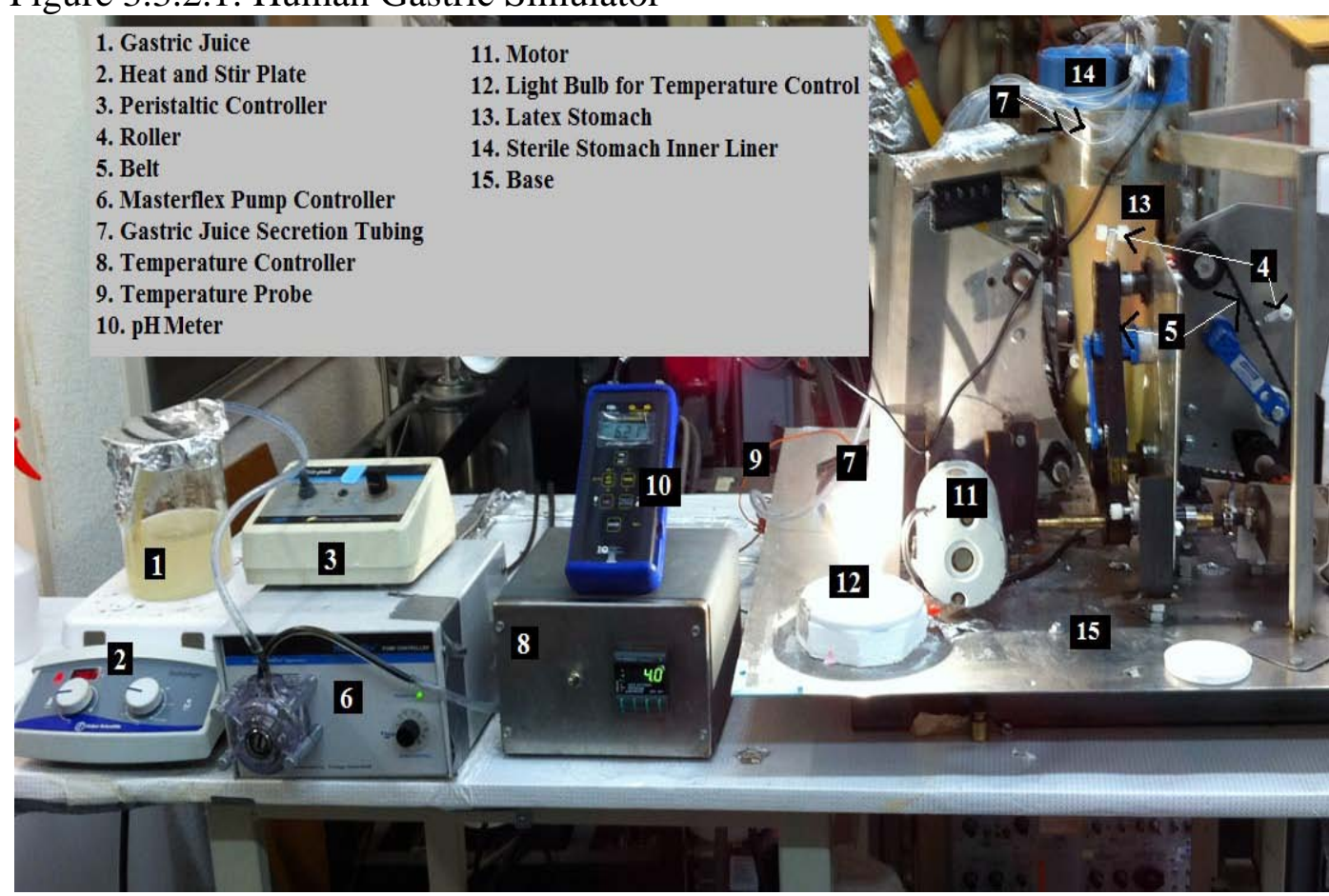

Two different ice cream mixes were made as per the flow chart in Figure 3.1.1.1. The level of viscosity was different in the two ice cream mix formulations and this was done by changing the amount of added stabilizer/ emulsifier blend. The formulation was based on a) 5\% fat, $11 \%$ MSNF, $15 \%$ sugar, $4 \%$ CSS, and $0.65 \%$ stab/emulsifier (Appendix II) b) 5\% fat, 11\% MSNF, 15\% sugar, 4\% CSS, 1.3\% stab/emulsifier (Appendix III). The ice cream mix with lower level of viscosity was divided into two equal parts and each of the two parts was inoculated with L. acidophilus La-5 to obtain an initial population of $10^{8} \mathrm{cfu} / \mathrm{g}$ and $10^{6} \mathrm{cfu} / \mathrm{g}$, respectively before freezing. Based on the results from section 3.1.2, approximately one log reduction was estimated upon freezing and air incorporation. The ice cream mix with higher level of viscosity was inoculated in a similar fashion as the one with lower viscosity to obtain an initial population of 
$10^{8} \mathrm{cfu} / \mathrm{g}$ and $10^{6} \mathrm{cfu} / \mathrm{g}$ respectively before freezing. All the ice cream mix samples (Table 3.3.2.1) were frozen with $60 \%$ over run after ageing overnight at $4^{\circ} \mathrm{C}$ and stored at $-10^{\circ} \mathrm{C}$ until the day of in vitro digestion experiments. Experimental samples were collected immediately before and after freezing to determine the counts of L. acidophilus La-5 in the mix and in the final ice cream, respectively using the procedure described in section

\subsection{2.}

Table 3.3.2.1 Probiotic ice cream samples and their codes

\begin{tabular}{|l|l|l|l|}
\hline Ice cream samples & $\begin{array}{l}\text { Amount of added } \\
\text { stabilizer/emulsifier } \\
\text { blend }\end{array}$ & $\begin{array}{l}\text { Amount of inoculation } \\
\text { (L. acidophilus La-5) }\end{array}$ & Code \\
\hline $\begin{array}{l}\text { Low viscosity, } \\
\text { high level of La-5 }\end{array}$ & $0.65 \%$ & $10^{8} \mathrm{cfu} / \mathrm{g}$ & LVHC \\
\hline $\begin{array}{l}\text { Low viscosity, } \\
\text { low level of La-5 }\end{array}$ & $0.65 \%$ & $10^{6} \mathrm{cfu} / \mathrm{g}$ & LVLC \\
\hline $\begin{array}{l}\text { High viscosity, } \\
\text { high level of La-5 }\end{array}$ & $1.3 \%$ & $10^{8} \mathrm{cfu} / \mathrm{g}$ & HVHC \\
\hline $\begin{array}{l}\text { High viscosity, } \\
\text { low level of La-5 }\end{array}$ & $1.3 \%$ & $10^{6} \mathrm{cfu} / \mathrm{g}$ & HVLC \\
\hline
\end{tabular}

Table 3.3.2.2: Experimental Design - HGS

\begin{tabular}{|c|c|c|c|}
\hline Factors & Treatment levels & Response & Repetition \\
\hline \multirow[t]{2}{*}{ Viscosity } & Low & \multirow{4}{*}{$\begin{array}{l}\text { Survival of } L \text {. } \\
\text { acidophilus La-5 }\end{array}$} & \multirow[t]{4}{*}{2} \\
\hline & High & & \\
\hline \multirow{2}{*}{$\begin{array}{l}\text { L. acidophilus La-5 } \\
\text { inoculation amount }\end{array}$} & Low & & \\
\hline & High & & \\
\hline
\end{tabular}

The simulated digestion process was repeated two times for each of the four ice cream samples (Table 3.3.2.1). Fresh simulated saliva (Table 3.3.2.2) was prepared by dissolving mucin (1 g/L; Mucin from porcine stomach, cat\# M2378-100G, SigmaAldrich, MO,USA), 50U/ml $\alpha$-amylase (from porcine pancreas, 22U/mg solid , Cat\# A3176-2.5MU, Sigma Aldrich, MO, USA; Engelen et al, 2003) into electrolyte solution containing $\mathrm{NaCl}(0.117 \mathrm{~g} / \mathrm{L}), \mathrm{KCl}(0.149 \mathrm{~g} / \mathrm{L})$ and $\mathrm{NaHCO}_{3}(2.1 \mathrm{~g} / \mathrm{L})$. It was used to simulate mastication process. Freshly prepared GS was added to a $1000 \mathrm{~mL}$ glass beaker 
which was placed on a heat/stir plate (Isotemp, Fisher Scientific, $12000 \mathrm{rpm}$ and $500^{\circ} \mathrm{C}$ max) set at $37^{\circ} \mathrm{C}$ to maintain its temperature at body temperature throughout $120 \mathrm{~min}$. One end of a small tube was placed in the beaker containing GS and the other end was connected to the peristaltic pump (Figure 3.3.2.1) to deliver gastric juice into the stomach during digestion process. A disposable sterile blue liner bag (SAVL-101-19/25, Animal Repro Systems, Chino, CA) similar to the shape of the latex stomach was placed inside the stomach before each simulated digestion process to minimize contamination of the ice cream samples. The bottom of the liner bag was sealed using Impulse sealer (Type TISH 300, 430W, Electric Heating Equipment Co. Ltd.). The control valve was used to adjust the rate of gastric secretion into the latex stomach.

A randomly selected ice cream cup (3.5oz, 60g; Table 3.3.2.1) was thawed for about 30 min while waiting for the system temperature to equilibrate at $37^{\circ} \mathrm{C}$. In the meanwhile, 50 mL simulated gastric juice, pH 1.75-1.80 (Masco et al., 2007; Sumeri et al., 2008) was added to the latex stomach to simulate fasting state stomach conditions. A temperature controller was set at $37^{\circ} \mathrm{C}$ to increase and maintain the temperature of the system and GS at body temperature. One and half $\mathrm{mL}$ of simulated saliva, $\mathrm{pH}$ 6.86-6.90 (Engelen et al., 2003; Madureira et al., 2011) was added to the ice cream, stirred for 10 sec and incubated for $50 \mathrm{sec}$ to mimic mastication in the mouth. The $\mathrm{pH}$ of the ice cream plus saliva was recorded and a sample was collected after one minute incubation.

The temperature and $\mathrm{pH}$ probe were inserted into the liner bag placed in the latex stomach to record the $\mathrm{pH}$ and temperature of the empty stomach as well as gastric digesta during simulated digestion. Then the ice cream was dropped into the stomach and peristaltic contractions (three cycles/ $\mathrm{min})$ and gastric secretion $(3.5 \mathrm{~mL} / \mathrm{min})$ was started 
to simulate gastric mixing, shear and hydrolysis of ice cream during $2 \mathrm{hr}$ digestion. Experimental setup is shown in Figure 3.3.2.3. Postprandial pH and temperature were recorded consistently every minute for first 30 min and every five minutes for last 90 min. Once the pH dropped to 2.5 (Pinto et al., 2006; Pitino et al., 2010; Faye et al., 2012), the rate of gastric juice secretion was lowered to $0.9 \mathrm{~mL} / \mathrm{min}$ until the end of the $120 \mathrm{~min}$ of simulated digestion. Twenty-five $\mathrm{mL}$ sample was also collected at each time point to enumerate live cells of L. acidophilus La-5 (section 3.2.3.1) and to measure the change in viscosity of ice cream due to shear and dilution in the stomach (section 3.2.2). LV spindle \# SC4 21 was used to measure viscosity at a range of shear rate $0.93 \mathrm{sec}^{-1}$ to186 $\mathrm{sec}^{-1}$ at body temperature $\left(37^{\circ} \mathrm{C}\right)$. The apparent viscosity was measured at shear rate $49.92 \mathrm{sec}^{-1}$ (Soukoulis et al., 2009). The power law model was used as described earlier.

\subsubsection{Statistical analysis}

Shaking water bath: The impact of $\mathrm{pH}$ and sampling point within each model (shaking water bath and HGS) on the survival of L. acidophilus La-5 was evaluated using GLM. Tukey's pairwise comparison test was done using one way analysis of variance (ANOVA) to determine significant differences in survivability of La-5 at each sampling point between the two models stomachs. Tukey's pairwise comparison test was also used to determine significant difference in the overall $\log$ reduction of $L$. acidophilus La-5 as a result of digestion in static bench top model, shaking water bath or HGS using survival rate as response and model type as main effect.

Human Gastric Simulator: GLM was used to evaluate the impact of viscosity level and initial inoculation level on the survivability of $L$. acidophilus La-5 when ice cream was digested in HGS. Tukey's pairwise comparison test was done using one way 
analysis of variance (ANOVA) to determine the significant differences in the apparent viscosity of gastric digesta at time points 30, 60 and 120 min of digestion between LVHC and HVHC samples (Table 3.3.2.1). Tukey's pairwise comparison test was also used to determine significant differences in survivability of $L$. acidophilus La-5 between sampling points (saliva, 30, 60, 120 min) within each variable and at each sampling point across four variables. The significance level used for all the analyses was $5 \%$. 


\subsection{Results and Discussion}

4.1 Phase I: Survivability of L. acidophilus La-5 in nonfermented low fat ice cream

4.1.1 Effect of manufacturing process and storage on the viability of L. acidophilus La-5

During freezing of the mix, the counts of viable L. acidophilus La-5 decreased by

0.35 and $1.39 \log$ units as a result of $60 \%$ and $100 \%$ overrun respectively. This log

reduction as a result of addition of $60 \%$ and $100 \%$ overrun was found to be statistically

non significant $(\mathrm{p}>0.05)$.

Table 4.1.1.1: Effect of different amount of air incorporation on the viable cells of $L$. acidophilus La-5

\begin{tabular}{|l|l|l|}
\hline & \multicolumn{2}{|l|}{ Counts of L. acidophilus La-5 $\left(\log _{10} \mathrm{cfu} / \mathrm{g}\right)$} \\
\hline Treatments & Before freezing $\left(4^{\circ} \mathrm{C}\right)$ & After freezing $\left(-4^{\circ} \mathrm{C}\right)$ \\
\hline $60 \%$ OR & $7.15 \pm 0.00^{\mathrm{aA}}$ & $6.80 \pm 0.28^{\mathrm{aA}}$ \\
\hline $100 \%$ OR & $7.15 \pm 0.00^{\mathrm{aA}}$ & $5.76 \pm 0.98^{\mathrm{aA}}$ \\
\hline
\end{tabular}

Data were means \pm standard deviations of two sample cups.

${ }^{\mathrm{a}}$ Means within the same column with different letters are significantly different $(\mathrm{p}<0.05)$.

${ }^{\mathrm{A}}$ Means within the same row with different letters are significantly different $(\mathrm{p}<0.05)$.

The viable counts of L. acidophilus La-5 remained in excess of recommended level of $10^{6} \mathrm{cfu} / \mathrm{g}$ throughout the storage of 90 days (Table 4.1.1.2) and did not differ significantly ( $>0.05)$ from day 1 to day 90 . This shows that storage at $-10^{\circ} \mathrm{C}$ did not have a significant effect on the survival of $L$. acidophilus La-5. The viable counts in the ice cream samples incorporated with $60 \%$ overrun were statistically significantly different $(\mathrm{p}<0.05)$ from those in the ice cream samples incorporated with $100 \%$ overrun which shows that level of overrun played a significant role in determining the survival rate of La-5 at the end of shelf life of 90 days (Figure 4.1.1.1). Fluctuations in the viable counts of La-5 were observed throughout storage period (Table 4.1.1.2). 
Table 4.1.1.2: Effect of storage of ice cream samples incorporated with $60 \%$ and $100 \%$ over run at $-10^{\circ} \mathrm{C}$ for 90 days on the survivability of L. acidophilus La-5

\begin{tabular}{|l|l|l|l|l|l|}
\hline & \multicolumn{5}{|c|}{ Counts of L. acidophilus La-5 $\left(\log _{10} \mathrm{cfu} / \mathrm{g}\right)$} \\
\hline Treatments & $\begin{array}{l}\text { Ice cream } \\
\text { mix }\left(4^{\circ} \mathrm{C}\right)\end{array}$ & Day 1 & Day 30 & Day 60 & Day 90 \\
\hline $60 \%$ OR & $7.15 \pm 0.00^{\mathrm{aA}}$ & $6.60 \pm 0.44^{\mathrm{aA}}$ & $6.71 \pm 0.11^{\mathrm{aA}}$ & $6.68 \pm 0.13^{\mathrm{aA}}$ & $6.82 \pm 0.10^{\mathrm{aA}}$ \\
\hline $100 \%$ OR & $7.15 \pm 0.00^{\mathrm{aA}}$ & $6.32 \pm 0.07^{\mathrm{aB}}$ & $6.43 \pm 0.07^{\mathrm{aB}}$ & $6.29 \pm 0.08^{\mathrm{aB}}$ & $6.19 \pm 0.11^{\mathrm{aB}}$ \\
\hline
\end{tabular}

Data were means \pm standard deviations of two sample cups.

${ }^{\mathrm{AB}}$ Means within the same column with different letters are significantly different $(\mathrm{p}<0.05)$.

${ }^{\mathrm{a}}$ Means within the same row with different letters are significantly different $(\mathrm{p}<0.05)$.

Figure 4.1.1.1: Effect of overrun and storage on the survivability of L. acidophilus La-5

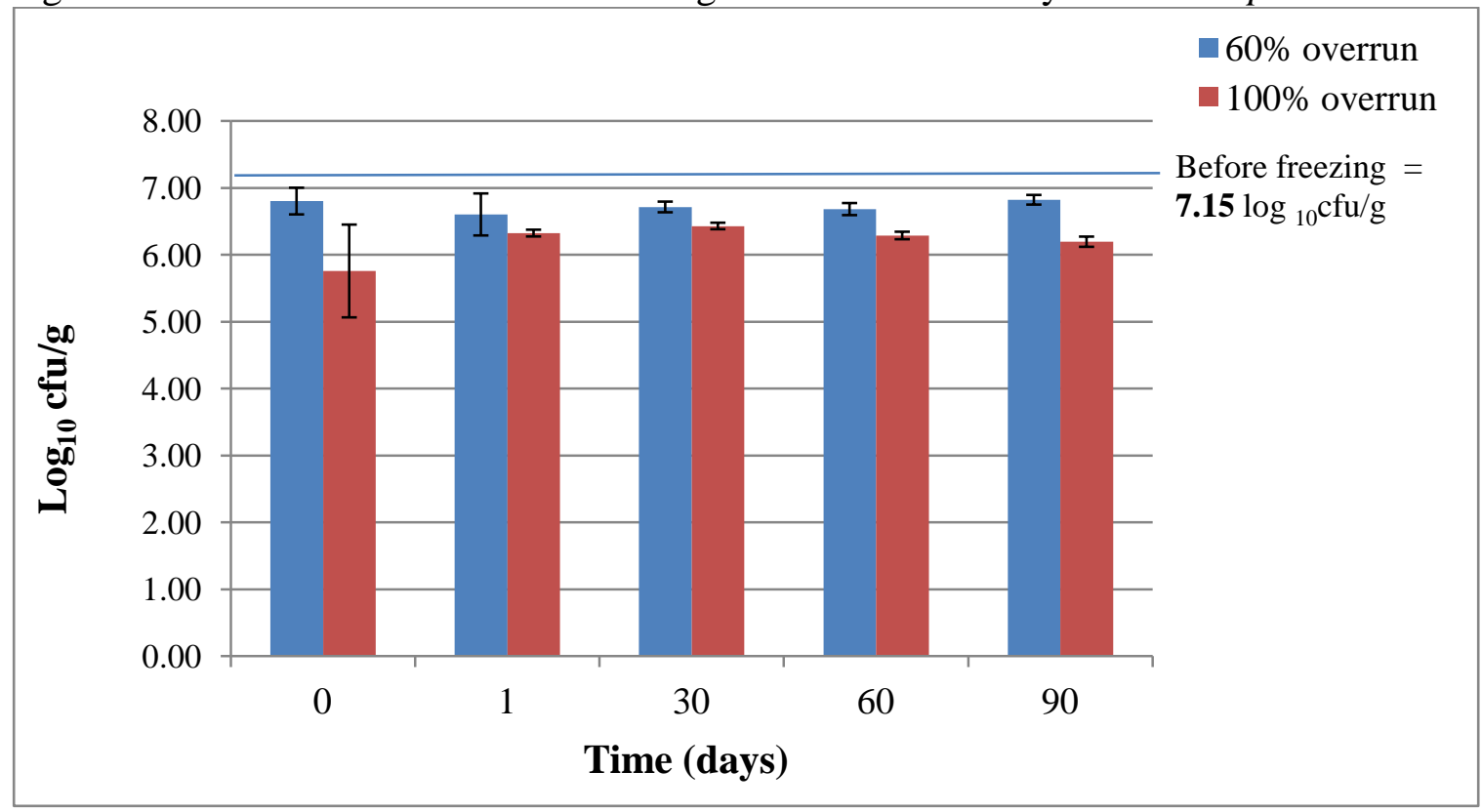

The results obtained for the viable counts after inclusion of $100 \%$ overrun were in contradiction to the results obtained by Magarinos et al. (2007) who found that freezing and inclusion of 108\% overrun and the subsequent hardening of the ice cream, permitted the survival rate of $91.3 \%$ of the $L$. acidophilus La-5 i.e reduction in viable counts by 0.6 log units immediately after freezing. Abghari et al. (2011) also found that in a nonfermented ice cream, inclusion of $90 \%$ over run resulted in a loss of 0.28 log units in the viable counts of L. acidophilus immediately after freezing. These differences in survival rate of L. acidophilus are possibly due to the additional stress caused by the technological 
hurdles during processing of ice cream mix with $100 \%$ over run in the present study resulting in an increased loss of viable counts of L. acidophilus La-5 immediately after freezing. Nevertheless, it can be seen in Table 4.1.1.2, that the day 1 counts were higher i.e $6.32 \log \mathrm{cfu} / \mathrm{g}$ compared to immediately after freezing which was $5.76 \mathrm{log} \mathrm{cfu} / \mathrm{g}$ since all the samples tested throughout storage for $100 \%$ over run were from new batch of ice cream that was processed after overcoming the hurdle.

The loss of less than one log unit in La-5 counts as a result of inclusion of $60 \%$ overrun immediately after freezing was in agreement with studies conducted by Salem et al. (2005) and Turgut and Cakmakci (2009). Although the fat content of ice cream sample in the present study was $4 \%$ which was lower than that of ice cream samples (8\%) tested in the study conducted by Salem et al. (2005), similar reduction of viable counts of $L$. acidophilus La-5 immediately after freezing was observed in both the studies. This shows that fat content may not influence or provide an additional protection against freezing. Favaro-Trindade et al. (2007) conducted a study on various L. acidophilus strains to determine the effect of $\mathrm{pH}(4.5$ and 5$)$ and cream level (5\% and 10\%) on the survivability of probiotic bacteria during ice cream manufacture process and during storage at $-18^{\circ} \mathrm{C}$ for 105 days. The results indicated that higher fat content did not provide better protection to the tested probiotic microorganisms (L. acidophilus 74-2 and L. acidophilus LAC 4). Haynes and Playne (2002) also found that the full fat ice cream mixes made with with $\sim 10 \%$ cream did not result in better survivability of the probiotic microorganisms during storage, when compared to the survivale rate of those incorporated in ice cream mix made with $3.8 \%$ fat. 
The ability of L. acidophilus La-5 to survive the freezing and air incorporation process at $60 \%$ and $100 \%$ overrun in this study was higher than those reported by Ferraz et al. (2012) who chose to add probiotic bacteria after the ageing of ice cream mix and used different $L$. acidophilus strain in a $10 \%$ fat ice cream mix . They reported reduction of 1 and $2 \log$ units in the viable counts of $L$. acidophilus DOWARU ${ }^{\mathrm{TM}}$ as a result of $60 \%$ and $90 \%$ air incorporation, respectively during storage. These differences in the results may be attributed to the differences in the strains of L. acidophilus that were tested. In addition, exposure of $L$. acidophilus La-5 to the cryoprotective components of ice cream mix such as proteins and sugar during overnight ageing at $4^{\circ} \mathrm{C}$ may play a role in protecting the bacteria during freezing process (Abghari et al., 2011). In the present study, if more repetitions were conducted, it may be possible to find significant effect of different levels of air addition on the viability of $L$. acidophilus La-5 after freezing.

During frozen storage, the results indiacted that the survival rate of $L$. acidophilus La-5 at each of the tested days $(1,30,60,90)$ was higher in samples incorporated with $60 \%$ overrun compared to $100 \%$ overrun. Ferraz et al. (2012) also found a significant influence of the overrun level on the survival of the probiotic strain throughout frozen storage $(\mathrm{p}<0.05)$ beginning on day 15 of storage. The observed effect of different amounts of air incorporation during storage may be due to initial damage caused due to air toxicity since $L$. acidophilus species are microaerophilic in nature and response to stress is found to be strain dependent (Talwalkar and Kailasapathy, 2003). In the present study, although statistical analysis found significant difference between viable cells in samples with $60 \%$ overrun compared to $100 \%$ overrun, biologically these differences are considered non significant . In both the cases, the log reduction at the end of 90 days was 
less than $1 \log$ which is considered biologically non significant reduction. According to Talwalkar and Kailasapathy (2003), an enzyme known as NADH peroxidase in $L$. acidophilus 2400 and 2409 was able to scavenge the presence of $\mathrm{H}_{2} \mathrm{O}_{2}$ produced as a result of presence of oxygen. Further investigation may be conducted to determine whether an enzyme such as NADH peroxidase is present and active in L. acidophilus La5 to correlate insignificant reduction in cell numbers as a result of air addition during freezing and storage.

\subsubsection{Physicochemical analysis of ice cream containing L. acidophilus La-5}

The results (Table 4.1.2.1) showed that values for $\%$ TS and $\%$ fat in the ice cream mix did not differ significantly $(\mathrm{p}>0.05)$ from the calculated values (Appendix I) and thereby, not affected by L. acidophilus La-5 addition. The E.coli/Coliform counts were found to be $<10 \mathrm{cfu} / \mathrm{g}$ which was an indication of successful pasteurization of ice cream mixes. The $\mathrm{pH}$ and titratable acidity values were not significantly affected ( $>0.05$ ) by the addition of $L$. acidophilus La-5 in the ice cream mix and did not change significantly ( $>>0.05$ ) throughout storage at $-10^{\circ} \mathrm{C}$ throughout tested shelf life of 90 days. This confirms that there was no metabolic activity in the ice cream mix inoculated with La-5 during ageing at $4^{\circ} \mathrm{C}$ and during frozen storage.

Table 4.1.2.1: Physical and microbial analysis of ice cream mix after ageing

\begin{tabular}{|l|l|l|l|l|l|l|}
\hline Variables & TS (\%) & Fat (\%) & $\mathrm{pH}$ & \% TA & $\begin{array}{l}\text { EC/CC } \\
(\mathrm{cfu} / \mathrm{ml})\end{array}$ & $\begin{array}{l}\text { APC } \\
(\mathrm{cfu} / \mathrm{ml})\end{array}$ \\
\hline Control (no La-5) & 35.17 & 3.95 & 6.55 & 0.20 & $<10$ & $<10$ \\
\hline Experimental (La-5) & 35.29 & 3.84 & 6.50 & 0.23 & $<10$ & $<10$ \\
\hline
\end{tabular}

Table 4.1.2.2: $\mathrm{pH}$ and titratable acidity (\%) during storage study

\begin{tabular}{|l|l|l|l|l|l|l|}
\hline & \multicolumn{3}{|l|}{30 days } & \multicolumn{2}{l|}{60 days } & \multicolumn{2}{l|}{ 90 days } \\
\hline & $\mathrm{pH}$ & $\%$ acidity & $\mathrm{pH}$ & $\%$ acidity & $\mathrm{pH}$ & \% acidity \\
\hline Control & 6.57 & 0.20 & 6.54 & 0.21 & 6.56 & 0.21 \\
\hline Experimental & 6.52 & 0.24 & 6.50 & 0.23 & 6.51 & 0.23 \\
\hline
\end{tabular}


In the present study, viscosity of ice cream mix with added L. acidophilus La-5 was compared with that of control mix with no added probiotic in order to determine any significant contribution of the presence of La- 5 on the viscosity of aged ice cream mix. The presence of $L$. acidophilus La- 5 in the experimental ice cream mix did not have a significant effect $(p>0.05)$ on the final viscosity of aged ice cream mix. The results also indicated that the viscosity of the mix decreased with an increase in shear rate and temperature (Figure 4.1.2.1). The testing temperature had a significant effect $(\mathrm{p}<0.05)$ on the viscosity $(\mathrm{p}<0.05)$. The consistency coefficient $(\kappa)$ indicates the relative thickness of a solution. The values of consistency coefficient $(\kappa)$ were found to decrease significantly $(\mathrm{p}<0.05)$ with an increase in temperature (Table 4.1.2.3) and were positively correlated with the apparent viscosity values. For all the samples tested in our study at $4^{\circ} \mathrm{C}$ and $3^{\circ} \mathrm{C}$, the values of flow behavior index (n) were found to be less than unity (Table 4.1.2.3). Therefore, it can be said that the samples exhibited pseudoplastic behavior i.e. overtime shear thinning.

Figure 4.1.2.1: Effect of shear rate $\left(\sec ^{-1}\right)$ and temperature $\left({ }^{\circ} \mathrm{C}\right)$ on viscosity (Pa.s) of aged ice cream mix with and without added L. acidophilus La-5

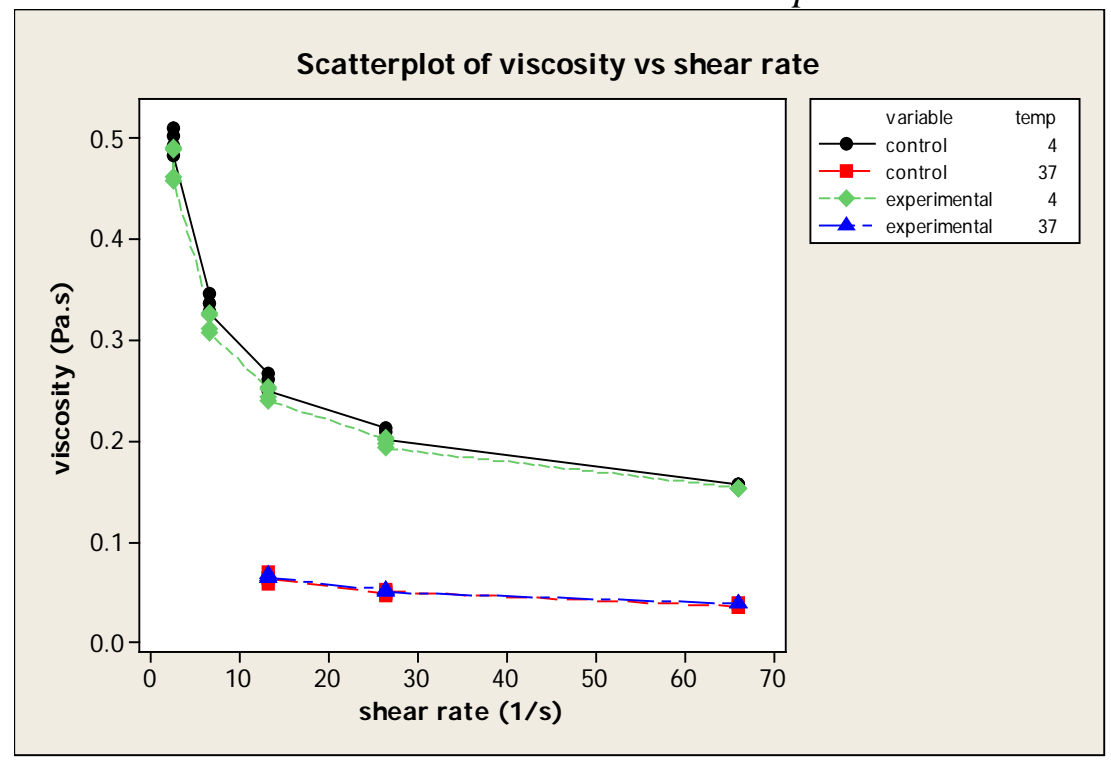


Table 4.1.2.3: Consistency index ( $\kappa)$ and flow behavior index (n)

\begin{tabular}{|l|l|l|l|}
\hline Variables & $\begin{array}{l}\text { Consistency index }(\kappa) \\
\text { Pas }^{\mathrm{n}}\end{array}$ & flow behavior index $(\mathrm{n})$ & $\mathrm{R}^{2}$ \\
\hline Control $\left(4^{\circ} \mathrm{C}\right)$ & 0.68 & 0.64 & 0.9969 \\
\hline Control $\left(37^{\circ} \mathrm{C}\right)$ & 0.14 & 0.65 & 0.9949 \\
\hline Experimental $\left(4^{\circ} \mathrm{C}\right)$ & 0.63 & 0.65 & 0.9966 \\
\hline Experimental $\left(37^{\circ} \mathrm{C}\right)$ & 0.14 & 0.68 & 0.9988 \\
\hline
\end{tabular}

The findings for $\mathrm{pH}$ was in accordance with those reported by Nousia et al. (2011) who indicated that $\mathrm{pH}$ was influenced neither by addition of freeze dried culture or activated cells of L. acidophilus LMPG-2138 during ageing or during frozen storage at $15^{\circ} \mathrm{C}$ or $-25^{\circ} \mathrm{C}$ for up to 45 weeks. Abghari et al. (2011) conducted a similar study by manufacturing non fermented ice cream and found that $\mathrm{pH}$ did not differ significantly before and after ageing and during storage in the samples inoculated with L. acidophilus (isolated from probiotic commercial capsules). This indicates that ageing of the inoculated ice cream mix at $4^{\circ} \mathrm{C}$ does not provide suitable conditions for bacteria to metabolize and produce acid validating that the mix is non-fermented.

Authors who fermented the ice cream mix (Akalin and Erisir, 2008; Hekmat and McMahon, 1992) reported the $\mathrm{pH}$ of the final product to be below 5.0 or 6.0 and consequently found that there was a significant reduction in the viable counts of tested probiotic strain, even in the presence of prebiotic (Akalin and Erisir, 2008). This shows that the $\mathrm{pH}$ of the final product could be detrimental to the viability of added probiotic bacteria. The $\mathrm{pH}$ of the ice cream samples in the present study may provide an advantage over fermented ice cream eliminating one of many stress factors resulting in reduction of bacterial cells during ice cream manufacture and storage.

The viscosity of an ice cream mix is principally influenced by the fat content and the stabilizer blend (Marshall and Arbuckle, 1996; Alamprese et al., 2002; El-Nagar et 
al., 2002). Besides fat and stabilizers, some strains of probiotic bacteria are capable of producing exopolysaccharides, which in turn affects the viscosity of the ice cream mix (Goh et al, 2008). Therefore, in the present study, viscosity of ice cream mix with added L. acidophilus La-5 was compared with that of control mix without probiotic in order to determine any significant contribution of La-5 on the viscosity of aged ice cream mix. The addition of $L$. acidophilus La-5 did not affect the viscosity in the present study. The unaffected viscosity in the present study could be explained by low acidity of the mix (Table 4.1.2.1). Some studies (Salem et al., 2005; Turgut and Cakmakci, 2009) tested the effect of supplementation of ice cream with $L$. acidophilus on the viscosity of ice cream mix compared to the effect of other probiotic bacteria and often found lowest viscosity values of the mix supplemented with $L$. acidophilus cells compared to the mix inoculated with other probiotic bacteria.

In both the studies, either ice cream mix was fermented or fermented milk was added to the ice cream mix and the low $\mathrm{pH}$ as a result of acid production during fermentation could be attributed to the increase in viscosity of the ice cream mix. $L$. acidophilus species is known to grow slowly in milk which may result in less acid production and lowering of $\mathrm{pH}$ in turn resulting in least effect on the viscosity compared to other probiotic bacteria such as L. reuteri (Salem et al., 2005) or B. bifidum (Turgut and Cakmakci, 2009). Investigators like Xu et al. (2006) and Mostafa et al. (2001) attributed high viscosity values to the fermentation process and the increase in acidity which consequently causes slight protein precipitation and low $\mathrm{pH}$ value. In a study conducted by Abghari et al. (2011) in which non-fermented ice cream matrix was tested, 
the authors found that addition of L. acidophilus and L. rhamnosus had no significant effect on the viscosity of the ice cream mix similar to the present study.

The results indicated that the mix viscosity decreased with an increase in shear rate and temperature. Similar results have been reported by other authors, who showed that viscosity is a temperature dependent property of the ice cream mix (Marshall and Arbuckle, 1996; Innocente et al, 2002; Metwally, 2007). The consistency coefficient ( $\kappa)$ values in the present study were found to decrease for the samples tested at higher temperature suggesting the temperature dependence nature of ice cream viscosity. These findings were similar to those of Aime et al. (2001).

\subsection{Phase II: Bench top experiments}

\subsubsection{Buffering capacity (BC)}

The addition of $L$. acidophilus La-5 in all the three samples had a significant $(\mathrm{p}<0.05)$ effect on the amount of gastric juice that was required to lower the initial $\mathrm{pH}$ of samples to the fasting state stomach $\mathrm{pH}$ 2.0. The BC of ice cream mix, milk and PBS increased significantly $(\mathrm{p}<0.05)$ in the presence of L. acidophilus La-5. In the absence of La-5, the BC was highest for the ice cream mix followed by milk and PBS. Whereas, it its presence, $B C$ of ice cream mix did not differ significantly $(\mathrm{p}>0.05)$ from milk. The $\mathrm{BC}$ values were observed to have slightly increased at body temperature versus room temperature for PBS (in the presence and absence of La-5) and for milk and ice cream only in the absence of La-5. Temperature (room or body) had a significant $(\mathrm{p}<0.05)$ effect on BC of all the samples with added L. acidophilus La-5 compared with those without La-5, but it did not have significant ( $>>0.05$ ) effect when samples were compared with each other within each group. Figures 4.2.1.2 and 4.2.1.3 show a graph which compares 
$\mathrm{BC}$ values between ice cream mix, milk and PBS in the presence and absence of La-5 at body and room temperature, respectively.

Table 4.2.1.1: Comparison of amount of gastric juice required to lower the native $\mathrm{pH}$ of PBS, milk and ice cream mix with no added $L$. acidophilus La-5.Data were means \pm standard deviations of two replicates

\begin{tabular}{|l|l|l|l|l|l|}
\hline Product & Temperature & $\begin{array}{l}\text { Native pH } \\
\text { (w/o La-5) }\end{array}$ & $\begin{array}{l}\text { Amount of GS } \\
\text { added (ml) } \\
\text { (w/o La-5) }\end{array}$ & $\begin{array}{l}\text { Native pH } \\
\text { (with La-5) }\end{array}$ & $\begin{array}{l}\text { Amount of GS } \\
\text { added (ml) } \\
\text { (with La-5) }\end{array}$ \\
\hline PBS & Room & 7.01 & $3.33 \pm 0.11$ & 6.17 & $12.95 \pm 0.64$ \\
\hline Milk & Room & 6.67 & $16.25 \pm 0.35$ & 6.29 & $25.50 \pm 0.71$ \\
\hline $\begin{array}{l}\text { Ice cream } \\
\text { mix }\end{array}$ & Room & 6.55 & $20.75 \pm 1.06$ & 6.50 & $26.75 \pm 0.35$ \\
\hline PBS & Body & 7.03 & $4.25 \pm 0.07$ & 6.36 & $18.25 \pm 1.77$ \\
\hline Milk & Body & 6.70 & $17.70 \pm 0.14$ & 6.45 & $26.00 \pm 1.41$ \\
\hline $\begin{array}{l}\text { Ice cream } \\
\text { mix }\end{array}$ & Body & 6.50 & $21.50 \pm 2.12$ & 6.32 & $26.00 \pm 0.71$ \\
\hline
\end{tabular}

Figure 4.2.1.1: Buffering capacity (BC) of ice cream mix, milk and PBS at body and room temperature in the presence and absence of L. acidophilus La-5

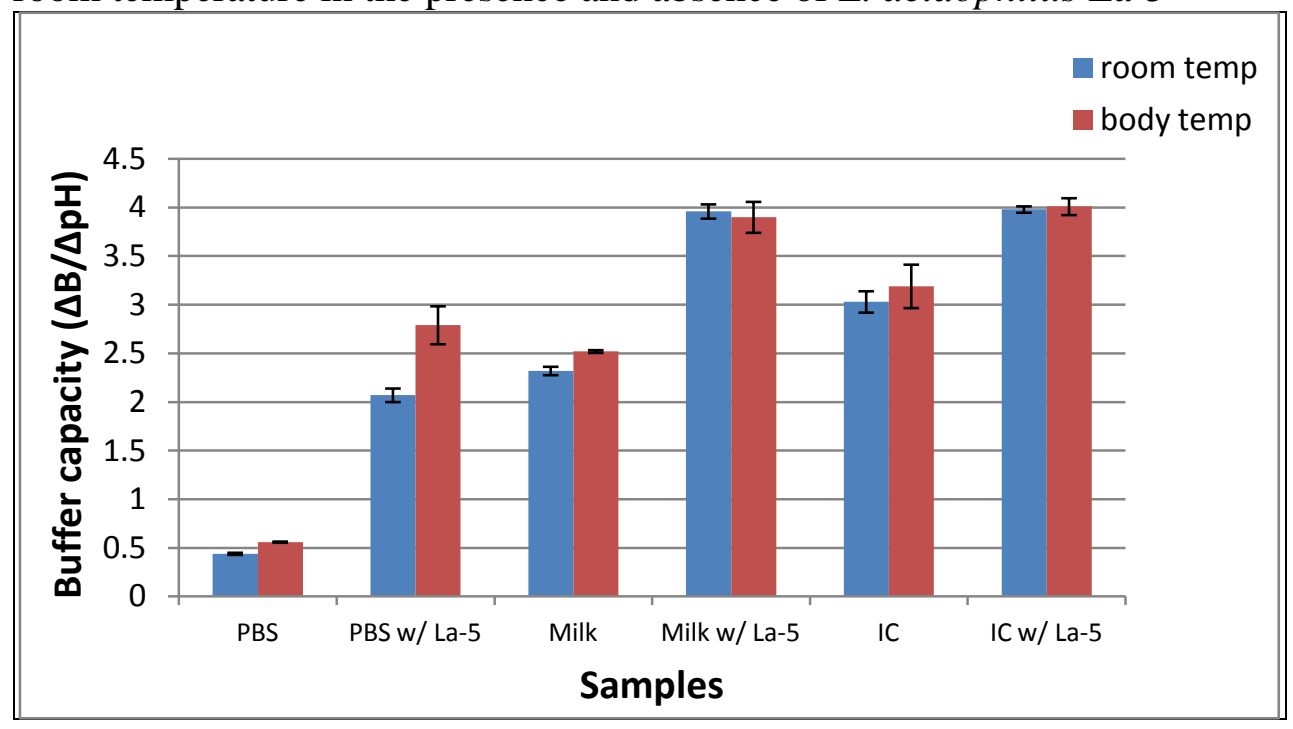

This difference in the BC of samples in the presence and absence of $L$.

acidophilus La-5 could be attributed to the addition of freeze dried form of bacteria whose major growth medium was skimmed milk powder/milk permeate in addition to other ingredients such as sodium caseinate, yeast extract and carbohydrates. Dairy products like ice cream mix and milk display high BC due to the presence of proteins and 
salts. It may be possible that addition of freeze dried form of La-5 may have added more proteins resulting in resistance to $\mathrm{pH}$ change and in turn higher $\mathrm{BC}$. These results indicate that incorporating freeze dried milk based form of probiotic bacteria in dairy products like milk and ice cream mix further enhanced their resistance to change of $\mathrm{pH}$ from 3.0 to 2.0. Since, $\mathrm{pH}$ below 3.0 is found to be most detrimental to the viability of probiotic bacteria, this increased resistance to the change in $\mathrm{pH}$ from 3.0 to 2.0 may allow probiotic bacteria to reach the intestine unaffected in large numbers during gastric emptying.

Al Dabbas et al. (2010) compared the buffering capacity of cow's milk with non dairy products and found that cow's milk had highest BC. They found BC value for cow’s milk to be $1.96 \pm 0.17$ which was slightly lower than the value found in present study (2.52 \pm 0.02$)$. This difference could be due the difference between the chemical composition of milk samples used in their study compared to our study. For example, milk from Jersey cows, which has higher protein and phosphate contents, has a higher buffering capacity than milk from Holstein cows (Park, 1992). Parameters affecting the $\mathrm{BC}$ and causing differences in BC value of different dairy products depend on several compositional factors including small constituents (inorganic phosphate, citrate, and organic acids), milk proteins (caseins and whey proteins) and solubilization of colloidal calcium phosphate (Lucey et al., 1996; Salaun et al., 2005). 
Figure 4.2.1.2: Buffering capacity (BC) of ice cream mix, milk and PBS for different $\mathrm{pH}$ values at body temperature in the presence and absence of L. acidophilus La-5.

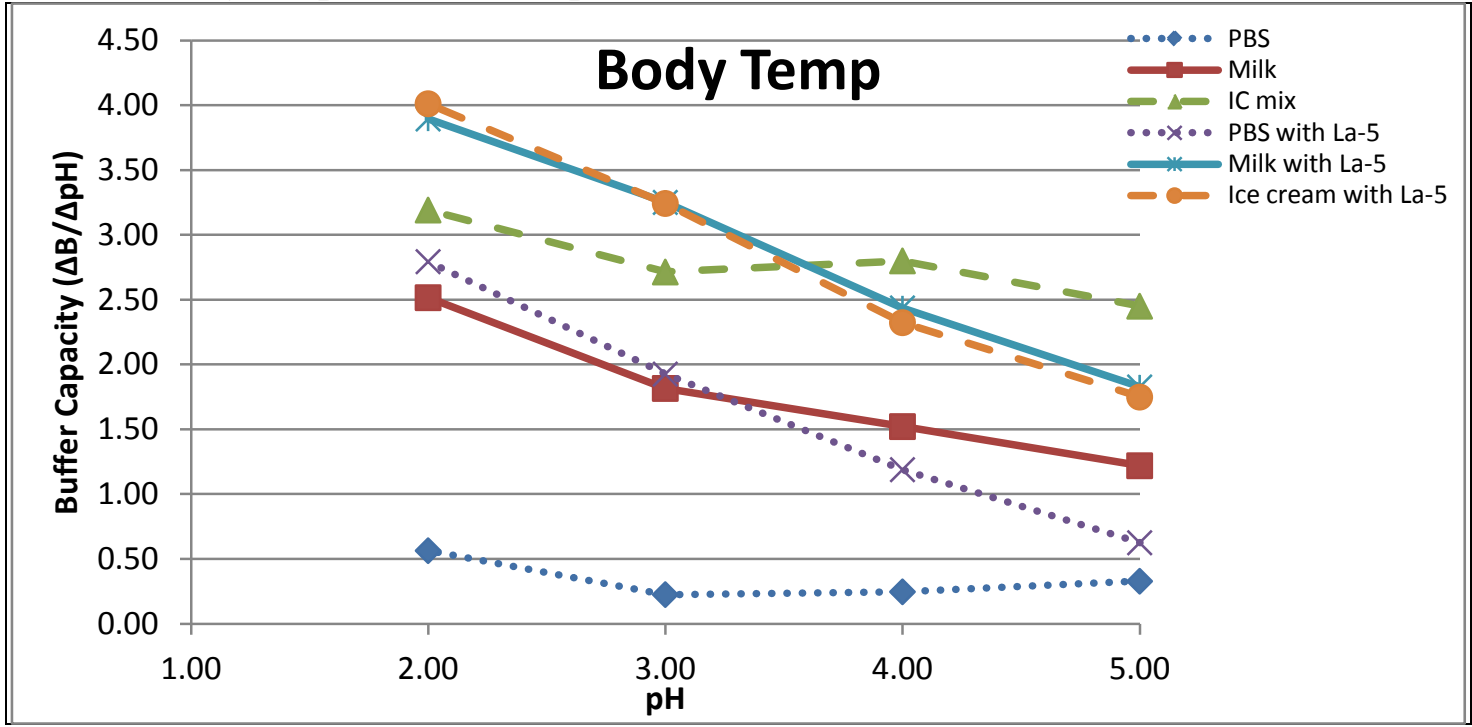

Figure 4.2.1.3: Buffering capacity (BC) of ice cream mix, milk and PBS for different $\mathrm{pH}$ values at room temperature in the presence and absence of L. acidophilus La-5.

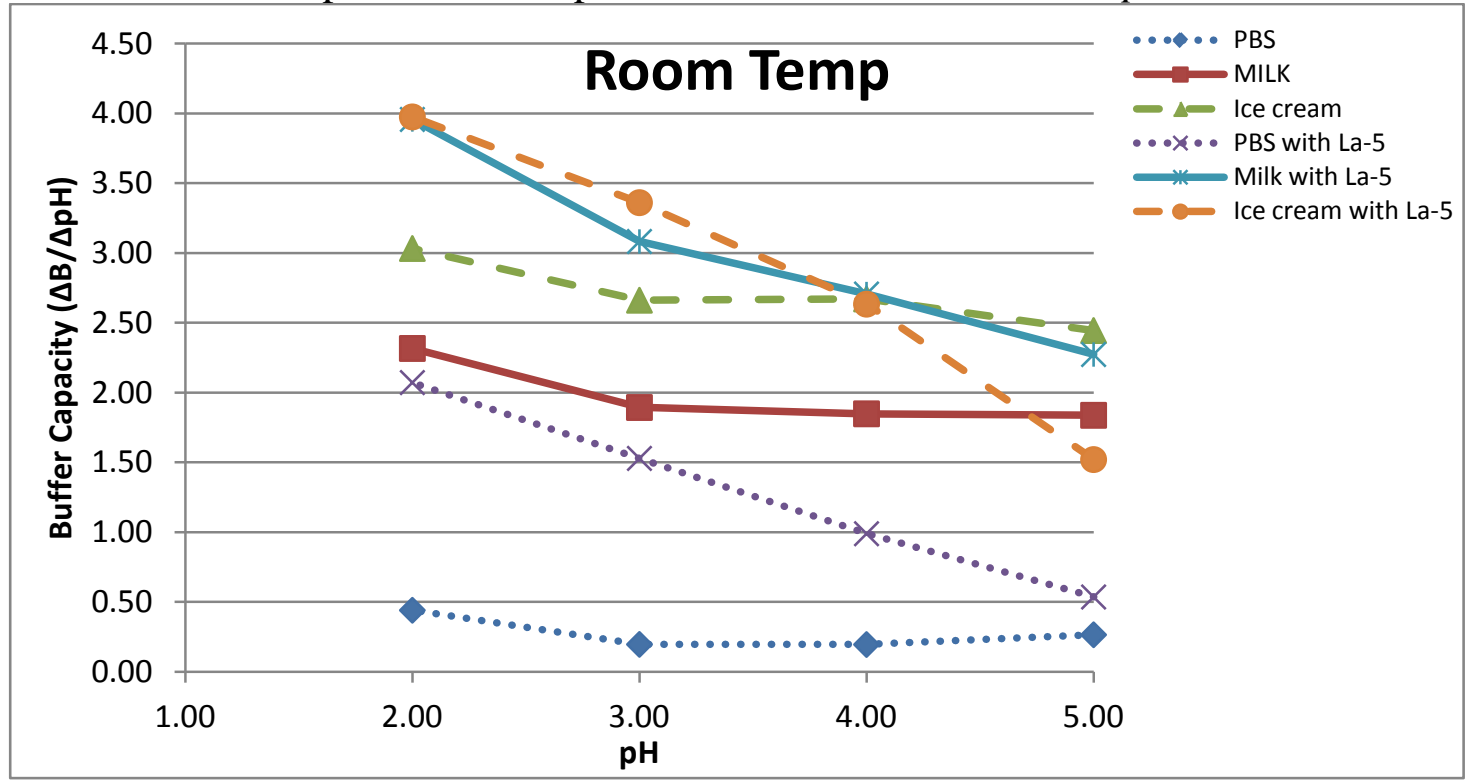

\subsubsection{Effect of shear and dilution}

As seen in Table 5.2.1.1, there was no significant effect of shear $(\mathrm{p}>0.05)$ and dilution ( $p>0.05$ ) on the survivability of La-5 whether in low viscosity or high viscosity sample. Effect of shear was found to be significantly $(\mathrm{p}<0.05)$ different from the effect of dilution on relative log survival of L. acidophilus La-5. Therefore, Tukey’s pairwise 
comparison test was done using one way analysis of variance (ANOVA) to determine which of the treatment pairs were significantly different. As shown in Table 4.2.2.1, the relative log survival at the end of $2 \mathrm{hr}$ of shear treatment on low viscosity ice cream sample was significantly $(\mathrm{p}<0.05)$ higher compared to the relative log survival after dilution treatment on the low viscosity ice cream sample with gastric juice for $2 \mathrm{hr}$. This could be due to an increase in bacterial count as a result of shear treatment which was not found as a result of dilution treatment. Since ice cream samples were thawed and plated when they were about $-4^{\circ} \mathrm{C}$ to $-5^{\circ} \mathrm{C}$ before treatment, this could have resulted in clumping of cells and an underestimation of actual number of colonies present in the control sample. Shearing the same sample for two hours at body temperature of $37^{\circ} \mathrm{C}$ would have resulted in disruption of chains and higher number of colonies after treatment was observed after the treatment.

Table 4.2.2.1: Effect of shear and dilution on survivability of L. acidophilus La-5 incorporated in low and high viscosity samples.

\begin{tabular}{|l|l|l|l|}
\hline Variable & Effect & $\begin{array}{l}\text { Before treatment } \\
\left(4^{\circ} \mathrm{C}\right)\end{array}$ & $\begin{array}{l}\text { After treatment } \\
\left(120 \text { min } \text { at } 37^{\circ} \mathrm{C}\right)\end{array}$ \\
\hline & & \multicolumn{2}{|c|}{$\log _{10} \mathrm{Cfu} / \mathrm{ml}$} \\
\hline Low viscosity & Shear & $7.72 \pm 0.12^{\text {Aa }}$ & $7.96 \pm 0.02^{\text {Aaa }}$ \\
\hline High viscosity & Shear & $7.49 \pm 0.06^{\text {Aa }}$ & $7.73 \pm 0.23^{\text {Aa }}$ \\
\hline Low viscosity & Dilution & $7.66 \pm 0.18^{\text {Aa }}$ & $7.28 \pm 0.06^{\text {Aab }}$ \\
\hline High viscosity & Dilution & $7.16 \pm 0.17^{\text {Aa }}$ & $7.02 \pm 0.13^{\text {Aa }}$ \\
\hline
\end{tabular}

Data were means \pm standard deviations of two replicates.

${ }^{\mathrm{ab}}$ Means within the same column with different letters are significantly different $(\mathrm{p}<0.05)$.

${ }^{A}$ Means within the same row with different letters are significantly different $(p<0.05)$.

\subsubsection{Conventional acid resistance test}

4.2.3.1 Survivability of L. acidophilus La-5 and L. paracasei 431 at $\mathrm{pH} 2.0$ and $\mathrm{pH} 5.0$ in the absence of ice cream

Incubation of probiotic bacteria in citrate-HCl buffer in the absence of ice cream mix for first $60 \mathrm{~min}$ at $\mathrm{pH} 2.0$ (fasting state stomach $\mathrm{pH}$ ) resulted in a reduction of cell 
count from $7.12 \log$ cfu/g to $<10 \mathrm{cfu} / \mathrm{g}$ for L. acidophilus La-5 and from $10.37 \mathrm{log}$ cfu/g to $<10 \mathrm{cfu} / \mathrm{g}$ for $L$. paracasei 431 (Table 4.2.3.1). Whereas, incubation for $120 \mathrm{~min}$ at $\mathrm{pH}$ $5.0(\mathrm{pH}$ of the stomach after ingestion of food) resulted in a log reduction from $6.37 \mathrm{log}$ cfu/g to $5.08 \log$ cfu/g for L. acidophilus La-5 and from $9.48 \log$ cfu/g to $6.35 \log \mathrm{cfu} / \mathrm{g}$ for L. paracasei 431 (Table 4.2.3.1 and Figure 4.2.3.1). The impact of incubation $\mathrm{pH}$ and the sampling time (0, 60 and $120 \mathrm{~min}$ ) on the viable counts of L. acidophilus La-5 and $L$. paracasei 431 was found to be significant $(\mathrm{p}<0.05)$.

Table 4.2.3.1: Effect of $\mathrm{pH} 2.0$ and 5.0 on viability of selected probiotic strains during 2 $\mathrm{hr}$ incubation using conventional acid resistance test

\begin{tabular}{|l|l|l|l|l|}
\hline $\begin{array}{l}\text { Sampling } \\
\text { Time }\end{array}$ & $\mathrm{pH} 2$ & $\mathrm{pH} 2$ & $\mathrm{pH} 5$ & $\mathrm{pH} 5$ \\
\hline & $\begin{array}{l}\text { L. acidophilus } \\
\text { La-5 }\end{array}$ & $\begin{array}{l}\text { L. paracasei } \\
431\end{array}$ & $\begin{array}{l}\text { L. acidophilus } \\
\text { La-5 }\end{array}$ & $\begin{array}{l}\text { L. paracasei } \\
431\end{array}$ \\
\hline & \multicolumn{2}{|c|}{$\log _{10} \mathrm{Cfu} / \mathrm{g}$} & \multicolumn{2}{|c|}{$\log _{10} \mathrm{cfu} / \mathrm{g}$} \\
\hline Control & $7.12 \pm 1.29^{\mathrm{Aa}}$ & $9.69 \pm 0.09^{\mathrm{Ba}}$ & $6.37 \pm 0.67^{\mathrm{ABa}}$ & $9.48 \pm 0.07^{\mathrm{ABb}}$ \\
\hline $60 \mathrm{~min}$ & $0.00 \pm 0.00^{\mathrm{Ba}}$ & $0.00 \pm 0.00^{\mathrm{Ca}}$ & $5.76 \pm 0.13^{\mathrm{Ba}}$ & $7.64 \pm 0.34^{\mathrm{BCb}}$ \\
\hline $120 \mathrm{mins}$ & $0.00 \pm 0.00^{\mathrm{Ba}}$ & $0.00 \pm 0.00^{\mathrm{Ca}}$ & $5.08 \pm 0.44^{\mathrm{Ba}}$ & $6.35 \pm 0.89^{\mathrm{Ca}}$ \\
\hline
\end{tabular}

Data were means \pm standard deviations of two replicates.

${ }^{\mathrm{ABC}}$ Means within the same column that do not share a letter are significantly different $(\mathrm{p}<0.05)$.

${ }^{\mathrm{ab}}$ Means within the same row $(\mathrm{pH}=2)$ that do not share a letter are significantly different $(\mathrm{p}<0.05)$ for $\mathrm{pH} 2.0$ and $\mathrm{pH} 5.0$.

Figure 4.2.3.1: Relative log survival of $L$. acidophilus La-5 and L. paracasei 431 at $\mathrm{pH}$ 2.0 and $\mathrm{pH} 5.0$ during $2 \mathrm{hr}$ incubation in citrate-HCl buffer

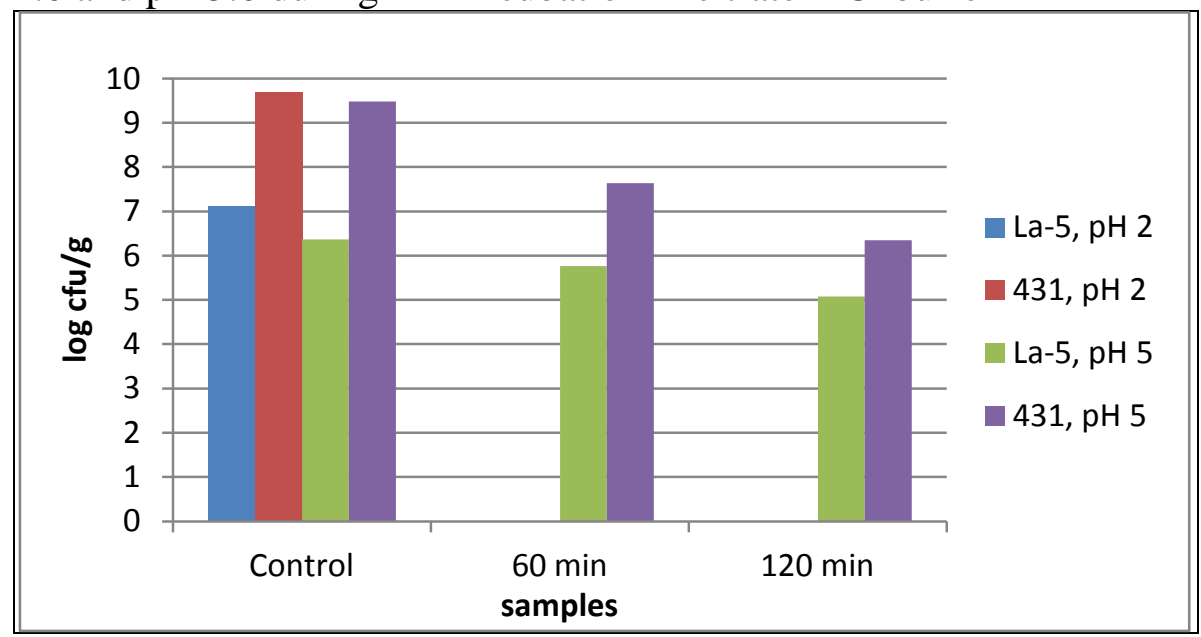


Similar effect of $\mathrm{pH}$ on the viability of L. acidophilus BG2F04 was observed by Hood and Zottola (1988). Their results demonstrated that no cells of L. acidophilus BG2F04 were recovered following 45 min exposure to $\mathrm{pH}$ 2.0. While at $\mathrm{pH} 4.0$, viability was maintained close to $7 \log \mathrm{cfu} / \mathrm{ml}$ after $2 \mathrm{hr}$ incubation. Abghari et al. (2011) and Alamprese et al. (2002) also reported significant impact of incubation $\mathrm{pH}$ (1.5, 2.5, 3.5 and 6.5) and sampling time on the survivability of tested probiotic bacteria. Abghari et al. (2011) demonstrated a significant reduction in viable counts of L. acidophilus (isolated from probiotic capsules) at pH 1.5 and 2.5 overtime during $3 \mathrm{hr}$ incubation in MRS broth. At pH 2.5, approximately $3.5 \mathrm{log}$ cfu/g survived at the end of $3 \mathrm{hr}$ incubation whereas, at $\mathrm{pH} 1.5$, almost no survival was observed similar to present study where the viability was $0 \%$ at the end of first hour incubation at $\mathrm{pH} 2.0$ for $L$. acidophilus La-5 as well as $L$. paracasei 431 (Table 4.2.3.1). On the other hand, Alamprese et al. (2002) reported significant reduction in viable counts of $L$. johnsonii La- 1 at $\mathrm{pH} 1.5$ at the end of $3 \mathrm{hr}$ incubation, but for $\mathrm{pH} 2.5$ and 3.5, the number of viable cells remained close to $8 \log$ cfu/ml during $3 \mathrm{hr}$ incubation which was not significantly different from the counts at $\mathrm{pH}$ 6.5. These differences in the level of impact of $\mathrm{pH}$ on the survivability of probiotic bacteria could be attributed to the difference in suspending medium, variability in tested probiotic species and strains and their response to acid shock and growth conditions (Chou and Weimer, 1999). In addition, when the cells are present in an environment of low external $\mathrm{pH}$, the energy consumption, which is required for maintenance of the intracellular $\mathrm{pH}$, is increased. As a result, other crucial cellular functions are depressed of ATP and the cells cannot survive (Corcoran et al., 2005; Shabala et al., 2006). Differences in the level of sensitivity towards stress factors have been reported for 
Bifidobacerium species isolated from human gastrointestinal tract in relation to those of animal origin (Sanz, 2007). Sanz (2007) suggested that response to acid stress and strain origin have a significant relationship and this could have an impact on species composition under extreme acidic conditions.

Table 4.2.3.2: Overall Log Reduction at $\mathrm{pH}$ 2, $\mathrm{pH} 5$ and in the presence of ice cream for L. acidophilus La-5 and L. paracasei 431

\begin{tabular}{|l|l|l|}
\hline & \multicolumn{1}{|c|}{ L. acidophilus La-5 } & \multicolumn{2}{c|}{ L. paracasei 431 } \\
\hline & \multicolumn{2}{|c|}{ overall $\log$ reduction $\left(\log _{10} \mathrm{cfu} / \mathrm{g}\right)$} \\
\hline pH 2 & $7.12 \pm 0.92^{\mathrm{Aa}}$ & $9.69 \pm 0.06^{\mathrm{Aa}}$ \\
\hline pH 5 & $1.30 \pm 0.79^{\mathrm{Ba}}$ & $3.13 \pm 0.58^{\mathrm{Ba}}$ \\
\hline Ice cream & $2.62 \pm 0.63^{\mathrm{ABa}}$ & $4.87 \pm 0.65^{\mathrm{Ba}}$ \\
\hline
\end{tabular}

Data were means \pm standard deviations of two replicates.

${ }^{\mathrm{AB}}$ Means within the same column that do not share a letter are significantly different $(\mathrm{p}<0.05)$.

${ }^{\mathrm{a}}$ Means within the same row that do not share a letter are significantly different $(\mathrm{p}<0.05)$.

Even though, L. acidophilus La-5 and L. paracasei 431 lacked the ability to survive harsh conditions of traditional screening at $\mathrm{pH} 2$ in citrate- $\mathrm{HCl}$ buffer, it's not an environment that is usually encountered in vivo during and after a meal because of buffering capacity of foods and variations in the response of various gastric juice components ( $\mathrm{HCl}$ and enzymes) based on food composition in which the bacteria is embedded (section 2.2.2.1). It has also been suggested that buffering of stomach $\mathrm{pH}$ by certain foods containing probiotic microbes improves their survival during gastric transit (Saxelin et al., 2010). Therefore, This difference in counts at sampling time points $60 \mathrm{~min}$ and 120 min could be attributed to the difference in acid shock response of each of the two bacteria at a specific $\mathrm{pH}$ as well as difference in the initial inoculation level of ice cream mix as shown in Table 4.2.3.3. Curto et al. (2011) also reported differences in the survival rate among the three probiotic bacteria that were tested (L. casei subsp. shirota, L. casei subsp. immunitas, L. acidophilus subsp. johnsonii) in the presence of milk. They 
also found that the survival rate was higher for all the bacteria in the presence of milk compared to water since water has a low buffering effect compared to milk (Holzapfel at al., 2001). Majority of the studies have conducted acid resistance test in the $\mathrm{pH}$ range of 1.0-5.0 and have found that $\mathrm{pH} 2.0$ or below has been most detrimental compared to $\mathrm{pH}$ 3.0, 4.0, and 5.0 to the viability of tested probiotic bacteria. At $\mathrm{pH} 1.0$ and 2.0, maximum mortality has been reported (Conway et al., 1987; Hood and Zottola., 1988; Abghari et al., 2011; Kawther et al., 2010), whereas, at pH 3.0 or above, survivability has been more or less maintained steady (Chou and Weimer, 1999; Alamprese et al., 2002; Basyigit et al., 2006) or has shown a slower reduction overtime maintaining viability of up to 4 log units or more (Collado et al., 2005; Faye et al., 2012) depending on the species and strains, initial inoculation level, incubation $\mathrm{pH}$ and suspension medium. Similarly, in this study, $\mathrm{pH} 2.0$ was found to be extremely detrimental and progressive reduction in viable counts were observed at $\mathrm{pH}$ 5.0.

4.2.3.2. Survivability of L. acidophilus La-5 and L. paracasei 431 in the presence of ice cream

The effect of ice cream mix was tested by mimicking gastric digestion on bench top in the presence of simulated gastric juice. The results showed that there was a reduction in the viable counts of L. acidophilus La-5 from $7.56 \log$ cfu/g to $4.94 \log$ cfu/g which is an overall $\log$ reduction of $2.62 \log \mathrm{cfu} / \mathrm{g}$ at the end of $2 \mathrm{hr}$ simulated digestion in the presence of ice cream. Similar reduction in viable counts from $8.55 \log \mathrm{cfu} / \mathrm{g}$ to $3.68 \log \mathrm{cfu} / \mathrm{g}$, an overall reduction of $4.87 \mathrm{log}$ cfu/g was found for L. paracasei $431 \mathrm{in}$ the presence of ice cream mix (Table 4.2.3.3). The results demonstrated a loss in viable counts of both La-5 and 431 at the end of 2 hr simulated digestion, but $65.34 \%$ of La-5 
and $43.04 \%$ of 431 were still alive even though the $\mathrm{pH}$ was maintained at $\sim 2.6$ for the last hour of digestion in the presence of ice cream compared to $0 \%$ for both the bacteria when they were incubated at $\mathrm{pH} 2.0$ for $2 \mathrm{hr}$ in the absence of ice cream. The probiotic strain had a significant $(\mathrm{p}<0.05)$ impact on the resulting overall log reduction at $\mathrm{pH} 5.0$ in the absence of ice cream and during simulated digestion in the presence of ice cream. This means that even though the presence of ice cream improved survivability of both the probiotic bacteria at low $\mathrm{pH}$, their response was strain dependent. In addition, at each time points (60 and $120 \mathrm{~min}$ ), there was a significant $(\mathrm{p}<0.05)$ difference between the counts of La-5 and 431 in the presence of ice cream (Table 4.2.3.3), but the overall reduction as a result of simulated digestion process for each of the two strains was not significantly ( $\mathrm{p}>0.05)$ different.

Table 4.2.3.3: Effect of presence of ice cream mix on the viable counts of selected probiotic strains during $2 \mathrm{hr}$ of simulated digestion process.

\begin{tabular}{|l|l|l|}
\hline Sampling time & \multicolumn{2}{|l|}{ In the presence of ice cream mix (simulated digestion process) } \\
\hline & L. acidophilus La-5 & L. paracasei 431 \\
\hline & \multicolumn{2}{|c|}{$\log _{10}$ cfu/g } \\
\hline Control & $7.56 \pm 0.70^{\mathrm{Aa}}$ & $8.55 \pm 0.67^{\mathrm{Aa}}$ \\
\hline $60 \mathrm{~min}$ & $6.51 \pm 0.16^{\mathrm{ABa}}$ & $8.09 \pm 0.38^{\mathrm{Ab}}$ \\
\hline $120 \mathrm{mins}$ & $4.94 \pm 0.19^{\mathrm{Ba}}$ & $3.68 \pm 0.24^{\mathrm{Bb}}$ \\
\hline
\end{tabular}

Data were means \pm standard deviations of two replicates.

${ }^{\mathrm{AB}}$ Means within the same column that do not share a letter are significantly different $(\mathrm{p}<0.05)$.

${ }^{\mathrm{ab}}$ Means within the same row that do not share a letter are significantly different $(\mathrm{p}<0.05)$. 
Figure 4.2.3.2 Relative log survival of L. acidophilus La-5 and L. paracasei 431 in the presence of ice cream mix during $2 \mathrm{hr}$ simulated digestion

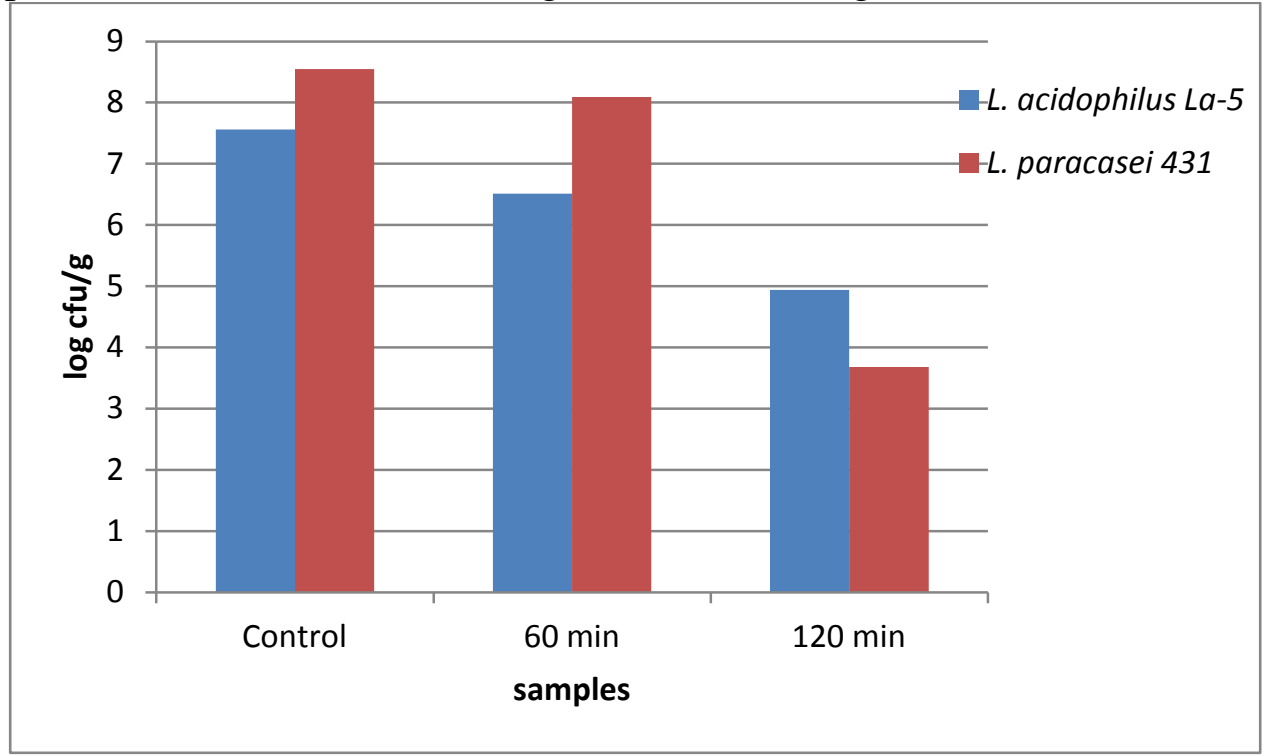

In this study, incubation at $\mathrm{pH} 2.0$ in the absence of ice cream mix was found to be extremely detrimental and progressive reduction in viable counts were observed at $\mathrm{pH}$ 5.0. Whereas, the presence of ice cream mix was found to improve survivability of both L. acidophilus La-5 and L. paracasei 431 at the end of simulated digestion. The observed protective effect of ice cream in this study could be attributed to the high buffering capacity of ice cream mix (section 4.2.1).

Mainville et al. (2005) tested kefir as a suspension medium for selected Bifidobacterium and Lactobacillus strains and isolates from kefir and reported that kefir improved the survivability of the tested strains during simulated digestion that were not able to survive the conventional acid resistance test i.e incubation at $\mathrm{pH} 2.0$ in the absence of kefir for more than 15 min (L. rhamnosus GG, B. longum RW002, and B. infantis ATCC 27920G). The authors also found that the simulated digestion time below pH 3.0 in the presence of kefir resulted in most cell death. Similar pH dependent survival of probiotic bacteria (L. johnsonii B-2178, L. gasseri B-14168 and L. salivarius B-1950) 
and improvement in their survivability in the presence of milk proteins during gastric transit was also demonstrated by Kawther et al. (2010). They found that all the strains showed progressive reduction in viable cell numbers at $\mathrm{pH} 2.0$ and $\mathrm{pH} 4.0$ in the absence of protective matrix such as sodium caseinate, whey protein or starch. The presence of milk proteins and starch played a role in enhancing the viability of tested probiotic bacteria during simulated digestion at $\mathrm{pH} 2.0$ and 3.0.

The results from these studies and the present study demonstrated the importance of $\mathrm{pH}$ and the protective effect of food matrix on the survivability of probiotic bacteria against the harsh stomach conditions during digestion. The presence of milk, milk proteins and milk based products have been shown to play a significant role in reducing the detrimental effects of lower $\mathrm{pH}$ values and enhancing the viability of strains that were completely inhibited by conventional acid resistance test or showed low acid tolerance (Conway et al., 1987, Miettinen et al., 1998; Mainville et al., 2005 and Fernández de Palencia et al., 2008; Kawther et al., 2010).

Milk and milk products generally have high initial $\mathrm{pH}$ and buffering capacity due to the presence of proteins and salts. This leads to an initial increase in the fasted state $\mathrm{pH}$ of the stomach and reduces the time of exposure of probiotic bacteria to hostile stomach pH protecting them from dying (Charteris et al., 1998; Conway et al., 1987; Huang and Adams, 2004; Tompkins et al., 2011; Faye et al., 2012). In case of cheese and ice cream, the fat content could be as high as $10-12 \%$ or more. The presence of fat (as low as $1 \%$ ) has been found to have improved the survivability of bacteria during gastric transit as compared to absence of fat as in skim milk (Varcoe et al., 2002) suggesting the importance of fat in ensuring the survival of tested probiotic bacteria through stomach. 
Some studies have also been conducted that demonstrated binding between probiotic bacteria and certain components of the milk fat globule membrane (Bachiero et al. 2007; Brisson et al., 2010). Therefore, it may be speculated that the $10 \%$ fat content and high buffering capacity of the in ice cream mix tested in the present study could be responsible for protecting L. acidophilus La-5 and L. paracasei 431 against low $\mathrm{pH}$ and presence of enzymes during simulated digestion.

\subsection{Phase III: In vitro digestion of ice cream}

\subsubsection{Shaking water bath}

Ice cream sample termed as LVHC (Table 3.3.2.1) was digested using shaking water bath model and HGS and the survivability of L. acidophilus La-5 during simulated gastric conditions in both the model stomachs was compared. No significant difference in the viable cell count ( $>0.05$ ) was found between the two models at each sampling time point except at 30 min. It was found that within each model, sampling point and $\mathrm{pH}$ had a significant effect $(\mathrm{p}<0.05)$ on the relative log survival of L. acidophilus La-5 (Table 4.3.1.1). The log reduction at the end of first hour of gastric digestion was observed to be $1.74 \log \mathrm{cfu} / \mathrm{g}$ for shaking water bath model and $2.18 \mathrm{log}$ cfu/g for HGS, whereas, at the end of second hour, the observed reduction was slightly lower i.e.1.31 log cfu/g and 1.95 $\log \mathrm{cfu} / \mathrm{g}$ for shaking water bath and HGS, respectively. One thing that was common in both the models was higher mortality during the first hour of digestion compared to the second hour of digestion. This indicates that $L$. acidophilus La-5 cells experienced slightly more stress during the first hour compared to the second hour, even though the $\mathrm{pH}$ was maintained above 3 for the first 45 minutes and then dropped to 2.5 in the next 15 min (Figure 4.3.1.2). As it can be seen in Figure 4.3.1.1, the percent survivability of 
L. acidophilus La-5 at each sampling points (30, 60 and 120min) during $2 \mathrm{hr}$ digestion was higher when the ice cream was digested using shaking water bath compared to HGS. The overall $\log$ reduction in the viable counts of La-5 was higher when ice cream was digested in HGS (4.13 $\pm 0.65 \log \mathrm{cfu} / \mathrm{g})$ compared to shaking water bath (3.05 $\pm 0.57 \log$ $\mathrm{cfu} / \mathrm{g}$ ), but this difference was not significant ( $\mathrm{p}>0.05$ ) possibly due to the small sample size.

Table 4.3.1.1: Survivability of L. acidophilus La-5 during $2 \mathrm{hr}$ simulated gastric digestion of ice cream in shaking water bath model and HGS.

\begin{tabular}{|c|c|c|}
\hline & Shaking Water Bath & HGS \\
\hline & \multicolumn{2}{|c|}{$\log _{10} \mathrm{cfu} / \mathrm{g}$} \\
\hline Initial (ice cream) & $7.84 \pm 0.10^{\mathrm{Aa}}$ & $7.89 \pm 0.10^{\mathrm{Aa}}$ \\
\hline $30 \mathrm{~min}$ & $6.77 \pm 0.01^{\text {Aab }}$ & $6.57 \pm 0.01^{\mathrm{Bat}}$ \\
\hline 60min & $6.10 \pm 0.22^{\mathrm{Abc}}$ & $5.71 \pm 0.11^{\mathrm{Ab}}$ \\
\hline 120min & $4.79 \pm 0.69^{\mathrm{Ac}}$ & $3.76 \pm 0.82^{\mathrm{Ac}}$ \\
\hline
\end{tabular}

Data were Means \pm Standard deviations of two replicates. ${ }^{\mathrm{A}}$ Means with different letters within same rows are significantly different $(\mathrm{p}<0.05)$.

${ }^{\mathrm{abc}}$ Means with different letters within same column are significantly different $(\mathrm{p}<0.05)$.

Figure 4.3.1.1: Relative log survival of L. acidophilus La-5 during 120 min simulated digestion in shaking water bath and Human Gastric Simulator (HGS)

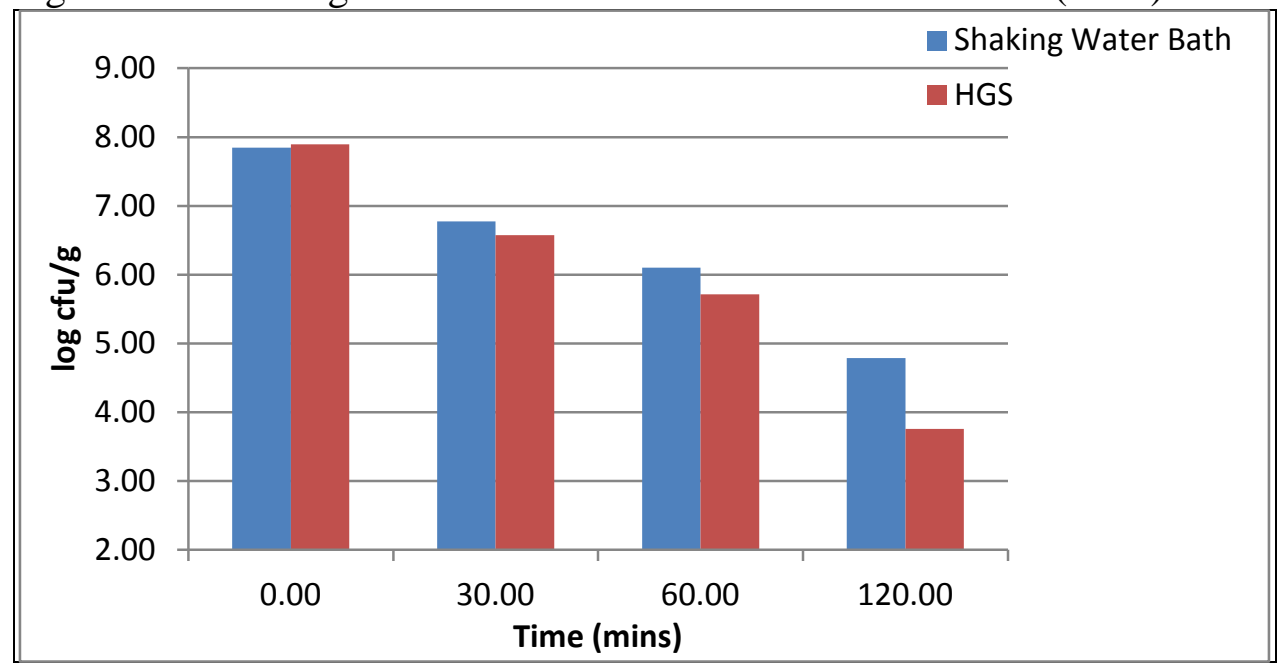


Figure 4.3.1.2: Postprandial $\mathrm{pH}$ decrease during simulated digestion of ice cream in shaking water bath and HGS

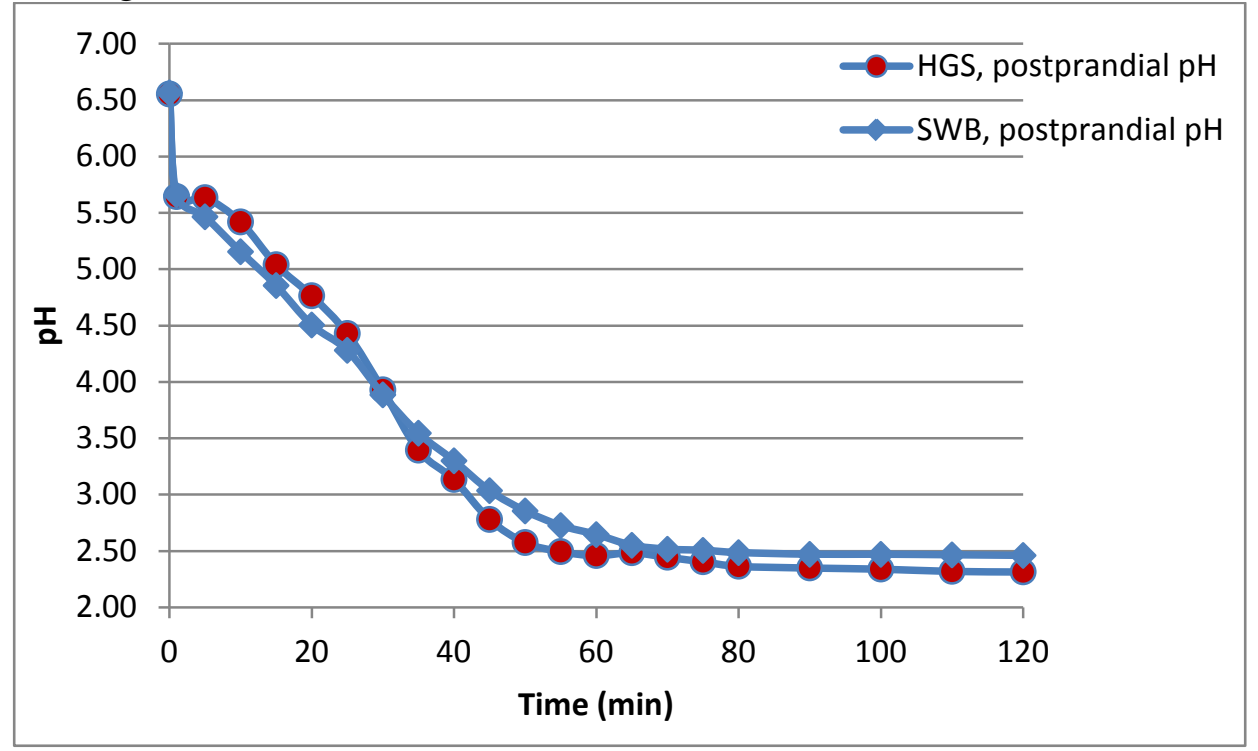

The decrease in viability of $L$. acidophilus La-5 was found to be more during first hour of simulated digestion compared to the second hour in the present study. Similarly, Masco et al. (2007) also reported that the relative decrease in viability of all the tested Bifidobacterium stains was higher after 1 min compared to that after $180 \mathrm{~min}$ and attributed this to possible adaptation to acidic conditions. Although, this mechanism remains to be investigated for $L$. acidophilus La-5 in the present study, it can be hypothesized that upregulation of genes involved in stress responses could be responsible for enhancing acid tolerance of probotic bacteria (Klaenhammer and Kullen, 1999).

A more legitimate reason for the initial shock during first hour could be the continuous flood of hydrogen ions during the first $60 \mathrm{~min}$ as a result of gastric secretion at a rate of $3.5 \mathrm{ml} / \mathrm{min}$ until $\mathrm{pH}$ was lowered to 2.5 after which it was reduced to a much lower rate of $0.9 \mathrm{ml} / \mathrm{min}$. Another possible explanation could be chemical stresses caused during melting (freeze-thaw) of the frozen ice cream before it was subjected to gastric digestion. In the present study, ice cream was thawed before simulated digestion to 
approximately $-5^{\circ} \mathrm{C}$ and saliva was added and mixed for $10 \mathrm{sec}$ as a result of which cells could be exposed to osmotic effects and melting of ice cream may result in hydrogen ions and oxygen poisonous to probiotic cells (Jay et al., 2005). The reduction in viable cells during second hour was possibly a result of acid shock due to maintenance of low $\mathrm{pH}$ ( 2.5) throughout that hour in accordance with the findings of Pinto et al. (2006), Zhu et al. (2006) and Ruiz-Moyano et al. (2008). In addition, it could also be a result of decrease in viscosity and increase in dilution exposing the probiotic cells to acid and enzymes. In both model stomachs, gastric emptying was not stimulated. Therefore, viable cells were exposed to $\mathrm{pH} 2.5$ for the whole second hour of digestion, whereas in vivo, the viable bacteria would have left the stomach with digested food as a result of emptying and reached the intestine unaffected.

The slightly lower survivability of $L$. acidophilus La-5 during simulated digestion in HGS compared to shaking water bath could be due to stomach contractions that generated fluid flow of the gastric content resulting in a shearing effect on the food causing damage to the cells eventually leading to their death. Therefore, presence of real peristaltic contractions and shear in addition to dilution in HGS could have enhanced the contact between probiotic cells and gastric juice contents resulting in additional detrimental effects compared to shaking water bath model. The morphology of the cell may also contribute to the extent of detrimental effect caused due to shear and grinding in HGS. Since L. acidophilus La-5 is rod shaped bacteria, it is probably more prone to adverse effect of mechanical shear compared to a bacteria such as streptococcus.

Even though the survivability of $L$. acidophilus La-5 was slightly, but not significantly affected by HGS, it was able to successfully demonstrate the importance of 
incorporating probiotic bacteria in a food product like ice cream since approximately 4 $\log$ units of La-5 were still viable at the end of simulated digestion which could reach their site of action to provide health benefits. It was also able to effectively simulate major conditions in the stomach, an increase in $\mathrm{pH}$ upon ingestion of food followed by restoration of fasted state stomach $\mathrm{pH}$ as well as peristaltic contractions. More studies and repetitions must be conducted with different conditions, strains and food products to further validate the preliminary results obtained in the present study.

It was speculated that the acid tolerance capacity of L. acidophilus La-5 that was observed in the presence of ice cream mix (section 4.2.3) would be lower in the frozen ice cream when exposed to low $\mathrm{pH}$ during simulated digestion because of the stress due to freezing process and storage at sub zero temperature possibly causing the cells to become acid sensitive. No significant ( $\mathrm{p}>0.05$ ) difference was found in the overall log reduction of $L$. acidophilus La-5 numbers in either of the three experiments (cells in ice cream mix, static model; cells in frozen ice cream, shaking water bath and HGS). This suggests that the freezing process during ice cream manufacture and the storage at subzero temperature did not have a detrimental effect on the bacterial acid tolerance capacity. These results indicate the importance of mimicking the actual digestion process, the rise and fall in the $\mathrm{pH}$ due to the presence of food matrix, its buffering effect and gastric secretion in response to the ingestion of a meal. In a study conducted by Abghari et al. (2011) authors did not include the effect of presence of food matrix when testing the low pH sensitivity of frozen thawed cells. The frozen thawed cells were washed with PBS and resuspended in saline followed by incubation at $\mathrm{pH} 2.5$ for $2 \mathrm{hr}$. They found that the frozen thawed cells had become acid sensitive which was in contradiction to the 
present study. The variability in the acid stress response by different strains tested in each of these studies could have also lead to differences in results.

\subsubsection{Human Gastric Simulator}

The results indicated that there was no significant difference ( $\mathrm{p}>0.05)$ in the apparent viscosity of gastric digesta measured at shear rate of $49.92 \mathrm{sec}^{-1}$ (Soukoulis et al., 2009) collected at 30, 60 and 120 min for both LVHC and HVHC samples (Figure 4.3.2.1 and 4.3.2.2). Analysis also showed that there was no significant difference $(\mathrm{p}>0.05)$ in viscosities tested at a range of shear rates at time points 30,60 and $120 \mathrm{~min}$ once both the samples (LVHC and HVHC) were diluted for first 30 min, irrespective of their initial viscosity level.

Figure 4.3.2.1: Effect of gastric dilution on low viscosity ice cream sample during simulated digestion in HGS

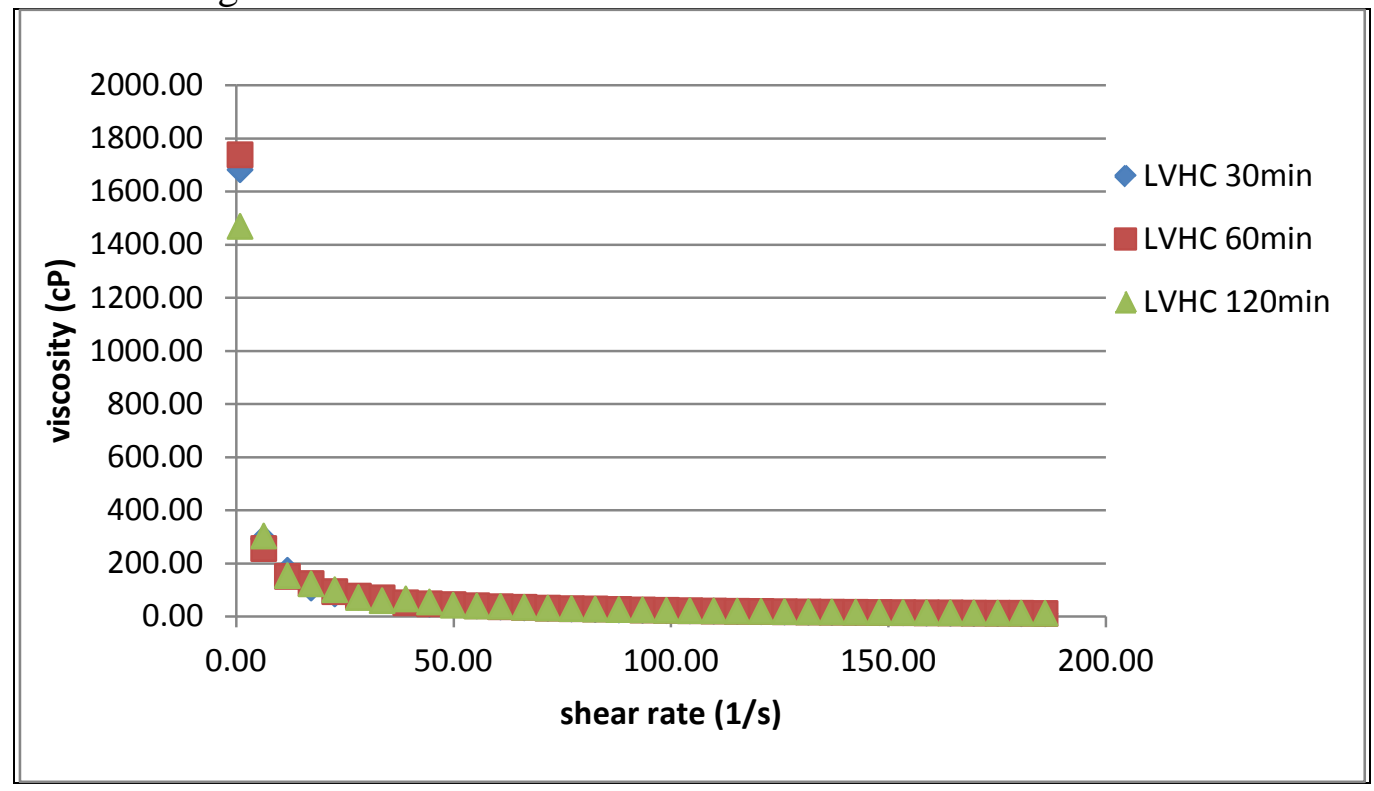


Figure 4.3.2.2: Effect of gastric dilution on high viscosity ice cream sample during simulated digestion in HGS

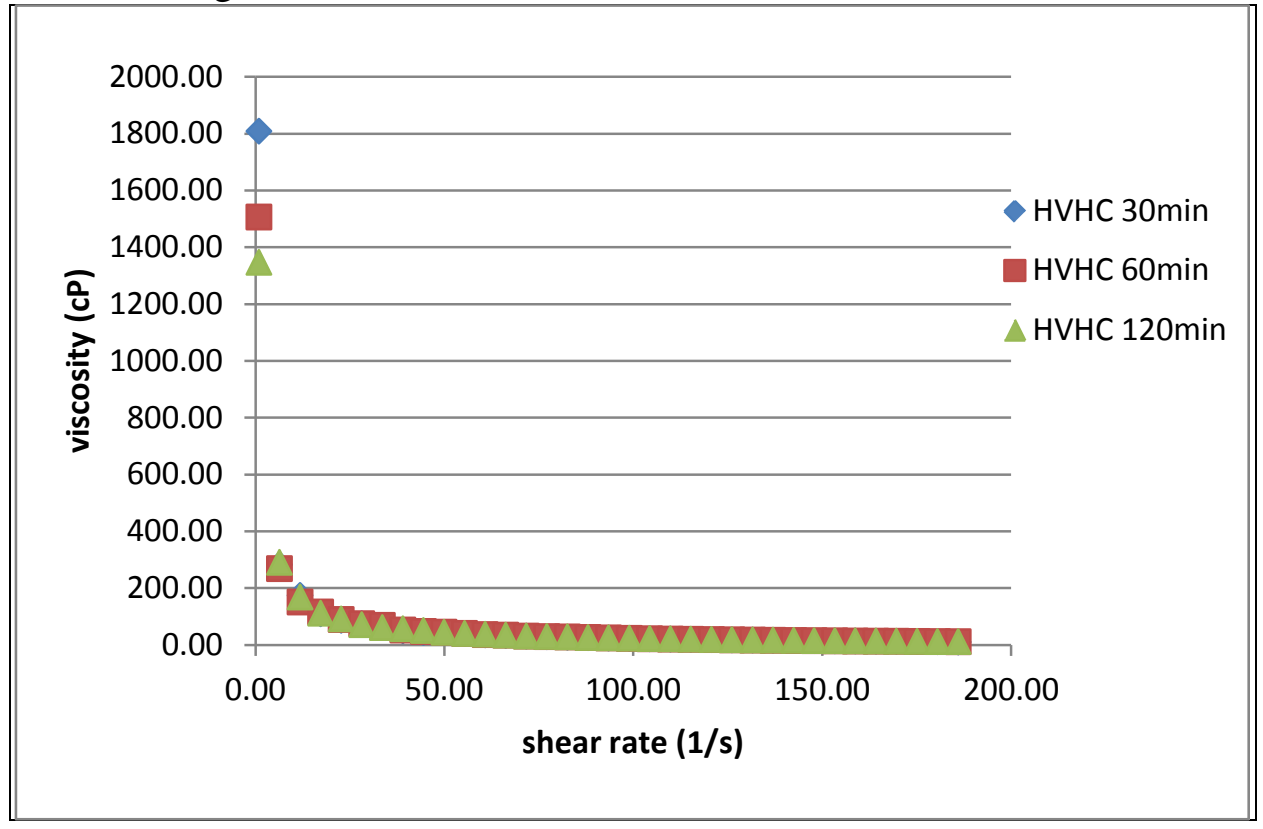

Power law model of non Newtonian fluid was used to describe the behavior of gastric digesta (Takahashi et al., 2004). The value of $n$ indicates the flow behavior of the product. When $n=1$, the fluid displays Newtonian flow behavior. The value of $n$ was highest (closest to 1) for HVHC, 120 min sample and lowest for LVHC, 30 min sample (Table 4.3.2.1). Hence, the HVHC, 120 min sample displayed least shear thinning behavior and more Newtonian like fluid. The consistency coefficient $(\kappa)$ indicates the relative thickness of a solution. The values of consistency coefficient ( $\kappa$ ) in Table 4.3.2.1 were found to decrease as the digestion process progressed towards 120 min for both LVHC and HVHC samples. This shows that the relative thickness was highest for samples collected at $30 \mathrm{~min}$ and it kept decreasing as samples were further diluted at 60 min until at 120 min during simulated digestion. 
Table 4.3.2.1: Consistency index ( $\kappa$ ) and flow behavior index (n)

\begin{tabular}{|c|c|c|c|c|c|c|}
\hline \multirow[t]{2}{*}{ Variables } & 30min & $60 \mathrm{~min}$ & $120 \mathrm{~min}$ & 30min & 60min & $120 \mathrm{~min}$ \\
\hline & \multicolumn{3}{|c|}{ Consistency index $(\kappa)$} & \multicolumn{3}{|c|}{ flow behavior index (n) } \\
\hline $\begin{array}{l}\text { Low viscosity } \\
\text { high conc. }\end{array}$ & 1.7567 & 1.6787 & 1.6065 & 0.0381 & 0.0607 & 0.0765 \\
\hline $\begin{array}{l}\text { High viscosity, } \\
\text { high conc. }\end{array}$ & 1.7165 & 1.5433 & 1.4864 & 0.053 & 0.0817 & 0.0949 \\
\hline
\end{tabular}

Statistical analysis was also conducted to determine the effect of saliva addition, viscosity level and initial inoculation amount on the survivability of L. acidophilus La-5 during $2 \mathrm{hr}$ simulated digestion. There was no significant detrimental effect $(\mathrm{p}>0.05)$ of addition of saliva to each of the four ice cream samples on the viability of L. acidophilus La-5 (Table 4.3.2.2) indicating no cumulative inhibitory action caused due to presence of $\alpha$-amylase and mucin on L. acidophilus La-5. It was also found that the high level of viscosity did not have a significantly different effect ( $>>0.05)$ on the survivability of La-5 at the end of digestion compared to that of low level of viscosity, irrespective of the initial inoculation level of $L$. acidophilus La-5. In addition, there was no significant difference ( $>0.05$ ) in the relative log survival of L. acidophilus La-5 between high and low viscosity ice cream samples, irrespective of the initial inoculation level at time points 30, 60 and 120 min (Table 4.3.2.2). The overall $\log$ survival of L. acidophilus La-5 at the end of 120 min for LVHC and HVHC ice cream samples was $3.76 \pm 0.82$ and $3.52 \pm 0.74$, respectively and did not differ significantly ( $\mathrm{p}>0.05)$. Similarly, the overall log survival of La-5 for LVLC and HVLC ice cream samples was $4.13 \pm 0.75$ and $4.04 \pm 0.31$, respectively and did not differ significantly ( $\mathrm{p}>0.05)$ (Figure 4.3.2.3). 
Table 4.3.2.2: Effect of difference in viscosity and initial inoculation amount of $L$. acidophilus La-5 on its survivability during 120 min of simulated digestion

\begin{tabular}{|l|l|l|l|l|}
\hline Sampling points & LVHC & HVHC & LVLC & HVLC \\
\hline & \multicolumn{4}{|c|}{$\log _{10} \mathrm{cfu} / \mathrm{ml}$} \\
\hline Initial (ice cream) & $7.89 \pm 0.10^{\mathrm{Aa}}$ & $7.54 \pm 0.06^{\mathrm{Aa}}$ & $6.40 \pm 0.14^{\mathrm{Ba}}$ & $6.26 \pm 0.25^{\mathrm{Ba}}$ \\
\hline Ice cream + Saliva & $7.84 \pm 0.00^{\mathrm{Aa}}$ & $7.61 \pm 0.06^{\mathrm{Ba}}$ & $6.38 \pm 0.03^{\mathrm{Ca}}$ & $6.08 \pm 0.00^{\mathrm{Da}}$ \\
\hline 30min & $6.57 \pm 0.01^{\mathrm{Aab}}$ & $6.65 \pm 0.19^{\mathrm{Aab}}$ & $5.71 \pm 0.57^{\mathrm{Aab}}$ & $5.37 \pm 0.27^{\mathrm{Aab}}$ \\
\hline $60 \mathrm{~min}$ & $5.71 \pm 0.11^{\mathrm{Ab}}$ & $5.57 \pm 0.27^{\mathrm{Ab}}$ & $5.17 \pm 0.80^{\mathrm{Aab}}$ & $4.97 \pm 0.21^{\mathrm{Abc}}$ \\
\hline $120 \mathrm{~min}$ & $3.76 \pm 0.82^{\mathrm{Ac}}$ & $3.52 \pm 0.74^{\mathrm{Ac}}$ & $4.13 \pm 0.75^{\mathrm{Ab}}$ & $4.04 \pm 0.31^{\mathrm{Ac}}$ \\
\hline $\begin{array}{l}\text { Overall Log } \\
\text { Reduction }\end{array}$ & $4.14 \pm 0.91^{\mathrm{A}}$ & $4.02 \pm 0.67^{\mathrm{A}}$ & $2.28 \pm 0.60^{\mathrm{A}}$ & $2.22 \pm 0.06^{\mathrm{A}}$ \\
\hline
\end{tabular}

Data were Means \pm standard deviations of two replicates.

${ }^{A B C D}$ Means with different letters within same row are significantly different $(p<0.05)$.

${ }^{\mathrm{abc}}$ Means with different letters within same column are significantly different $(\mathrm{p}<0.05)$.

The initial inoculation level of $L$. acidophilus La-5 had a significant impact $(\mathrm{p}<0.05)$ on its survivability during the simulated digestion of ice cream samples, irrespective of the difference in viscosity. Minimum differences were observed in the log survival for both LVLC and HVLC samples compared to LVHC and HVHC samples, these differences were found to be statistically non significant ( $p>0.05$ ). The overall reduction on an average for LVLC and HVLC samples was found to be $4.08 \mathrm{log} \mathrm{cfu} / \mathrm{g}$ and for LVHC and HVHC sampes was $2.25 \mathrm{log} \mathrm{cfu} / \mathrm{g}$. These differences were also found to be statistically non significant ( $\mathrm{p}>0.05$ ) (Table 4.3.2.2.). Even though, most of the bacterial death occurred after first 30 min and decreased progressively until $120 \mathrm{~min}$, the survivability of La-5 was normalized at about 4 log cfu/g for all the samples (LVHC, HVHC, LVLC and HVLC) at the end of digestion, irrespective of the difference in initial supplementation amount of L. acidophilus La-5 and in the viscosity (Figure 4.3.2.2). The $\mathrm{pH}$ of gastric digesta was also found to have a significant effect $(\mathrm{p}<0.05)$ on the viable counts of L. acidophilus La-5 during 120 min modeled digestion. As the $\mathrm{pH}$ decreased progressively throughout $120 \mathrm{~min}$, the survivability of L. acidophilus La-5 also 
decreased and resulted in $4 \log$ cfu/g survival for all the samples (LVHC, HVHC, LVLC and HVLC), irrespective of difference in initial level of La-5 and initial viscosity.

Figure 4.3.2.3: Relative survival ( $\left.\log _{10} \mathrm{cfu} / \mathrm{g}\right)$ of L. acidophilus La-5 during simulated digestion of ice cream in the HGS

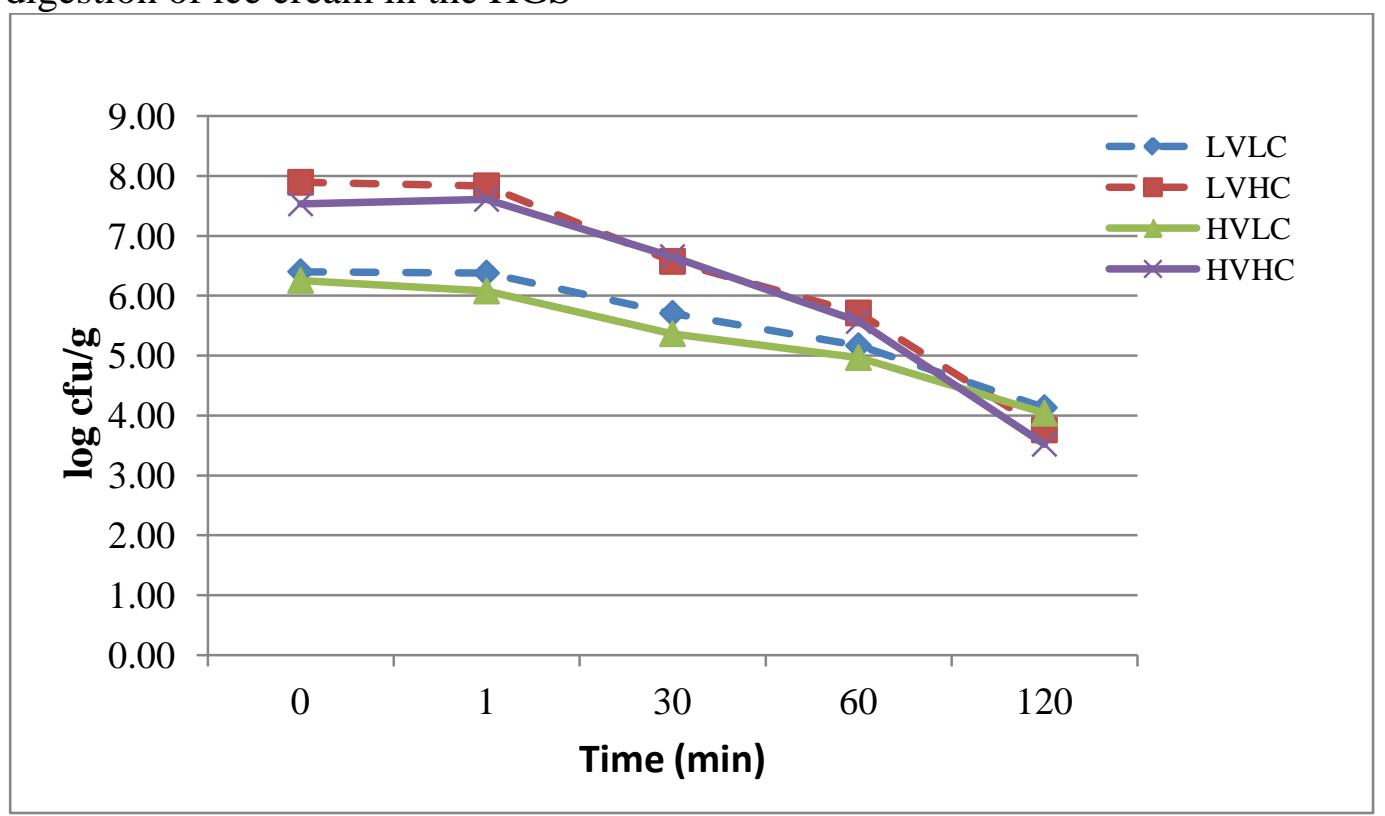

Few studies conducted by Marciani et al. (1999 and 2001) tested the effect of digestion process on the viscosity of samples in vivo. They found that the viscosity of the ingested food, irrespective of initial viscosity reduced significantly in vivo in the first 40 min of digestion as a result of progressive dilution, acidification by gastric juice and shear due to peristaltic contractions. Cameron-Smith et al. (1994) and Cherbut et al. (1990) also reported in line marked reductions in meal viscosity after ingestion of meal in rats and pigs largely due to dilution. Marciani et al. (1999) reported that the dilution of each ingested meal was similar, but viscosity of most viscous meal was found to decrease more compared to the less viscosu meal. This was suggested to be due to the exponential relationship between viscosity and concentration of added gums and increase in gastric secretion because of increased distending of the stomach walls in response to high 
viscosity of the meal. Edwards et al. (1987) found that the acidification changed the viscosity of the X/LBG (1:1 combination of xanthan and locust bean gum) and X/Mey (1:1 combination of xanthan and Meyprodyn $\left.{ }^{\circledR}\right)$ gum mixtures. These gum mixtures had the highest initial viscosity, but upon acidification resulted in lowest viscosity compared to other gums.

In the presen study, similar decrease in viscosity was observed because as the time of digestion increased, dilution of the ice cream also increased in the presence of constant mechanical shear. Even though, viscosity of both LVHC and HVHC ice cream samples reduced significantly $(\mathrm{p}<0.05)$ at the end of first 30min itself and remained low throughout gastric digestion, the protective effect of ice cream still persisted which was demonstrated by survival of 4 log units of L. acidophilus La-5 at the end of $120 \mathrm{~min}$ simulated digestion. Hence, it could be suggested that viscosity is not the factor that was mainly responsible for the high viability of L. acidophilus La-5 at the end of digestion. One thing to consider is that in this study, gastric secretion rate $(3.5 \mathrm{ml} / \mathrm{min})$ and peristaltic contractions (3 cycles/min) were kept constant for consistency purposes, irrespective of viscosity levels of ice cream contradictory to the situation in vivo. This may be a reason why an effect of initial viscosity was not observed on the viability of $L$. acidophilus La-5 during simulated digestion.

Another factor tested in this study was the initial inoculation level. It was found that there was no statistically significant difference in the overall log reduction in viable cells of L. acidophilus La-5 at the end of $2 \mathrm{hr}$ digestion. It is important to note that absence of statistical significant difference could be a result of small sample size because biologically difference of 2 log units in the overall log reduction between low 
concentration and high concentration samples is significant. Nevertheless, an important finding from the present study was the survival of $\sim 4 \log \mathrm{cfu} / \mathrm{g}$ for all the four tested samples (LVLC, HVLC, LVHC and HVHC) irrespective of the initial amount of inoculation of L. acidophilus La-5 in the ice cream.

The survivability results obtained in the present study indicated that supplementation with lower amount of L. acidophilus La-5 in ice cream could be as effective as higher amount and this may be cost effective for ice cream producers and may eliminate possible advserse effects of adding high amount of L. acidophilus La-5 on the organoleptic properties and texture of the ice cream. Gomes et al. (2011) and Olson and Aryana (2008) reported changes in properties such as appearance, aroma, taste and texture of cheese and yogurt, respectively due to supplementation with high concentration of L. acidophilus. In addition, sensory defects and consumer rejection of cheeses supplemented with high levels of L. acidophilus in comparison to control cheese were also reported (Martin-Diana et al., 2003 and Gomes et al., 2011). Daily consumption of probiotic bacteria containing products is important for the probiotic bacteria to provide health benefits. Therefore, it’s important for producers to consider making healthy products which have pleasant taste and texture so that consumers like the products and look forward to consuming them everyday (Saxelin et al., 1999; Champagne et al., 2005).

Results for survival of L. acidophilus La-5 found in the present study were in contradiction with those reported by Fernández de Palencia et al. (2008). They reported close to $20 \%$ survivability of L. acidophilus La-5 incorporated in skim milk at the end of simulated in vitro digestion. Whereas in this study, minimum survivability observed for same strain at the end of $2 \mathrm{hr}$ simulated digestion was close to $50 \%$ or more depending on 
the ice cream sample (LVLC, HVLC, LVHC or HVHC) that was digested. This difference in viability of same L. acidophilus La-5 strain in two different studies may be attributed to the difference in matrix that was tested (skim milk versus ice cream), components incorporated in the in vitro digestion model such as $\mathrm{pH}$ and time of digestion and fat content $(<0.3 \%$ versus $5 \%)$. In a study conducted by Sumeri et al. (2008), they tested survivability of L. rhamnosus GG in different commercial products in addition to MRS as a model food and found that it behaved differently in different products during its transit through an in vitro gastrointestinal model. It survived very well in Gefilus cheese and milk compared to its low survival $<0.1 \%$ when digested with MRS matrix and Tuttely baby formula. In addition to food properties such as buffering capacity as observed in the present study, fat may also play an important role in protecting the probiotic bacteria against harsh stomach conditions during digestion. Buriti et al. (2010) found that addition of milk fat to frozen guava mousse improved survival of tested probiotic bacteria during simulated digestion conditions when incubated at $\mathrm{pH}$ 1.4-1.9 for 2 hr. Possemiers et al. (2010) found that L. helveticus I-1722 and B. longum I-3470 when microencapsulated in stearate, yielded nearly $100 \%$ survival when ingested in either dark chocolate or milk chocolate.

Bezkorovainy (2001) reviewed several studies described by other researchers that evaluated the survival of different probiotic strains in vitro and in vivo during their passage through the upper GIT and observed that survival values ranged from $20 \%$ to 40\%. The percent survival of L. acidophilus La-5 when ingested in ice cream in this study was above this range for all the samples. The variability in survival rate of probiotic bacteria in various studies depends on number of factors such as type of probiotic 
bacteria and its response mechanism to stress, form of probiotic bacteria (harvested, freeze dried or free flowing powders), number of bacteria ingested, the composition of food vehicle in which they are ingested, physical protection of bacteria by food, buffering of gastric content, type of in vitro model used and difference in its components compared to other models and rate of gastric emptying (Gianella et al, 1972; Curto et al., 2011).

Comparison of our results with other studies that have conducted survivability tests using in vitro digestion models has revealed that it is important to study the combination of food product and probiotic bacteria of interest to understand any synergistic or antagonistic effects of food matrix on the viability of probiotic bacteria during in vitro digestion, effect of $\mathrm{HCl}$ and enzymes and to mimic real mixing and shearing caused due to peristaltic contractions as in vivo. In addition, the extent of protection provided by the food vehicle against harsh stomach conditions would also depend on whether the product is consumed before eating a meal, with the meal or after the meal as in a typical case of ice cream. Tompkins et al. (2011) showed that the survival of tested probiotic bacteria through the stomach and duodenum was highly dependent on the time of ingestion and the protective capacity of the meal or beverage. They reported that the bacterial survival was best when consumed within 30 min before or simultaneously with a meal or beverage that contained some fat content and poorest when taken after a meal or with products such as spring water or apple juice that does not contain fat. 


\subsection{Conclusions}

Probiotic bacteria have been extensively incorporated in various fermented dairy products, especially yogurt and fermented milk. It is extremely important that the viable numbers of the probiotic bacteria are maintained above the recommended level of $10^{6} \mathrm{cfu} / \mathrm{g}$ throughout the shelf life of the product. The low $\mathrm{pH}$, presence of starter cultures and organic acids has been found to be detrimental on the viability of Lactobacillus and Bifidobacterium during the storage of fermented dairy products. In this thesis, potential of non-fermented low fat ice cream was investigated to deliver high amount of $L$. acidophilus La-5 to the host. The viability of L. acidophilus La-5 was not only studied throughout ice cream's shelf life of 90 days, but also during simulated digestion of ice cream in an in vitro model stomach called Human Gastric Simulator (HGS) to ensure high numbers of viable cells of L. acidophilus La-5 are maintained throughout storage and after gastric transit.

The viability of L. acidophilus La-5 was maintained throughout shelf life at $\sim 10^{6}$ $\mathrm{cfu} / \mathrm{g}$ of $3.5 \mathrm{oz}$ low fat ice cream incorporated with $60 \%$ and $100 \%$ overrun. The effect of freezing and different levels of overrun was found to be non significant $(\mathrm{p}>0.05)$ on the survivability of La-5 when tested post freezing process. The storage of ice cream samples incorporated with $60 \%$ and $100 \%$ overrun at $-10^{\circ} \mathrm{C}$ for 90 days did not result in a significant ( $\mathrm{p}>0.05)$ negative impact on the viability of L. acidophilus La-5 throughout shelf life.

The conventional acid resistance test of incubating the probiotic bacteria at $\mathrm{pH} 2.0$ in the absence of ice cream mix was found to be extremely detrimental resulting in $<10$ cfu/g of viable cells of L. acidophilus La-5 and L. paracasei 431 at the end of first hour 
of two hour incubation study. Whereas, in the presence of ice cream mix, percent survival of $L$. acidophilus La-5 and L. paracasei 431 was found to be $65.34 \%$ and $43.04 \%$ respectively at the end of simulated digestion using a static model stomach. This shows that the acid tolerance in the presence of ice cream mix was species specific. This protective effect of ice cream mix due to its high buffering capacity was successfully validated during modeled digestion of frozen ice cream using shaking water bath model and HGS model.

The percent survivability of L. acidophilus La-5 was found to be $65.34 \%, 61.1 \%$ and $47.66 \%$ at the end of simulated digestion using static model stomach, shaking water bath model stomach and human gastric simulator, respectively. The mechanical shearing and mixing due to peristaltic contractions during ice cream's digestion in the HGS could have caused additional negative impact on the viability of L. acidophilus La-5 resulting in the lowest percent survivability of $L$. acidophilus La-5. The protective effect of ice cream components against harsh stomach conditions was mainly due to the high buffering capacity of ice cream. Difference in viscosity of ice cream samples did not appear to be the factor that contributed to the protective effect of ice cream. The lower initial inoculation level of $L$. acidophilus La-5 resulted in higher percent survival (64.53\%) of Lactobacillus acidophilus La-5 at the end of $2 \mathrm{hr}$ simulated digestion process compared to its survival at the end of digestion of ice cream sample supplemented with higher initial amount of La-5 (47.17\%).

This study showed that human gastric simulator is a good platform for simulating in vitro conditions, to determine acid resistance capacity of probiotic bacteria and to evaluate protective effect of food vehicle on the survivability of probiotic bacteria in the 
presence of harsh conditions like low $\mathrm{pH}$, presence of enzymes and peristaltic contractions. Non-fermented low fat ice cream can be an excellent carrier of $L$. acidophilus La-5 to provide clinical benefits to the host. 


\subsection{Future Research}

- Perform a study to determine the genetic response of L. acidophilus La-5 to stress caused during air incorporation and freezing that allowed it to survive the ice cream manufacture process extremely well.

- Conduct a sensory analysis comparing non-fermented and fermented low fat ice creams both supplemented with high and low amounts of L. acidophilus La-5.

- Conduct a study by supplementing other species of genus Lactobacillus along with $L$. acidophilus La-5 in an ice cream matrix to determine existence of any synergistic or antagonistic activity between the two species of Lactobacillus.

- Analyze the effect of bile present in the intestine on the survivability of L. acidophilus La-5 incorporated in ice cream matrix to determine whether after a period of acid stress in the human gastric simulator, $L$. acidophilus La-5 are able to resurrect their viability if they are exposed to more suitable conditions like those in the small intestine.

- Validate the protective effect of ice cream observed in the present study with an in vivo study.

- Compare the results obtained by plating method with confocal microscopy to take into account the presence of sublethally damaged or dormant cells that are unable to form visible colonies in the plating method.

- Conduct a study to determine whether L. acidophilus La-5 expressed any genes in response to acid stress that allowed its higher viability at the end of simulated digestion in this study.

- Use confocal microscopy to visualize interactions between L. acidophilus La-5 and Phospholipids present in the ice cream. 


\section{References}

Abghari, A., M. Sheikh-Zeinoddin, and S. Soleimanian-Zad. 2011. Nonfermented ice cream as a carrier for Lactobacillus acidophilus and Lactobacillus rhamnosus. Int J Food Science and Technology. 46:84-92.

Abu-Taraboush, H. M., M. M. Al-Dagal, and M. A. Al-Roy. 1998. Growth, viability, and proteolytic activity of Bifidobacteria in whole camel milk. Journal of Dairy Science. 81:354-361.

Aime, D. B., S. D. Arntfield, L. J. Malcolmson, and D. Ryland. 2001. Textural analysis of fat reduced vanilla ice cream products. Food Research International. 34: 237-246.

Akalin, A. S., and D. Erişir. 2008. Effects of inulin and oligofructose on the rheological characteristics and probiotic culture survival in low fat probiotic ice cream. J Food Sci. 73:184-188

Akin, S. 2005. Effects of inulin and different sugar levels on viability of probiotic bacteria and the physical and sensory characteristics of probiotic fermented ice cream. Milchwisssenschaft. 60:297-301.

Alamprese, C., R. Foschino, M. Rossi, C. Pompei, and L. Savani. 2002. Survival of Lactobacillus johnsonii La1 and influence of its addition in retail-manufactured ice cream produced with different sugar and fat concentrations. Int Dairy J. 12:201-208.

Alamprese, C., R. Foschino, M. Rossi, C. Pompei, and S. Corti. 2005. Effects of Lactobacillus rhamnosus GG addition in ice cream. International Journal of Dairy Technology. 58: 200-206.

Alander, M., R. Satokari, R. Korpela, M. Saxelin, T. Vilpponen-Salmela, T. MattilaSandholm, and A. von Wright. 1999. Persistence of colonization of human colonic mucosa by a probiotic strain, Lactobacillus rhamnosus GG, after oral consumption. Appl. Environ. Microbiol. 65:351-354.

Al-Dabbas, M. M., K. AI-Ismail, R. A. Taleb, and S. Ibrahim. 2010. Acid-Base buffering properties of five legumes and selected food in vitro. American Journal of Agricultural and Biological Sciences. 5:154-160.

Anonymous. 2009. Marketsandmarkets: Global probiotics market worth US\$32.6 billion by 2014. Accessed April 18, 2012.

http://www.marketsandmarkets.com/PressReleases/global-probiotics-market-worth-US32-billion-by-2014.asp

Antunes, A. E. C., T. F. Cazetto, and H. M. A. Bolini. 2005. Viability of probiotic microorganisms during storage, postacidification and sensory analysis of fat-free yogurts with added whey protein concentrate. International Journal of Dairy Technology. 58:169-173. 
Antunes, A.E.C., E.R.A. Silva, A.G.F. Van Dender, E.T.G. Marasca, I. Moreno, E.V. Faria, M. Padula, and A.L.S. Lerayer. 2009. Probiotic buttermilk-like fermented milk product development in a semi industrial scale: Physicochemical, microbiological and sensory acceptability. International Journal of Dairy Technology. 62: 556-563.

Arihara, K., and J. B. Luchansky. 1994. Dairy Lactobacilli. Pages 609-643 in Food Biotechnology: Microorganisms. Y.H. Hui and G.G. Khachatourians, Ed. VCH Publishers, New York.

Arihara, K., H. Ota, M. Itoh, Y. Kondo, T. Samashima, H. Yamanaka, M. Akimoto, S. Kanai, and T. Miki. 1998. Lactobacillus acidophilus group lactic acid bacteria applied to meat fermentation. Journal of Food Science. 63: 547-547

Bachiero, D., S. Uson, and R. Jimenez-Flores. 2007. Lipid binding characterization of lactic acid bacteria in dairy products. Proceedings of the Annual American Society for Microbiology. Washington, DC.

Başyğit, G., H. Kuleaşan, and A.G. Karahan. 2006. Viability of human derived probiotic Lactobacilli in ice cream with sucrose and aspartame. J Ind Microbiol Technol. 33:96800.

Bermúdez-Soto, M. J., M. Larrosa, J. García-Cantalejo, J. C. Espín, F. A. TomásBarberan, M. T. Garcia-Conesa. 2007. Transcriptional changes in human Caco-2 colon cancer cells following exposure to a recurrent non-toxic dose of polyphenol-rich chokeberry juice. Genes and Nutrition. 2:111-113.

Berrada, N., J. F. Lemelan, G. Laroche, P. Thouvenot, and M. Piaia. 1991. Bifidobacterium from fermented milks: survival during gastric transit. J. Dairy Sci. 74:409-414.

Bertram, U. 1967. Xerostomia: Clinical aspects, pathology and pathogenesis. Acta Odontol Scand. 25(Suppl.49):12-15.

Bezkorovainy, A. 2001. Probiotics: determinants of survival and growth in the gut. American Journal Clinial Nutrition. 73:399S-405S

Bhadoria, P. B. S., and S. C. Mahapatra. 2011. Prospects, Technological Aspects and Limitations of Probiotics -A Worldwide Review. European Journal of Food Research and Review 1: 23-42.

Bhatia, S. J., N. Kochar, P. Abraham, N. G. Nair, and A. P. Mehta. 1989. Lactobacillus acidophilus inhibits growth of Campylobacter pylori in vitro. Journal of Clinical Microbiology. 27:2328-2330. 
Bilecen. D., K. Scheffler, E. Seifritz, G. Bongartz, and W. Steinbrich. 2000. Hydro-MRI for the visualization of gastric wall motility using RARE magnetic resonance imaging sequences. Abdom Imaging. 25:30-34

Boisson, S., and B. O. Eggum. 1991. Critical evaluation of in vitro methods for estimat'ing digestibility in simple-stomach animals. Nutrition Research Reviews. 4:141162.

Bolliger, S., H. D. Goff, and B. W. Tharp. 2000. Correlation between colloidal properties of ice-cream mix and ice-cream. International Dairy Journal. 10:303-309.

Bolwig, T. G., O. J. Rafaelsen. 1972. Salivation in affective disorders. Psychol Med. 2:232-238.

Bourne, M. C. 2004. Relation between texture and mastication. J Texture Stud. 35:125 143.

Brenelli, S.L., S.D.S. Campos and M.J.A. Saad. 1997. Viscosity of gums in vitro and their ability to reduce postprandial hyperglycemia in normal subjects. Brazilian Journal of Medical and Biological Research. 30:1437-1440

Brisson, G., H. F. Payken, J. P. Sharpe, and R. Jimenez-Flores. 2010. Characterization of Lactobacillus reuteri interaction with milk fat globule components in dairy products. Journal of

Burns, P., F. Patrignani, D. Serrazanetti, G. C. Vinderola, J. A. Reinheimer, R. Lanciotti, and M. E. Guerzoni. 2008. Probiotic Crescenza cheese containing Lactobacillus casei and Lactobacillus acidophilus manufactured with high-pressure homogenized milk. J. Dairy Sci. 91:500-512

Buriti, F.C.A., I. A. Castro, and S. M. I. Saad. 2010. Viability of Lactobacillus acidophilus in symbiotic guava mousses and its survival under in vitro simulated gastrointestinal conditions. International Journal of Food Microbiology. 137:121-129.

Cameron-Smith, D., G. R. Collier, and K. O’Dea. 1994. Effect of soluble dietary fibre on the viscosity of gastrointestinal contents and the acute glycaemic response in the rat. British Journal of Nutrition. 71:563- 571.

Camilleri, M., and C. M. Prather. 1994. Axial Forces During Gastric Emptying in Health and Models of Disease. Digestive Diseases and Sciences, 39 (Suppl):14S-17S.

Cardarelli, H. R., L. C. Aragon-Alegro, Alegro, J.H.A. Alegro, I. A. De Castro, and S.M.I. Saad. 2008. Effect of inulin and Lactobacillus paracasei on sensory and instrumental texture properties of functional chocolate mousse. J Sci Food Agric. 88:1318-1324. 
Champagne, C. P., N. J. Gardner, and D. Roy. 2005. Challenges in the addition of probiotic cultures to foods. Critical Reviews in Food Science and Nutrition. 45:61-84.

Chandan, R. C. 1999. Enhancing market value of milk by adding cultures. Journal of Dairy Science. 82:2245-2256.

Charteris, W.P, P. M. Kelly, L. Morelli, and J. K. Collins. 1998. Development and application of an in vitro methodology to determine the transit tolerance of potentially probiotic Lactobacillus and Bifidobacterium species in the upper human gastrointestinal tract. Journal of Applied Microbiology. 84:759-768.

Charteris, W.P., P. M. Kelly, L. Morelli, and J. K. Collins. 2002. Edible table (bio) spread containing potentially probiotic Lactobacillus and Bifidobacterium species. International Journal of Dairy Technology. 55: 44-56.

Cherbut, C., E. Albina, M. Champ, J.L. Doublier and G. Lecannu. 1990. Action of guar gums on the viscosity of digestive contents and on the gastrointestinal motor function in pigs. Digestion. 46: 205-213.

Chew, C. S. 1983. Inhibitory action of somatostatin on isolated gastric glands and parietal cells. Am J Physiol. 245: G221-G229.

Chou, L., and B. Weimer. 1999. Isolation and characterization of acid and bile tolerant isolates from strains of Lactobacillus acidophilus. Journal Dairy Science. 82:23-31.

Christianesen, P. S., D. Edelten , J. R. Kristiansen, and E. W. Nielsen. 1996. Some properties of ice cream containing Bifidobacterium bifidum and Lactobacillus acidophilus. Milchwissenschaft. 51:502-504

Collins, J. K., and G. Thornton. 1998. Selection of probiotic strains for human applications. Int. Dairy J. 8:487-490

Collado, M. C. Y. Moreno, E. Hernández, J.M. Cobo, and M. Hernández. 2005. In vitro viability of Bifidobacterium strains isolated from commercial dairy products exposed to human gastrointestinal conditions. Food Sci Tech Int. 11:307-314.

Conway, P. L., S.L. Gorbach, and B. R. Goldin. 1987. Survival of lactic acid bacteria in the human stomach and adhesion to intestinal cells. Journal of Dairy Science. 70:1-12.

Corcoran, B. M., C. Stanton, G. F. Fitzerald, and R. P. Ross. 2005. Survival of probiotic Lactobacilli in acidic environments is enhanced in the presence of metabolizable sugars. Applied and Environmental Microbiology. 71:3060-3067.

Coupe A. J., S.S. Davis, and I.R. Wilding. 1991. Variation in gastrointestinal transit of pharmaceutical dosage forms in healthy subjects. Pharm Res. 8:360-364. 
Cruz, A.G., A. E. C. Antunes, Ana L. O. P. Sousa, J. A. F. Faria, and S. M. I. Saad. 2009. Ice cream as a probiotic food carrier. Food Research International. 42:1233-1239.

Curto, A. L., I. Pitino, G. Mandalari, J. R. Dainty, R.M. Faulks; M. S. J. Wickham. 2011. Survival of probiotic Lactobacilli in the upper gastrointestinal tract using an in vitro gastric model of digestion. Food Microbiology 28: 1359-1366

Czinn, S.J., and S.S. Blanchard. 2009. Probiotics in foods and supplements. Pages 299306 in Nutrition and Health: Probiotics in Pediatric Medicine. S. Michail and P. M. Sherman, Ed., Humana Press, Totowa, NJ.

Dave, R. I., and N. P. Shah. 1998. Ingredient supplementation effects on viability of probiotic bacteria in yogurt. J Dairy Sci. 81:2804-2816.

Davidson, J. M., R. S. T. Linforth, and A. J. Taylor. 1998. In-mouth measurement of pH and conductivity during eating. Journal of Agricultural and Food Chemistry. 46:52105214.

Davidson, R. H., S. E. Duncan, C. R. Hackney, W. N. Eigel, and J. W. Boling. 2000. Probiotic culture survival and implications in fermented frozen yoghurt characteristics. J Dairy Sci. 83:666-673

Dawes, C. 1969. The effects of flow rate and duration of stimulation on the concentrations of protein and the main electrolytes in human parotid saliva. Arch Oral Biol. 14:277-294.

Dawes, C. 1975. Circadian rhythms in the flow rate and composition of unstimulated and stimulated human submandibular saliva. J Physiol. 244:535-548.

Dean, J. R., and R. Ma. 2007. Approaches to assess the oral bioaccessibility of persistent organic pollutants: a critical review. Chemosphere. 68:1399-1407.

Debas, H. T., and S. H. Carvajal. 1994. Vagal regulation of acid secretion and gastrin release. Yale J Biol Med. 67:145-151.

Ding, W. K., and N. P. Shah. 2007. Acid, bile, and heat tolerance of free and microencapsulated probiotic bacteria. J. Food Sci. 72: M446-M450

Donkor, O. N., S. L. I. Nilmini, P. Stolic, T. Vasiljevic, and N. P. Shah. 2007. Survival and activity of selected probiotic organisms in set-type yoghurt during cold storage. International Dairy Journal. 17:657-665.

Drago, S. R., M. Panouillé , A. Saint-Eve, E. Neyraud, G. Feron, and I. Souchon. 2011. Relationships between saliva and food bolus properties from model dairy Products. Food Hydrocolloids. 25:659-667 
Dressman, J. B., G. L. Amidon, C. Reppas, and V. P. Shah. 1998. Dissolution testing as a prognostic tool for oral drug absorption: immediate release dosage forms. Pharml Res. 15:11-22.

Dressman, J. B., R. R. Berardi, L. C. Dermentzoglou, T. L. Russell, S. P. Schmaltz, J. L. Bamett, and K. M. Jarvenpaa. 1990. Upper Gastrointestinal (GI) pH in Young, Healthy Men and Women. Pharmaceutical Research. 7: 756-761

Edwards, C. A. 1987. Viscosity of food gums determined in vitro related to their hypoglycemic actions. Am J Clin Nutr. 46:72-77

El-Nagar, G., G. Clowes, C.M. Tudorica, and V. Kuri. 2002. Rheological quality and stability of yog-ice cream with added inulin. Int J Dairy Technol. 55:89-93.

Engelen, L., R. A. de Wijk, J. F. Prinz, A. M. Janssen, A. Van der Bilt, and H. Weenen H. 2003. A comparison of the effects of added saliva, $\alpha$-amylase and water on texture perception in semisolids. Physiol Behav.78:805-811.

Engelen, L., R. A. de Wijk, J. F. Prinz, A. van der Bilt, and F. Bosman. 2003. The relation between saliva flow after different stimulations and the perception of flavor and texture attributes in custard desserts. Physiol Behav. 78:165 - 169.

Ericson, S. 1971. The variability of the human parotid flow rate on stimulation with citric acid, with special reference to taste. Arch Oral Biol. 16:9-19.

FAO/WHO. 2001. Health and nutritional properties of probiotics in food including powder milk with live lactic acid bacteria. Report of a joint FAO/WHO expert consultation on evaluation of health and nutritional properties in food including powder milk with live lactic acid bacteria. Cordoba, Argentina.

Favaro-Trindade, C. S., J. C. de Carvalho Balieiro, P. F. Dias, F. A. Sanino, and C. Boschini. 2007. Effects of culture, $\mathrm{pH}$ and fat concentration on melting rate and sensory characteristics of probiotic fermented yellow mombin (Spondias mombin L) ice Creams. Food Science and Technology International. 13: 285-290

Faye, T., A. Tamburello, G. E. Vegarud , and S. Skeie. Survival of lactic acid bacteria from fermented milks in an in vitro digestion model exploiting sequential incubation in human gastric and duodenum juice. J. Dairy Sci. 95:558-566.

Fernández de Palencia, P., P. López, A. L. Corbí, C. Peláez, and T. Requena. 2008. Probiotic strains: survival under simulated gastrointestinal conditions, in vitro adhesion to Caco-2 cells and effect on cytokine secretion. Eur Food Res Technol. 227:1475-1484.

Ferraz, J. L., A. G. Cruz, R. S. Cadena, M. Q. Freitas, U. M. Pinto, C. C. Carvalho, J. A. F. Faria, and H. M. A. Bolini. 2012. Sensory acceptance and survival of probiotic 
bacteria in ice Cream produced with different overrun levels. Journal of Food Science. 71: S24-S28.

Figueroa-González, I., G. Quijano, G. Ramírez, and A. Cruz-Guerrero. 2011. Probiotics and prebiotics_-perspectives and challenges. J. Sci. Food Agric. 91: 1341-1348..

Frece, J. 2003. In vitro and in vivo studies of probiotic mechanism effects in bacteria: Lactobacillus acidophilus M92, Lactobacillus plantarum L4 and Enterococcus faecium L3. MS Thesis. University of Zagreb, Croatia.

Frece, J., B. Kos, I. K. Svetec, Z. Zgaga, V. Mrša, and J. Šuškoviæ. 2005. Importance of S-layer proteins in probiotic activity of Lactobacillus acidophilus M92. Journal of Applied Microbiology. 982: 285-292.

Fuller, R. 1989. Probiotics in man and animals. A review. J Appl Bacteriol. 66:365-378.

Fuller, R. 1992. History and development of probiotics. Pages 1-8 in Probiotics, the scientific basis. R. Fuller, Ed. Chapman and Hall, London.

Gardiner, G. E., E. O’Sullivan, J. Kelly, M. A. Auty, G. F. Fitzgerald, J. K. Collins, R. P. Ross, and C. Stanton. 2000. Comparative survival rates of human derived probiotic Lactobacillus paracasei and L. salivarius strains during heat treatment and spray drying. Appl Environ Microbiol. 66:2605-2612.

Garrett, D. A., M. L. Failla, and R. J. Sarama. 1999. Development of an in vitro digestion method to assess carotenoid bioavailability from meals. Journal of Agricultural Food Chemistry. 47:4301-4309.

Gilliland, S. E. and D. K. Walker. 1990. Factors to consider when selecting a dietary adjunct to produce a hypocholesteroleric effect in humans. Journal of Dairy Science. 73:905-911.

Gilliland, S. E., and M. L. Speck. 1977. Instability of Lactobacillus acidophilus in yogurt. Journal of Dairy Science. 60:1394-1397.

Glass, G.B. J. 1968. Introduction to gastrointestinal physiology. Pages 43-97 in Physiology of Stomach. R. Levine, Ed. Prentice-Hall, Inc., Englewood Cliffs, New Jersey.

Godward, G., and K. Kailasapathy. 2003. Viability and survival of free, encapsulated and co-encapsulated probiotic bacteria in ice-cream. Milchwissenschaft. 58:161-164.

Godward, G., K. Sultana, K. Kailasapathy, P. Peiris, R. Arumugaswamy, and N. Reynolds. 2000. The importance of strain selection on the viability and survival or probiotics bacteria in dairy foods. Milchwissenschaft. 55:441-445. 
Goff, H. D., V.J. Davidson, and E. Cappi. 1994. Viscosity of ice cream mix at pasteurization temperature. Journal of Dairy Science. 77: 2207-2213.

Goh, K. K. T., R. S. Nair, and L. Matia-Merino. 2008. Exploiting the functionality of lactic acid bacteria in ice cream. Food Biophysics. 3:295- 04.

Gomes, A. A., S. P. Braga, A. G. Cruz, R. S. Cadena, P. C. B. Lollo, C. Carvalho, J. Amaya-Farfán, J. A. F. Faria, and H. M. A. Bolini. 2011. Effect of the inoculation level of Lactobacillus acidophilus in probiotic cheese on the physicochemical features and sensory performance compared with commercial cheeses. J. Dairy Sci. 94: 47774786.

Gorbach, S. L. 2000. Probiotics and gastrointestinal health. American Journal of Gastroenterology. 95:S1-S4.

Gueimonde, M., S. Delgado, B. Mayo, P. Ruas-Madiedo, A. Margolles. and C. G. De los Reyes-Gavilán. 2004. Viability and diversity of probiotic Lactobacillus and Bifidobacterium populations included in commercial fermented miles. Food Research International. 37: 839-914.

Guyton, A. C., and J. E. Hall. 1996. Secretory functions of the alimentary tract. Pages 815-832 in Textbook of Medical Physiology. 9th ed. W.B. Saunders Company, Philadelphia.

Hamilton-Miller, J. M. T., G.R. Gibson, and W. Bruck. 2003. Some insight into the derivation and early uses of the word 'probiotics'. British Journal of Nutrition. 90:845845

Hagen, M., and J. A. Narvhus. 1999. Production of ice cream containing probiotic bacteria. Milchwissenschaft. 54:265-268.

Hammes, W.P., and R. F. Vogel. 1995. The genus Lactobacillus. Pages 19-54 in The Genera of Lactic Acid Bacteria. vol. 2. B. J. B. Wood and W.H. Holzapfel, Ed. Blackie Academic and Professional, UK.

Haukioja, A., H. Yli-Knuuttila, V. Loimaranta, K. Kari, A. C. Ouwehand, J. H. Meurman, and J. Tenovuo. 2006. Oral adhesion and survival of probiotic and other Lactobacilli and Bifidobacteria in vitro. Oral Microbiology Immunology. 21: 326-332

Haynes, I. N., and M. J. Playne. 2002. Survival of probiotic cultures in low fat ice cream. Aust J Dairy Technol. 57:10-14.

Heatley, R. V., and G. M. Sobala. 1993. Acid suppression and the gastric flora. Baillere's Clin. Gastroenterol. 7:167-181 
Hedren, E., G. Mulokozi, and U. Svanberg. 2002. In vitro accessibility of carotenes from green leafy vegetables cooked with sunflower oil or red palm oil. International Journal of Food Science and Nutrition. 53:445-453.

Heenan, C.N., M.C. Adams, R.W. Hosken, and G.H. Fleet. 2004. Survival and sensory acceptability of probiotic microorganisms in a nonfermented frozen vegetarian dessert. Lebensm.-Wiss. u.-Technol. 37: 461-466.

Heintze, U., D. Birkhed, and H. Bjørn. 1983. Secretion rate and buffer effect of resting and stimulated whole saliva as a function of age and sex. Swed Dent J. 7:227-238.

Hekmat, S., and D. McMahon. 1992. Survival of Lactobacillus acidophilus and Bifidobacterium bifidum in ice cream for use as a probiotic food. J Dairy Sci. 75:14151422.

Heller, K. J. 2001. Probiotic bacteria in fermented foods: Product characteristics and starter organisms. American Journal of Clinical Nutrition. 73:374S-379S.

Helm, J. F., W. J. Dodds, D. R. Riedel DR. 1983. Determinants of esophageal acid clearance in normal subjects. Gastroenterology. 85:607-612.

Helm, J. F., W. J. Dodds, L. R. Pelc. 1984. Effect of esophageal emptying and saliva on clearance of acid from the oesophagus. N Engl J Med. 310:284-288.

Hibberd, P. L., and L. Davidson. 2008. Probiotic foods and drugs: Impact of US regulatory status on design of clinical trials. Clin Infect Dis. 46(Supplement 2): S137S140.

Holzapfel, W.H. 2006. Introduction to prebiotics and probiotics. Pages 1-33 in Probiotics in Food Safety and Human Health. I. Goktepe, V.K. Juneja and M. Ahmedna, E. CRC Taylor and Francis Group, U.S.A.

Holzapfel, W.H., P. Haberer, R. Geisen, J. Bjorkroth, and U. Schillinger. 2001. Taxonomy and important features of probiotic microorganisms in food and nutrition. Am. J. Clin. Nutr. 73:365S-373S.

Homayouni, A., A. Azizi, M. R Ehsani, M. S. Yarmand, and S. H, Razavi. 2008. Effect of microencapsulation and resistant starch on the probiotic survival and sensory properties of symbiotic ice cream. Food Chem. 111:50-55.

Homayouni, A., M. R. Ehsani, A. Azizi, S. H. Razavi, and M.S. Yarmand. 2008. Growth and survival of some probiotic strains in simulated ice cream conditions. J Appl Sci. 8:379-382. 
Hood, S. K., and E. A. a Zottola. 1988. Effect of low pH on the ability of Lactobacillus acidophilus to survive and adhere to human intestinal cells. Journal of Food Science. 53:1514-1516.

Huang Y., and M. C. Adams. 2004. In vitro assessment of the upper gastrointestinal tolerance of potential probiotic dairy Propionibacteria. International Journal of Food Microbiology. 91:253-260.

Humphrey, S. P., and R. T. Williamson. 2001. A review of saliva: normal composition, flow, and function. The Journal of Prosthetic Dentistry. 85:162-169.

Hur, S.J., O.L. Beong, E.A.Decker, and D. J. McClements. 2011. In vitro human digestion models for food applications. Food Chemistry.125:1-12.

Innocente, N., D. Comparin, and C. Corradini. 2002. Proteose-peptone whey fraction as emulsifier in ice-cream preparation. International Dairy Journal. 12:69-74.

Jay, J. M. 1992. Modern Food Microbiology. $4^{\text {th }}$ Edn. Chapman and Hall Inc. New York, USA.

Jay, J.M., M.J. Loessner, and D.A. Golden. 2005. Modern food microbiology. Springer, New York

Jayamanne, V. S., and M. R. Adams. 2006. Determination of survival, identity and stress resistance of probiotic bifidobacteria in bio-yoghurts. Letters in Applied Microbiology. 42:189-194.

Johansson, I., A. K. Saellstrom, and B. P. Rajan. 1992. Salivary flow and dental caries in Indian children suffering from chronic malnutrition. Caries Res. 26:38-43.

Joseph, P. J., R. I. Dave, and N. P. Shah. 1998. Antagonism between yogurt bacteria and probiotic bacteria isolated from commercial starter cultures, commercial yogurts, and a probiotic capsule. Food Aust. 50:20-23.

Kailasapathy, K., and J. Chin. 2000. Survival and therapeutic potential of probiotic organisms with reference to Lactobacillus acidophilus and Bifidobacterium spp. Immunology Cell Biology. 78:80-88.

Kailasapathy, K., and K. Sultana .2003. Survival of $\beta$-D-galactosidase activity of encapsulated and free Lactobacillus acidophilus and Bifidobacterium lactis in ice cream. Aust J Dairy Technol. 58:223-227

Kalantzi, L., K. Goumas, V. Kalioras, B. Abrahamsson, J. B. Dressman, and C. Reppas. 2006. Characterization of the human upper gastrointestinal contents under conditions simulating bioavailability/bioequivalence studies. Pharm Res. 23:165-176. 
Kawasaki, S., T. Mimura, S. Satoh, K. Takeda, and Y. Nimura. 2006. Response of the microaerophilic Bifidobacterium species, B. boum and B. thermolum, to oxygen. Appl Environ Microbiol. 72:6854-6858.

Kawther., E. L. Shafei, N. F. Tawfik, Nadia, M. A. Dabiza, O. M. Sharaf, and B .A. Effat. 2010. In vitro assessment of gastrointestinal viability of potentially probiotic Lactobacilli. Journal of American Science. 6:357-367

Khalil, A.H., and E.H. Mansour. 1998. Alginate encapsulated Bifidobacteria survival in mayonnaise. Journal of Food Science. 63: 702-705.

Khalf, M., N. Dabour, E. Kheadr, and I. Fliss. 2010. Viability of probiotic bacteria in maple sap products under storage and gastrointestinal conditions. Bioresource Technology.101:7966-7972

Kheadr, E . E., A. Zihler, N. Dabour, C. Lacroix, G. Le Blay, and I. Fliss. 2009. Study of the physico-chemical and biological stability of pediocin PA-1 in the gastrointestinal tract condition using dynamic in vitro model. J. Appl. Microbiol. 109:54-64.

Klaenhammer, T. R. and M. J. Kullen. 1999. Selection and design of probiotics. Int. J. of Food Microbiol. 50:45-57.

Kollath, W. 1953. Ernährung und Zahnsystem. Deutsche Zahnärztliche Zeitschrift. 8:716.

Kong, F., and R. P. Singh. 2008. Disintegration of Solid Foods in Human Stomach. Journal of Food Science. 73: R67-R80.

Kong. F., and R. P. Singh. 2010. A Human Gastric Simulator (HGS) to Study Food Digestion in Human Stomach. Journal of Food Science. 75:E627-E635.

Kopeloff, L. M., J. L. Etcheils, and N. Kopeloff. 1934. Bacteriological changes in acidophilus milk at room and ice-box temperatures. J. Bacteriol. 28:489-500.

Kourkoutas, Y., L. Bosnea, S. Taboukos, C. Baras, D. Lambrou, and M. Kanellaki. 2006. Probiotic cheese production using Lactobacillus casei cells immobilized on fruit pieces. J. Dairy Sci. 89:1439-1451.

Lavermicocca, P., F. Valerio, S.L. Lonigro, M.D. Angelis, L. Morelli, M.L. Callegari, C. G. Rizzello, and A. Visconti. 2005. Study of adhesion and survival of Lactobacilli and Bifidobacteria on table olives with the aim of formulating a new probiotic food. Applied and Environmental Microbiology. 71:4233-4240.

Lin, M. Y., and T. W. Chen. 2000. Reduction of cholesterol by Lactobacillus acidophilus in culture broth. Journal of Food and Drug Analysis. 8: 97-102. 
Liong, M. T., and N. P. Shah. 2004. Acid and bile tolerance and cholesterol removal ability of Lactobacilli strains. J Dairy Sci. 88:55-6.

Lucey, J. A., C. Gorry, B. O’Kennedy, M. Kalab, R. Tan-Kinita, and P. F. Fox. 1996. Effect of acidification and neutralization of milk on some physico-chemical properties of casein micelles. International Dairy Journal. 6: 257-272.

Maathuis, A. 2009. The effect of the undigested fraction of maize products on the activity and composition of the microbiota determined in a dynamic in vitro model of the human proximal large intestine. J Am Coll Nutr. 28:657-666.

Mackie, D. A., and R. M. Pangborn. 1990. Mastication and its influence on human salivary flow and alpha-amylase secretion. Physiol Behav. 47:593 - 595.

Madureira, A.R., A. Manuela, M. G. Ana, E. P. Manuela, and F.X. Malcata. 2011. Protective effect of whey cheese matrix on probiotic strains exposed to simulated gastrointestinal conditions; Food Research International 44:465-470.

Magami, Y., T. Azuma, H. Inokuchi, F. Moriyasu, K. Kawai and T. Hattori. 2002. Cell kinetics of slow renewing cell populations in mice stomach. J Gastroenterol Hepatol. 17:262-269.

Magarinos, H., S. Selaive, M. Costa, M. Flores, and O. Pizarro. 2007. Viability of probiotic microorganisms (Lactobacillus acidophilus La-5 and Bifidobacterium animalis subsp. lactis Bb-12) in ice cream. International Journal of Dairy Technology. 60:128-134

Mainville, I., Y. Archand, and E. R. Farnworth. 2005. A dynamic model that simulates the human upper gastrointestinal tract for the study of probiotics. International Journal of Food Microbiology. 99:287-296.

Malagelada, J. R., and Y. L.W. Go, and W. H. J. Summerskill. 1979. Different gastric, pancreatic, and biliary responses to solid-liquid or homogenized meals. Digestive Disease and Sciences. 24: 101-110.

Malagelada, J. R., G. F. Longstreth, W. H. J. Summerskill, V. L. W. Go. 1976. Measurement of gastric functions during digestion of ordinary solid meals in man. Gastroenterol. 70:203-210.

Marciani, L., P. A. Gowland, A. Fillery-Travis, P. Manoj, J. Wright, A. Smith, P. Young, R. J. Moore, and R. C. Spiller. 2001. Assessment of antral grinding of a model solid meal with echo planar imaging. Am J Physiol. 280:G844-G849.

Marciani, L., P. A. Gowland, R. C. Spiller, P. Manoj, R. J. Moore, P. Young, S. AlSahab, D. Bush, J. Wright, and A. J. Fillery-Travis. 1999. Gastric response to increased meal viscosity assessed by echo-planar magnetic resonance imaging in humans. J Nutr. 130:122-127 
Marshall, R. T., and W.S. Arbuckle. 1996. Ice cream. $5^{\text {th }}$ Ed. Chapman and Hall, New York.

Marshall, R., H. Goff, and R. Hartel. 2003. Page 357 in Ice Cream. Springer, New York.

Marteau, P., M. Minekus, R. Havenaar, and J. H. J. H. Veld. 1997. Survival of lactic acid bacteria in a dynamic model of the stomach and small intestine: validation and the effects of bile. Journal of Dairy Science. 80:1031-1037.

Martin-Diana, A. B., C. Janer, C. Pelaez, and T. Requena. 2003. Development of a fermented goat’s milk containing probiotic bacteria. Int. Dairy J. 13:827-833.

Martinez, R. C. R., A. Aynaou, S. Albrecht, H. A. Schols, E. C.P. De Martinis , E. G. Zoetendal, K. Venema, S. M.I. Saad, and H. Smidt. 2011. In vitro evaluation of gastrointestinal survival of Lactobacillus amylovorus DSM 16698 alone and combined with galactooligosaccharides, milk and/or Bifidobacterium animalis subsp. lactis Bb-12. International Journal of Food Microbiology. 149:152-158.

Masco, L., C. Crockaert, K. Van Hoorde, J. Swings, and G. Huys. 2007. In Vitro Assessment of the Gastrointestinal Transit Tolerance of Taxonomic Reference Strains from Human Origin and Probiotic Product Isolates of Bifidobacterium. Journal of Dairy Science. 90:3572-3578.

Mashayekh, M., and R. J. Brown. 1992. Stability of Lactobacillus delbrueckii ssp. bulgaricus, Streptococcus salivarius ssp. thermophilus and beta galactosidase activity in frozen cultured ice cream. Cultured Dairy Products Journal. 27:4-8.

Mayer, E.A. 1994. The physiology of gastric storage and emptying. Pages 929-976 in Physiology of the gastrointestinal tract. L.Johnson, Ed. 3rd ed. Raven Press, New York.

Metchnikoff , E. 1907. The prolongation of life. Optimistic studies. London: William Heinemann.

Metwally, A.M.M. E. 2007. Effect of enzymatic cross-linking of milk proteins on properties of ice cream with different composition. International Journal of Food Science and Technology. 42: 939-947.

Miettinen, M., M. Alander, A. Wright, J. Vuopio-Varkila, P. Marteau, J. H. Veld and T. Mattila-Sandholm. 1998. The survival of and cytokine induction by lactic acid bacteria after passage through a gastrointestinal model. Microbial Ecology in Health and Disease. $10: 141-147$.

Mitsuoka, T. 1992. The human gastrointestinal tract. Lactic Acid Bacteria 1:69-114. 
Minekus, M., P. Marteau, R. Havenaar and J. H.J. Huis in't Veld. 1995. A Multi compartmental Dynamic Computer controlled Model Simulating Stomach and Small Intestine. Alternatives to Laboratory Animals. 23:197-209.

Modler, H., R. McKellar, H. Goff, and D. Mackie. 1990. Using ice cream as a mechanism to incorporate Bifidobacteria and fructooligosaccharides into the human diet. Cult Dairy Prod J. 25:4-9.

Mohammadi, R., A. M. Mortazavian, R. Khosrokhavar and A. G. da Cruz. 2011. Probiotic ice cream: viability of probiotic bacteria and sensory properties. Ann Microbiol. 61:411-424.

Mortazavian, A. M., A. Azizi, M.R. Ehsani, S.H. Razavi, S.M. Mousavi, S. Sohrabvandi, and J.A. Reinheimer. 2008. Survival of encapsulated probiotic bacteria in Iranian yogurt drink (Doogh) after the product exposure to simulated gastrointestinal conditions. Milchwissenschaft 63: 427-429

Mortazavian, A. M., M. R. Ehsani, S. M. Mousavi, K. Rezaei, S. Sohrabvandi, and J. A. Reinheimer. 2007. Effect of refrigerated storage temperature on the viability of probiotic micro-organisms in yogurt. International Journal of Dairy Technology. 60:123-127.

Moss, S. 1995. Clinical implications of recent advances in salivary research. J Esthet Dent. 7:197-203.

Medellin - Pena, M.J. and M. W. Griffiths. 2009. Effect of molecules secreted by Lactobacillus acidophilus strain La-5 on Escherichia coli 0157:H7 colonization. Appl. Environ. Microbiol. 75: 41165-41172.

Mostafa, M.M., F.A. Abd EI-Malek, and A. I. Okasha. 2001. Utilization of some dairy by-products in the manufacture of reduced cholesterol frozen yoghurt. Proc. 8th Egypt Conf Dairy Sci. and Technol. 551-560.

Muir J.G, and K. O’Dea. 1992. Measurement of resistant starch: factors affecting the amount of starch escaping digestion in vitro. Am J Clin Nutr. 56:123-7.

Nagah, A. M., and C. J. Seal. 2005. In vitro procedure to predict apparent antioxidant release from wholegrain foods measured using three different analytical methods. J Sci Food Agr. 85:1177-85.

Ng, E. W. 2009. Effect of Starter cultures on Lactobacillus Acidophilus survival and gene expression in yogurt. MS Thesis. Cal Polytechnic State University, San Luis Obispo.

Nousia, F. G., P. I. Androulakis, and D. J. Fletouris. 2011. Survival of Lactobacillus acidophilus LMGP-21381 in probiotic ice cream and its influence on sensory acceptability. International Journal of Dairy Technology. 64:130-136. 
Oliveira, M. N., I. Sodini, F. Remeuf, and G. Corrieu. 2001. Effect of milk supplementation and culture composition on acidification, textural properties and microbiological stability of fermented milks containing probiotic bacteria. International Dairy Journal. 11:935-942.

Ong, L., A. Henriksson, and N. P. Shah. 2006. Development of probiotic Cheddar cheese containing Lactobacillus acidophilus, Lb. casei, Lb. paracasei and Bifidobacterium spp. and the influence of these bacteria on proteolytic patterns and production of organic acid. International Dairy Journal. 16: 446-456.

Oomen, A.G., C. J. M. Rompelberg, M. A. Bruil, C. J. G. Dobbe, D. P. K. H. Pereboom, and A. J. A. M. Sips. 2003. Development of an in vitro digestion model for estimating the bioaccessibility of soil contaminants. Arch. Environ. Contam. Toxicol. 44: 281-287.

Ouwehand, A.C., T. Kurvinen, and P. Rissanen. 2004. Use of a probiotic Bifidobacterium in a dry food matrix, an in vivo study. International Journal of Food Microbiology 95: 103-106.

Olson, D. W., and K. J. Aryana. 2008. An excessively high Lactobacillus acidophilus inoculation level in yogurt lowers product quality during storage. Lebenson. Wiss. Technol. 41:911-918.

Pacheco, K. C. and G. V. del Toro. 2010. Viability of Lactobacillus delbrueckii under human gastrointestinal conditions simulated in vitro. American Journal of Agricultural and Biological Sciences. 5: 37-42.

Parada, J., and J. M. Aguilera. 2007. Food microstructure affects the bioavailability of several nutrients. J Food Sci. 72:R21-R32.

Park, Y. W. 1992. Comparison of buffering components in goat and cow milk. Small Ruminant Research. 8:75-81.

Parker, R.B. 1974. Probiotics, the other half of the antibiotic story. Animal Nutr. Health. 29:4-8.

Parvez, S., K. A. Malik, S. Kang, S. Ah. and H. Kim. 2006. Probiotics and their fermented food products are beneficial for health. Journal of Applied Microbiology 100:1171-1185.

Pinto, M. G. V., C. M. A. P. Franz, U. Schillinger, W. H. Holzapfel. 2006. Lactobacillus spp. with in vitro probiotic properties from human faeces and traditional fermented products. International Journal of Food Microbiology. 109: 205-214

Pitino, I., C. L. Randazzo, G. Mandalari, A. L. Curto, R. M. Faulks, Y. L. Marc, C. Bisignano, C. Caggia, M. S. J. Wickham. 2010. Survival of Lactobacillus rhamnosus strains in the upper gastrointestinal tract. Food Microbiology. 27:1121-1127. 
Possemiers, S., M. Marzorati, W. Verstraete, and T. Van de Wiele. 2010. Bacteria and chocolate: a successful combination for probiotic delivery. International Journal of Food Microbiology. 141: 97-103.

Prasad, J., H. Gill, J. Smart, and P.K. Gopal. 1998. Selection and characterisation of Lactobacillus and Bifidobacterium strains for use as probiotics. International Dairy Journal. 8:993-1002.

Ramasubramanian, L., C. Restuccia, and H. C. Deeth. 2008. Effect of calcium on the physical properties of stirred probiotic yogurt. J. Dairy Sci. 91:4164-4175

Ravula, R. R., and N. P. Shah. 1998. Effect of acid casein hydrolyzates and cysteine on the viability of yogurt and probiotic bacteria in fermented frozen dairy desserts. Aust $\mathrm{J}$ Dairy Technol. 53:174-179

Ray, B. 1996. Probiotics of lactic acid bacteria: science or myth? Pages 101-136 in Lactic Acid Bacteria: Current Advances in Metabolism, Genetics and Applications. T.F. Bozoglu and B. Ray, Ed. Springer-Verlag, Berlin.

Rajpal, S. and V.K. Kansal. 2009. Probiotic dahi containing Lactobacillus acidophilus and Bifidobacterium bifidum stimulates antioxidant enzyme pathways in rats. Milchwissenschaft. 64: 287 - 290.

Richardson, H.G. 1986. Standard Methods for the Examination of Dairy Products. $15^{\text {th }}$ Ed. American Public Health Association, Washington D.C.

Ritter, P., C. Kohler and U. Von Ah. 2009. Evaluation of the passage of Lactobacillus gasseri K7 and Bifidobacteria from the stomach to intestines using a single reactor model. BMC Microbiology. 9: 1-9.

Rodgers, S., and R. Odongo. 2002. Survival of Lactobacillus acidophilus, L. casei and Bifidobacterium lactis in coleslaw during refrigerated storage. Food Australia. 54:185-8.

Ross, R. P., C. Desmond, G. F. Fitzgerald and, C. Stanton. 2005. Overcoming the technological hurdles in the development of probiotic foods. Journal of Applied Microbiology. 98:1410-1417

Rößle, C., M. A. E. Auty, N. Brunton, R. T. Gormley, and F. Butler. 2010. Evaluation of fresh-cut apple slices enriched with probiotic bacteria. Innovative Food Science and Emerging Technologies .11:203-209.

Ruiz-Moyano, S., A. Martín, M. J. Benito, F. P. Nevado, M. G. Córdoba. 2008. Screening of lactic acid bacteria and Bifidobacteria for potential probiotic use in Iberian dry fermented sausages. Meat Science. 80:715-721 
Salaun, F., B. Mietton, and F. Gaucheron. 2005. Buffering capacity of dairy products. International Dairy Journal. 15:95-109.

Salem, M. M. F., F. A. Fathi, and R. A Awad .2005. Production of probiotic ice cream. Pol J Food Sci Nutr. 55:267-271.

Salminen, S., A. von Wright, L. Morelli, P. Marteau, D. Brassart, W. M. de Vos, R. Fonden, M. Saxelin, K. Collins, G. Mogensen, S. E. Birkeland, and T. MattilaSondholm. 1998. Demonstration of safety of probiotics - a review. International Journal of Food Microbiology. 44:93-106.

Salminen, S., E. Isolauri, and E. Salminen. Clinical uses of probiotics for stabilizing the gut mucosal barrier: successful strains and future challenges. 1996. Antonie Van Leeuwenhoek. 70:347-58.

Sanders, M. E. 2000. Symposium: Probiotic Bacteria: Implications for Human Health Considerations for use of probiotic bacteria to modulate human health. American Society for Nutritional Sciences. 130: 384S-390S.

Sanders, M. E., D. C. Walker, and K. M. Walker. 1996. Performance of commercial cultures in fluid milk application. Journal of Dairy Science. 79:943-953.

Sanders, M.E. 2003. Probiotics: Considerations for human health. Nutrition Reviews. 61:91- 99.

Sanders, M.E. 2008. Products with probiotics. www.usprobiotics.org.

Sanz, T., and H. Luyten. 2006. Effect of thickening agent in the in vitro mouth, stomach and intestine release of tyrosol from enriched custards. Food Hydroc. 20:703-11.

Sanz, Y. 2007. Ecological and functional implications of the acid-adaptation ability of Bifidobacterium: A way of selecting improved probiotic strains. International Dairy Journal. 17:1284-1289.

Saxelin, M., A. Lassig, H. Karjalainen, S. Tynkkynen, A. Surakka, H. Vapaatalo, S. Järvenpää, R. Korpela, M. Mutanen, and K. Hatakka. 2010. Persistence of probiotic strains in the gastrointestinal tract when administered as capsules, yoghurt, or cheese. Int. J. Food Microbiol. 14: 293-300.

Saxelin, M., B. Grenov, U. Svensson, R. Fonden, R. Reniero, and T. Mattila-Sandholm. 1999. The technology of probiotics. Trends in Food Science and Technology. 10: 387392.

Schubert, M. L., N. F. Edwards, A. Arimura, and G. M. Makhlouf. 1987. Paracrine regulation of gastric acid secretion by fundic somatostatin. Am J Physiol Gastrointest Liver Physiol. 252:G485-G490. 
Schulze K. 2006. Imaging and modeling of digestion in the stomach and the duodenum. Neuro gastroenterol Motil 18:172-83.

Schwizer, W., A. Steingoetter, and M. Fox. 2006. Magnetic resonance imaging for the assessment of gastrointestinal function. Scandinavian J Gastro. 41:1245-1260.

Seelee, W., W. Tungjaroenchai, and M. Natvaratat. 2009. Development of low fat settype probiotic yoghurt from goat milk. As. J. Food Ag-Ind. 2:771-779.

Senok, A. C., A. Y. Ismaeel, and G. A. Botta. 2005. Probiotics: Facts and myths. Clinical Microbiology \& Infection.11:958-966

Shabala, L., T. McMeekin, B. B. Budde, and H. Siegumfeldt. 2006. Listeria innocua and

Shah, N. P. 2000. Probiotic bacteria: selective enumeration and survival in dairy products. Journal of Dairy Science. 83:894-907.

Shah, N. P. 2006. Probiotics and fermented milks. Pages 341-354 in Manufacturing yogurt and fermented milks. R.C. Chandan, Ed. Blackwell Publishing, Oxford

Shah, N. P. 2007. Functional cultures and health benefits. International Dairy Journal 17:1262-1277.

Shah, N. P., and P. Jelen. 1990. Survival of lactic acid bacteria and their lactases under acidic conditions. Journal of Food Science. 55:506- 509.

Shah, N. P., and W. E. V. Lankaputhra. 1997. Improving viability of Lactobacillus acidophilus and Bifidobacterium spp. in yogurt. Int Dairy J. 7:349-356.

Shah, N. P., W. E. V. Lankaputhra, M. Britz, and W. S. A. Kyle. 1995. Survival of Lactobacillus acidophilus and Bifidobacterium bifidum in commercial yoghurt during refrigerated storage. International Dairy Journal. 5:515-521.

Shah, N.P. 2001. Functional foods from probiotics and prebiotics. Food Technology. 55:46-53.

Shah, N.P. 2007. Functional cultures and health benefits. Int Dairy J. 17:1262-1277. Shannon, I. L. 1966. Climatological effects on human parotid gland function. Arch Oral Biol. 11:451-453.

Simon, G. L., and S. L. Gorbach. 1987. Intestinal flora and gastrointestinal function. Page 1729 in Physiology of the Gastrointestinal Tract. Vol. 2. $2^{\text {nd }}$ ed. L. R. Johnson, Ed. Raven Press, New York, NY. 
Sodini, I., A. Lucas, M. N. Oliveira, F. Remeuf, and G. Corrieu. 2002. Effect of milk base and starter culture on acidification, texture, and probiotic cell counts in fermented milk processing. J. Dairy Sci. 85:2479-2488.

Sofjan, R. P., and R. W. Hartel. 2004. Effects of overrun on structural and physical characteristics of ice cream. International Dairy Journal. 14:255-262

Soukoulis, C., D. Lebesi, and C. Tzia. 2009. Enrichment of ice cream with dietary fibre: Effects on rheological properties, ice crystallisation and glass transition phenomena. Food Chemistry 115: 665-671

Sreebny, L. M. 2000. Saliva in health and disease: an appraisal and update. Int Dent J. 50:140-161.

Stanton, C., C. Desmond, M. Coakley, J. K. Collins, G. Fitzgerald, and P.Ross. 2003. Challenges facing development of probiotic-containing functional foods. Pages 27-58 in Handbook of fermented functional foods. G. Mazza, Ed. CRC, Boca Raton.

Sumeri, I., L. Arike, J. Stekolštšikova, R. Uusna, S. Adamberg, K. Adamberg, and T. Paalme. 2010. Effect of stress pretreatment on survival of probiotic bacteria in gastrointestinal tract simulator. Appl Microbiol Biotechnol .86:1925-1931.

Sumeri, I., L. Arike, K. Adamberg, and T. Paalme. 2008. Single bioreactor gastrointestinal tract simulator for study of survival of probiotic bacteria. Appl Microbiol Biotechnol. 80:317-324.

Sheu, B. S., J. J. Wu, C. Y. Lo, H. H. W. Wu, J. H. Chen, Y. S. Lin, and M. D. Lin. 2002. Impact of supplement with Lactobacillus and Bifidobacterium containing yogurt on triple therapy for Helicobacter pylori eradication. Alimentary Pharmacology \& Therapeutics. 16: 1669-1675.

Tabak, L. A. 1995. In defence of the oral cavity: structure, biosynthesis, function of salivary mucins. Annu Rev Physiol. 57:547-564.

Taha, S. H., A. M. A. EI· Fattah, and Y. E. Sofie. 2005. Probiotic ice cream: Manufacture, properties and survival of added probiotic microorganisms. Egyptian J. Dairy Sci.

33:105-113.

Talwalkar, A., and K. Kailasapathy. 2003. A review of oxygen toxicity in probiotic yogurts: Influence on the survival of probiotic bacteria and protective techniques. Comprehensive Reviews in Food Science and Food Safety. 3:117-124.

Talwalkar, A., C. W. Miller, K. Kailasapathy, and M. H. Nguyen. 2004. Effect of packaging materials and dissolved oxygen on the survival of probiotics bacteria in yoghurt. International Journal of Food Science and Technology. 39:605-611. 
Talwalkar, A., K. Kailasapathy, P. Peiris, and R. Arumugaswamy. 2001. Application of RBGR- a simple way for screening of oxygen tolerance in probiotic bacteria. Int. J. Food

Tamime, A. Y. 2002. Fermented milks: A historical food with modern applications - a review. European Journal of Clinical Nutrition. 56:S2-S15.

Tamime, A.Y., M. Saarela, A.K. Sondergaard, V.V. Mistry, and N.P. Shah. 2005. Production and maintenance of viability of probiotic microorganisms in dairy products. Pages 39-72 in Probiotic dairy products. A. Y. Tamime, Ed. Blackwell, Oxford.

Tannock, G. W. 2002. The Bifidobacteria and Lactobacillus microflora of humans. Clinical Reviews in Allergy and Immunology. 22:231-253

Teitelbaum, J. E., and W. A. Walker. 2002. Nutritional Impact of pre and probiotics as protective gastrointestinal organisms. Annual Review of Nutrition. 22: 107-138.

Tharmaraj, N., and N. P. Shah. 2004. Survival of Lactobacillus acidophilus, Lactobacillus paracasei subsp. paracasei, Lactobacillus rhamnosus, Bifidobacterium animalis and Propionibacterium in cheese-based dips and the suitability of dips as effective carriers of probiotic bacteria. International Dairy Journal. 14:1055-1066.

Tabasco, R., T. Garcia-Cayuela, and T. Requena. 2009. Lactobacillus acidophilus La-5 increases lactacin B production when it senses live target bacteria. International Journal of Food Microbiology. 132: 109 - 116.

Tompkins, T. A., I. Mainville and Y. Arcand. 2011. The impact of meals on a probiotic during transit through a model of the human upper gastrointestinal tract. Beneficial Microbes. 2: 295-303

Turgut, T., and S. Cakmakci. 2009. Investigation of the possible use of probiotics in ice cream manufacture. Int J Dairy Technol. 62:444-451.

Varcoe, J., C. Zook, J. Sui, S. Leighton, F. Busta, and L. Brady. 2002. Variable response to exogenous Lactobacillus acidophilus NCFM consumed in different delivery vehicles. Journal of Applied Microbiology. 93: 900-906.

Vasiljevic, T., and N. P. Shah. 2008. Probiotics - from Metchnikoff to bioactives. International Dairy Journal. 18:714-728.

Vertzoni, M., J. Dressman, J. Butler, J. Hempenstall, and C. Reppas. 2005. Simulation of fasting gastric conditions and its importance for the in vivo dissolution of lipophilic compounds. Eur J Pharm Biopharm. 60:413-7.

Walsh, K. R., Y. C. Zhang, Y. Vodovotz, S. J. Schwartz, and M. L. Failla. 2003. Stability and bioaccessibility of isoflavones from soy bread during in vitro digestion. J Agric Food Chem. 51:4603-9. 
Waterman, S. R., and P. I. Small. 1998. Acid-sensitive enteric pathogens are protected from killing under extremely acidic conditions of $\mathrm{pH} 2.5$ when they are inoculated onto certain solid food sources. Appl. Environ. Microbiol. 64:3882-3886.

Wehr, H. M. 2004. Chemical and Physical Methods. Pages 433-435 in Standard Methods for the Examination of Dairy Products, $17^{\text {th }}$ edition. H. M Wehr and J.F. Frank, Ed. American Public Health Association, Washington, D.C.

Wickham, M., R. Faulks, and C. Mills. 2009. In vitro digestion methods for assessing the effect of food structure on allergen breakdown. Mol. Nutr. Food Res. 53: 952-958

Wollin, A. 1987. Regulation of gastric acid secretion at the cellular level. Clin Invest Med. 10:209-14.

Xu, S., T.D. Boylston, and B. A. Glatz. 2006. Effect of inoculation level of Lactobacillus rhamnosus and yogurt cultures on conjugated linoleic acid content and quality attributes of fermented milk products. Journal of Food Science. 71: C275-C280.

Yoo, J. Y, and X.D. Chen. 2006. GIT physicochemical modeling—a critical review. Int J Food

Zacarchenco, P.B., and S. Massaguer-Roig. 2006. Properties of Streptococcus Thermophilus fermented milk containing variable concentrations of Bifidobacterium longum and Lactobacillus acidophilus. Brazilian Journal of Microbiology. 37: 338-344.

Zhu, H. C. A. Hart, D. Sales and N. B. Roberts. 2006. Bacterial killing in gastric juice effect of $\mathrm{pH}$ and pepsin on Escherichia coli and Helicobacter pylori. Journal of Medical Microbiology. 55:1265-1270. 


\section{Appendices}

I: Ice cream formulation for determining the effect of $60 \%$ and $100 \%$ overrun on $L$. acidophilus La-5 survivability

\begin{tabular}{|l|l|l|l|l|}
\hline Ingredients & $\mathrm{Wt}(\mathrm{lbs})$ & Fat (lbs) & NMS (lbs) & TS (lbs) \\
\hline $38 \%$ cream & 3.97 & 1.51 & 0.22 & 1.73 \\
\hline $3.5 \%$ fat milk & 70.55 & 2.47 & 6.13 & 8.6 \\
\hline $97 \%$ NMS & 5.83 & & 5.66 & 5.66 \\
\hline Sucrose & 15 & & & 15 \\
\hline Corn Syrup Solids & 4 & & & 4 \\
\hline Stab/Emulsifier & 0.65 & & & 0.65 \\
\hline Total & 100 & 3.98 & 12.01 & 35.64 \\
\hline
\end{tabular}

II: Ice cream formulation for determining effect of shear and dilution on L. acidophilus La-5 survivability (bench top) and effect of HGS and shaking water bath on its survivability during simulated digestion of low viscosity, high concentration sample

\begin{tabular}{|l|l|l|l|l|}
\hline Ingredients & Wt (lbs) & Fat (lbs) & NMS (lbs) & TS (lbs) \\
\hline $38 \%$ cream & 6.83 & 2.60 & 0.38 & 2.98 \\
\hline $3.5 \%$ fat milk & 68.73 & 2.40 & 5.97 & 8.37 \\
\hline 97\% NMS & 4.79 & & 4.65 & 4.65 \\
\hline Sucrose & 15 & & & 15 \\
\hline Corn Syrup Solids & 4 & & & 4 \\
\hline Stab/Emulsifier & 0.65 & & & 0.65 \\
\hline Total & 100 & 5 & 11 & 35.65 \\
\hline
\end{tabular}

III: Ice cream formulation for determining effect of shear and dilution on L. acidophilus La-5 survivability (bench top) and effect of HGS and shaking water bath on its survivability during simulated digestion of high viscosity, high concentration sample

\begin{tabular}{|l|l|l|l|l|}
\hline Ingredients & Wt (lbs) & Fat (lbs) & NMS (lbs) & TS (lbs) \\
\hline 38\% cream & 6.89 & 2.62 & 0.38 & 3 \\
\hline 3.5\% fat milk & 67.95 & 2.38 & 5.90 & 8.28 \\
\hline 97\% NMS & 4.86 & & 4.71 & 4.71 \\
\hline Sucrose & 15 & & & 15 \\
\hline Corn Syrup Solids & 4 & & & 4 \\
\hline Stab/Emulsifier & 1.3 & & & 1.3 \\
\hline Total & 100 & 5 & 11 & 36.29 \\
\hline
\end{tabular}

